Florida International University FIU Digital Commons

FIU Electronic Theses and Dissertations

University Graduate School

3-26-2014

\title{
Socio-ecological Vulnerability to Climate Change in South Florida
}

Emily Eisenhauer

Florida International University, eeise002@fiu.edu

DOI: $10.25148 /$ etd.FI14040839

Follow this and additional works at: https://digitalcommons.fiu.edu/etd

Part of the Human Geography Commons, Nature and Society Relations Commons, Place and Environment Commons, and the Social and Cultural Anthropology Commons

\section{Recommended Citation}

Eisenhauer, Emily, "Socio-ecological Vulnerability to Climate Change in South Florida" (2014). FIU Electronic Theses and Dissertations. 1269.

https://digitalcommons.fiu.edu/etd/1269

This work is brought to you for free and open access by the University Graduate School at FIU Digital Commons. It has been accepted for inclusion in FIU Electronic Theses and Dissertations by an authorized administrator of FIU Digital Commons. For more information, please contact dcc@fiu.edu. 


\section{FLORIDA INTERNATIONAL UNIVERSITY}

Miami, Florida

SOCIO-ECOLOGICAL VULNERABILITY TO CLIMATE CHANGE IN SOUTH

FLORIDA

A dissertation submitted in partial fulfillment of the

requirements for the degree of

DOCTOR OF PHILOSOPHY

in

COMPARATIVE SOCIOLOGY

by

Emily Eisenhauer

2014 
To: Dean Kenneth G. Furton

College of Arts and Sciences

This dissertation, written by Emily Eisenhauer, and entitled Socio-ecological

Vulnerability to Climate Change in South Florida, having been approved in respect to style and intellectual content, is referred to you for judgment.

We have read this dissertation and recommend that it be approved.

Matthew Marr

Laura Ogden

Alex Stepick

Keqi Zhang

Gail Hollander, Major Professor

Date of Defense: March 26, 2014

The dissertation of Emily Eisenhauer is approved.

Dean Kenneth G. Furton

College of Arts and Sciences

Dean Lakshmi N. Reddi

University Graduate School

Florida International University, 2014 


\section{ACKNOWLEDGMENTS}

I'd like to thank my advisor Dr. Gail Hollander who gave me the opportunity to complete this project as part of the ULTRA-Ex grant. She has been unwaveringly enthusiastic for and willing to share her keen insights into both my scholarly and public work. I would also like to sincerely thank my committee members, Dr. Matt Marr, Dr. Laura Ogden, Dr. Alex Stepick and Dr. Keqi Zhang for their support and guidance through my years at FIU. Peter W. Harlem was extremely generous with his GIS help and in teaching me about South Florida geology and tides, without which I couldn't have completed this research. I owe an enormous amount to Dr. Bruce Nissen and Carol Stepick for inspiring me with their commitment to social justice work and for giving me invaluable research training, and to everyone at the Research Institute on Social and Economic Policy and all of our fearless community partners in the struggle for justice in South Florida. Finally I am grateful to my friends and family for supporting and believing in me.

This material is based upon work supported in part by the National Science Foundation through the Miami-Dade Urban Long Term Research Area program under Grant No. BCS-0948988, as well as a Dissertation Evidence Acquisition fellowship from the Florida International University Graduate School. 


\section{ABSTRACT OF THE DISSERTATION \\ SOCIO-ECOLOGICAL VULNERABILITY TO CLIMATE CHANGE IN SOUTH \\ FLORIDA}

by

Emily Eisenhauer

Florida International University, 2014

Miami, Florida

\section{Professor Gail Hollander, Major Professor}

Awareness of extreme high tide flooding in coastal communities has been increasing in recent years, reflecting growing concern over accelerated sea level rise. As a low-lying, urban coastal community with high value real estate, Miami often tops the rankings of cities worldwide in terms of vulnerability to sea level rise. Understanding perceptions of these changes and how communities are dealing with the impacts reveals much about vulnerability to climate change and the challenges of adaptation.

This empirical study uses an innovative mixed-methods approach that combines ethnographic observations of high tide flooding, qualitative interviews and analysis of tidal data to reveal coping strategies used by residents and businesses as well as perceptions of sea level rise and climate change, and to assess the relationship between measurable sea levels and perceptions of flooding. I conduct a case study of Miami Beach's storm water master planning process which included sea level rise projections, one of the first in the nation to do so, that reveals the different and sometimes competing logics of planners, public officials, activists, residents and business interests with regards 
to climate change adaptation. By taking a deeply contextual account of hazards and adaptation efforts in a local area I demonstrate how this approach can be effective at shedding light on some of the challenges posed by anthropogenic climate change and accelerated rates of sea level rise.

The findings highlight challenges for infrastructure planning in low-lying, urban coastal areas, and for individual risk assessment in the context of rapidly evolving discourse about the threat of sea level rise. Recognition of the trade-offs and limits of incremental adaptation strategies point to transformative approaches, at the same time highlighting equity concerns in adaptation governance and planning. This new impact assessment method contributes to the integration of social and physical science approaches to climate change, resulting in improved understanding of socio-ecological vulnerability to environmental change. 


\section{TABLE OF CONTENTS}

CHAPTER $\quad$ PAGE

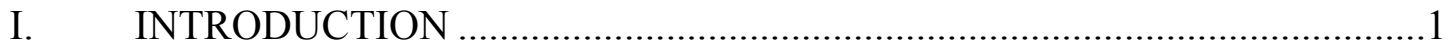

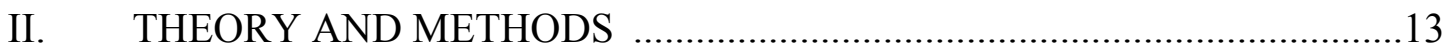

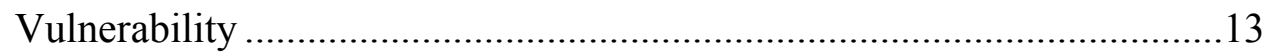

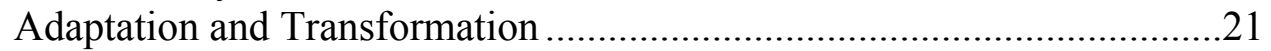

Urban Challenges of Adaptation.............................................................32

Methodological Approach …………….................................................33

Research Design......................................................................................41

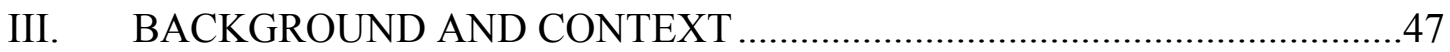

South Florida's Development .................................................................

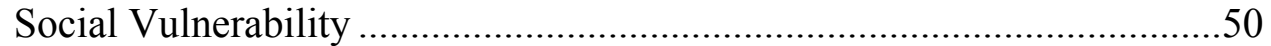

The Emergence of Regional Climate Governance....................................52

IV. IMPACTS AND PERCEPTIONS ………………..................................

Biophysical Impacts of Sea Level Rise in the Study Area ........................71

Field Observations and Data Analysis ......................................................77

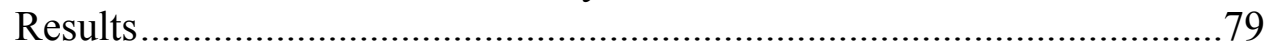

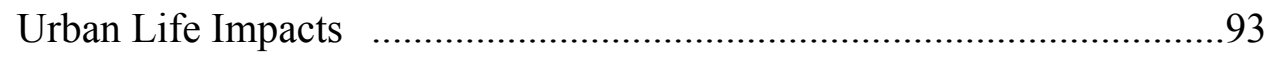

Perceptions and Decision....................................................................104

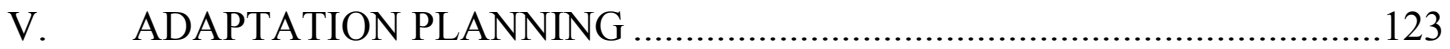

Adaptation Planning in Miami Beach......................................................123

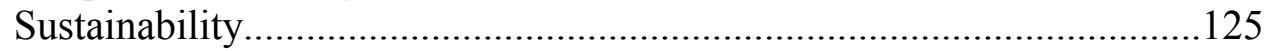

The Boundary Condition......................................................................127

Quality of Life vs. Economic Development ...........................................148

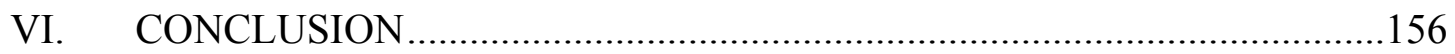

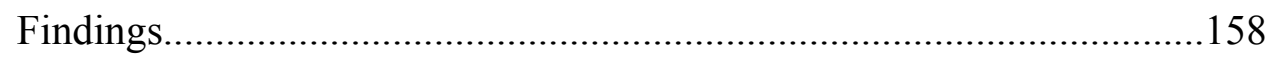

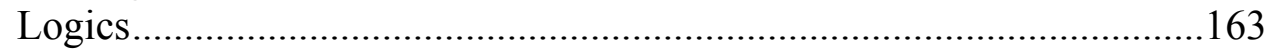

Vulnerability and Adaptation.................................................................167

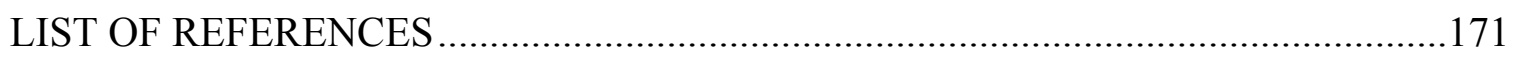

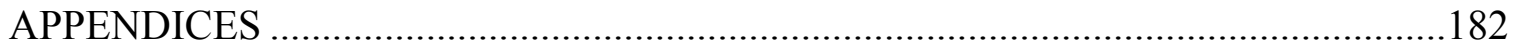

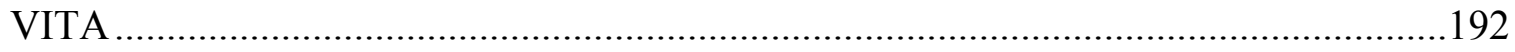




\section{LIST OF FIGURES}

FIGURE

PAGE

1. Inundation maps of southern Miami Beach ............................................................. 72

2. 2012 Verified minus predicted hourly water height values, Virginia Key, FL ............76

3. Ground-truthing $5^{\text {th }}$ Street to Lincoln Road with $2 \mathrm{ft}$. Inundation Scenario ..................80

4. Ground-truthing $2 \mathrm{ft}$. inundation scenario with street elevation profile graph .............81

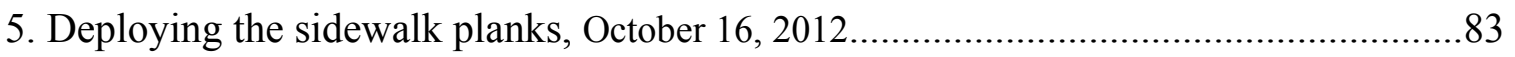

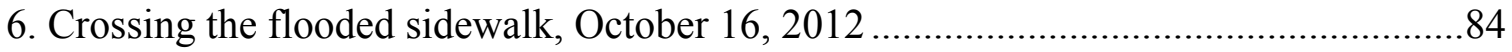

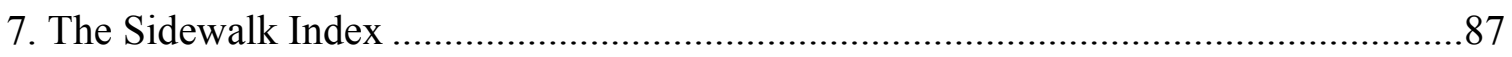

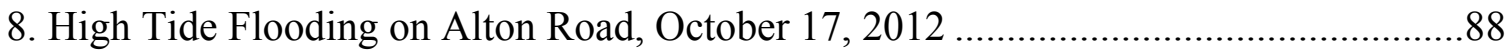

9. Man Waiting to Cross Alton Road, November 2, 2012 .......................................90

10. Intersection of Alton Road and 10th St.: Times when crosswalks observed to be no longer usable for pedestrians as tide rises ........................................................ 91

11. Intersection of Alton Road and 10th St.: Times when crosswalks observed to be no longer usable for pedestrians as tide recedes ................................................. 91

12. Tide Hours above $0.45^{\prime}$ NAVD, 1996-2012, Virginia Key, FL................................92

13. Man With a Walker in Flooded Street, October 16, 2012 ....................................94

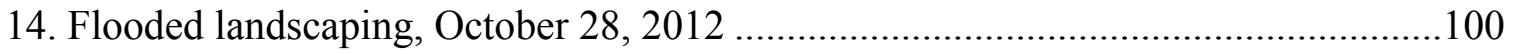

15. Flood-proofed Landscaping, February 9, 2014. Photo by author ...........................100

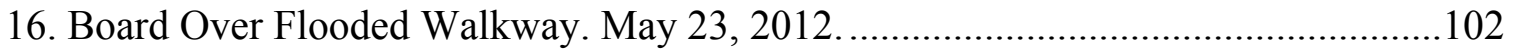

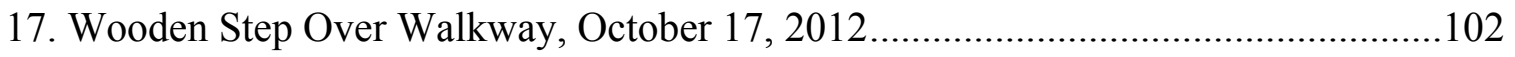

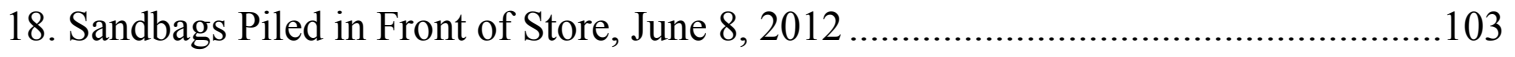

19. Sandbag Ring in Front of Store, October 27, 2012 ...........................................103 
20. Historic and Projected Mean High Water Levels at Virginia Key, Chart from

Miami Beach SWMMP Public Presentation, August 17, 2012 .......................................134 


\section{ABBREVIATIONS AND ACRONYMS}

\begin{tabular}{|c|c|}
\hline $\mathrm{ACE}$ & Army Corps of Engineers \\
\hline ARRA & American Recovery and Reinvestment Act \\
\hline CHANS & Coupled Human and Natural Systems \\
\hline DEM & Digital Elevation Model \\
\hline $\mathrm{ECC}$ & Energy and Climate Commission \\
\hline FDOT & Florida Department of Transportation \\
\hline GIS & Geographic Information Systems \\
\hline GHG’s & Greenhouse gasses \\
\hline ICLEI & ICLEI - Local Governments for Sustainability \\
\hline LiDAR & Light Detection and Ranging \\
\hline LOS & Level of Service \\
\hline MDCCTF & Miami-Dade County Climate Change Task Force \\
\hline MHW & Mean High Water \\
\hline MHHW & Mean Higher High Water \\
\hline NGO & Non-governmental organization \\
\hline NOAA & National Oceanographic and Atmospheric Administration \\
\hline RCAP & Regional Climate Action Plan \\
\hline SFRCCC & Southeast Florida Regional Climate Change Compact \\
\hline SFWMD & South Florida Water Management District \\
\hline SWMMP & Storm water management master plan \\
\hline
\end{tabular}




\section{CHAPTER I - INTRODUCTION}

A decade ago seen primarily as a global issue, the subject of international negotiations and global justice protests, climate change is now a local issue. As the impacts of climate change are beginning to be felt in a growing number of areas, local communities are now facing the issue in day to day life. While the impacts are not recognized everywhere, they are becoming more and more obvious for coastal communities, many of which are experiencing the early stages of sea level rise. Over the last several years, Miami and the southeast Florida region have been experiencing increased urban flooding, prompting governments to begin infrastructure improvement projects and adaptation planning. These efforts represent both practical measures to deal with impacts and a process of grappling with difficult questions about the region's future. This dissertation is a study of socio-ecological vulnerability to climate change in the context of early adaptation efforts in a major urban coastal community.

The experience of local areas in dealing with the impacts of climate change will play a key role in shaping the human dimensions of Global Environmental Change. Cities play a prominent role in moving forward ideas, and city leaders have emerged as leaders in responding to climate change ("C40 Cities Climate Leadership Group”). Hampered by still contentious politics of climate change at the nation level, the federal government's role has been limited to incorporating climate adaptation into its own agencies, and to providing technical assistance and some limited funding to local areas. This leaves cities and states to create their own adaptation policy and practice, and as some of the first to experience impacts, coastal cities are on the front lines of dealing with very thorny issues of planning for and responding to changes. 
Climate change has been recognized as the result of human activity, leading some scholars to label the current era the "anthropocene" (Gibson-Graham and Roelvink 2010). This is supported by the evolving understanding of Coupled Human and Natural Systems (CHANS), the idea that "human and environmental systems are inextricably connected in webs of mutual causation," and that climate change is CHANS on a global scale (Rosa and Dietz 2010, 4). The recognition of the impact that human societies have had, through the emission of historically high amounts of greenhouse gasses (GHG's) due largely to industrial activity, has focused attention on the human drivers of climate change (Hannigan 1995). The social-psychological and political-economic processes that drive continued production of these harmful gasses is the subject of research in a wide variety of fields and disciplines in the social and behavioral sciences (O'Brien 2011a). Although many have argued that eminently workable solutions are presently available (Moser and Boykoff 2013, Felgenhauer and Webster 2012), there is no silver bullet. Reducing GHG's needs to happen quickly and dramatically in order to avoid the worst impacts (IPCC 2007) and for this change is needed across multiple sectors and scales. As shown by the results of efforts thus far however, the barriers to broad change are significant (Ekstrom and Moser 2013).

Dealing with the human drivers of climate change is just one side of the human dimensions of environmental change. In the climate change literature this aspect is known as "mitigation" (IPCC 2007), the term for efforts to reduce emissions of GHG's, and much has been written about options for mitigation (Kasperson and Ram 2013, IPCC 2007) as well as barriers, politics, and justice concerns (Dawson 2010, ManuelNavarrete 2010, Giddens 2009, Beckman and Page 2008, Adger 2001). But we know 
very little about the other side, "adaptation," or how humans are adapting to climate change, and how adaptation fits into CHANS. This is in large part because relatively few areas had begun adaptation until just recently. But now that climate change impacts are being felt we are starting to get a better look at how cities are responding, planning, and questioning. How the experience and perception of environmental change influences the social-psychological and political-economic drivers of action (or inaction) on climate change will be an important area of study, to glean lessons as early as possible and inform subsequent efforts.

Understanding adaptation is also key to understanding vulnerability to climate change. Vulnerability has traditionally been conceptualized in two ways: spatially, being located in such a way as to be exposed to environmental hazards, and contextually, a state of greater exposure or sensitivity to environmental hazards due to socio-political disadvantage (O’Brien et al. 2007). The locational approach tends to lead to technological solutions, such as protective infrastructure, while the contextual conceptualization leads to more of a human security approach such as improving livelihoods (O'Brien et al. 2007). While the approaches can be complementary, human security often gets short shrift, particularly in non-development contexts. Nevertheless, for decades social science researchers concerned with vulnerability and disasters have argued that "the need to understand and modify human and social forces is far more important than any technological answer to greater resilience" (Haque and Etkin 2007) and as climate impacts mount this understanding will be more and more crucial.

In this dissertation I argue that vulnerability has been conceptualized mostly in relation to "first-order" impacts, that is the damage caused by environmental hazards 
such as floods and droughts, and what makes people and systems susceptible to being harmed by these phenomenon. But as adaptation gains steam there is a need to pay attention to another layer of impacts, so-called "second-order" impacts which are the socio-economic changes prompted by environmental change and efforts to adapt to it (PROVIA). Although others have previously noted that, as with any socio-economic changes adaptation has uneven consequences and the potential to for greater impacts on those who are already disadvantaged (Adger et al. 2006) as adaptation efforts expand in local areas it will be important to study these efforts to increase our understanding of how they affect vulnerable populations.

If the goal of adaptation is to minimize the impacts of climate change on human societies, we must understand the nature of vulnerability to climate change and be deliberate about protecting those most vulnerable. But planning processes have not yet fully accepted this responsibility. Just as with first-order impacts, both spatial and contextual dimensions are important for understanding vulnerability in adaptation. The adaptation plans created by cities and regions typically focus on infrastructure needs, but rarely on the needs of vulnerable populations. The widely used adaptation framework for sea level rise_-protect, accommodate, retreat (Few, Brown and Tompkins 2007)—is a physical-technical approach that treats vulnerability only in relation to the hazard itself, rather than a contextual condition, the result of multiple stressors including globalization and economic changes (Adger 2006, Leichenko, O’Brien and Solecki 2010). Studying communities that are facing the early impacts of sea level rise provides insight into the nature of vulnerability, and the challenges, responses, and consequences of adaptation. As a coastal city very exposed to sea level rise, and with large socio-economic inequality, 
Miami provides a unique window into these issues and one that is highly relevant as Miami is earlier facing challenges that eventually many other locations will face as well. I undertake to document and understanding the experience of Miami in these early stages, which represents as an opportunity to vastly improve our understanding of the enormous challenges ahead.

South Florida is on the "front lines" of sea level rise due to having a large populated area at very low elevation. While the entire region is often referred to as "Miami" by outsiders, it is known as "South Florida" to insiders. Located at the southern tip of Florida, Miami is the core city of the southeast Florida region, a region of 5.5 million people that stretches 250 miles from Key West to Palm Beach. The region encompasses 112 municipalities in four counties, which are connected economically and through transportation but have recognizable cultural differences and separate identities within the South Florida identity.

In a study of port cities worldwide, Miami (really the south Florida region) was ranked number four for exposure to sea level rise in terms of population and number one in terms of assets (Nicholls et al. 2008). Though there is little consensus on the timing and rate of rise, the conclusions by the International Panel on Climate Change (2007) predict that at least two degrees of warming is likely by the end of the century. Even if GHG emissions peaked by 2015 and began declining, temperature would continue to rise and sea level could rise by up to 1.4 meters (IPCC 2007).

This is a very sobering fact for South Florida, which has large areas just a few feet above sea level, putting them at risk of inundation in the early stages of sea level rise. A Vulnerability Analysis performed by the Southeast Florida Regional Climate Change 
Compact (SFRCCC), an agreement among the four counties in the region to cooperate on climate change policy and planning, found that one foot of rise would affect 80,000 acres and $\$ 4$ billion of taxable property value across the region, ${ }^{1}$ including two airports, three power plants, and three hospitals. For Miami-Dade one foot of rise would impact twelve percent of land area, rising to eighteen percent for a three-foot scenario. Although most of the land impacted at one-foot is conservation land, a nuclear power plant would also be significantly impacted. In a three-foot scenario nearly 11,000 acres of agricultural land is impacted, over 4,000 acres of residential area, and over 500 miles of roads in MiamiDade County alone (SFRCCC 2012).

Sea level rise is perhaps the most significant impact that climate change will have on South Florida due to its low elevation and porous geological substrate. Likened to "Swiss cheese" by geologists because of the many holes that perforate the rock, this structure allows rainwater to percolate down into the aquifers but also means that South Florida has a high ground water table (SFWMD Public Meeting February 25, 2013). As sea level rises it pushes up the water table and reduces the ability of the gravity-driven system to discharge through canals to the ocean. Reduced drainage capacity means that low-lying areas are less protected from flooding caused by intense rainfall (SFWMD 2009). For this reason it is not only coastal areas that are at risk for inundation, but also low-lying inland areas.

Sea level rise will also exacerbate the problem of salt water intrusion into South Florida's water supply. South Florida draws most of its water supply from ground water

\footnotetext{
${ }^{1}$ The analysis was performed using LiDAR data and the number of acres includes only unincorporated areas of Miami-Dade and Palm Beach Counties, and urban areas of Miami-Dade and Broward Counties. The taxable value figure does not include Miami-Dade County which declined to perform this type of analysis.
} 
aquifers (Berry et al. 2011) and as rising sea level pushes the interface between freshwater and salt water further inland, wells located further towards the coast become increasingly saline. Salt water intrusion began in the early 1900's when canals were dug to drain inland areas, and in the 1970's well fields in the east that had become too saline had to be closed (Sonenshein 1995). Salinity control structures constructed on the canals and maintaining high water levels inland have reduced and in some cases reversed the inland movement of the interface (Sonenshein 1995), which requires carefully managed water levels in order to prevent flooding (SFWMD 2009).

Climate change and sea level rise also mean potentially more destructive hurricanes, due to higher storm surge levels and potentially more intense storms driven by warmer ocean water. Warming oceans mean that hurricanes may become stronger, with "the number of category 4 or 5 storms forming in the Atlantic basin roughly doubling after 80 years of greenhouse warming," although the number of overall Atlantic storms may decrease by twenty-eight percent by one prediction (Misra et al. 2011). Stronger storms cause exponentially more damage, and "an $11 \%$ increase in wind speed translates to roughly a $60 \%$ increase in damage" (Borenstein 2010). Recent research has concluded that the relationship between sea level rise and storm surge is non-linear, and that extreme tidal events will occur more frequently (Obeysekera and Park 2013).

Many of these challenges associated with climate change are not qualitatively new to South Florida. Hurricanes are a natural phenomenon, and salt water intrusion has been a problem since the early days of development efforts altered the physical landscape (Sonenshein 1995). A sophisticated technological and governance apparatus has developed over decades of learning how to protect life and property in South Florida-- 
flood control and hurricane prediction being two of the most crucial areas. These are multi-scalar networks involving significant federal support, cooperation of state and local governments, and efforts to educate residents (Carter 1974). Water conservation efforts to protect the aquifer from sea level rise have existed for decades (Blake 1980). Efforts to curb development in the most vulnerable coastal areas have also existed since the 1970's (Carter 1974). The large, billion dollar Comprehensive Everglades Restoration Plan is the culmination of decades of political wrangling and acquiring technical knowledge about the landscape and its natural processes (Hollander 2008).With all this experience, a strong foundation of knowledge for understanding and dealing with climate change impacts already exists in South Florida.

Nevertheless, the challenges are formidable and the options for further protective infrastructure appear to be limited and costly. A South Florida Water Management District (SFWMD) analysis indicates that eighteen control structures along the coast will be compromised with only six inches more of sea level rise, meaning they will no longer be able to provide flood control (SFWMD 2009). Replacing them with forward pumping stations could cost more than $\$ 50$ million each (Morgan 2012). A study for one municipality estimated that constructing protection measures for the next seventy to one hundred years, including draining, water supply, and raising roads would cost $\$ 500$ million to $\$ 1$ billion (Bloetscher, Meeroff and Heimlich 2010). A recent regional planning effort that included sea level rise scenarios recommended a variety of strategies including retreat from some areas and fortifying coastline in others both with natural buffers such as mangroves and sand dunes, and with engineered solutions such as water controls structures, raising land, levees, and even an ice wall (Southeast Florida Regional 
Partnership 2013). Though no cost estimates were attached, the plan acknowledged that high cost is a serious challenge.

Miami Beach is one of the first cities in the country to be experiencing significant sea level rise impacts, and so makes an ideal location to explore the challenges of urban adaptation and the nature of urban vulnerability to climate change. The densely populated city is contained entirely on a barrier island with an average elevation of four feet. The island is very vulnerable to storm surge and high tide flooding, which has been increasing in recent years especially in low-lying areas of the city, disrupting urban life and increasing the risk of property damage, as my research shows. As a reaction to these problems the City has taken the initial step of improving storm water management, and has received attention for being the first municipality in the region to include sea level rise projections into infrastructure planning when it proposed a new storm water management master plan (SWMMP) in 2009. This proposal was made independently of the regional Compact, as a reaction to increasing concerns about storm water management and flooding, and only later became an example of climate change adaptation. As I document, this shift from traditional infrastructure planning to climate adaptation planning reveals tensions between different logics of climate vulnerability and urban development which challenge current adaptation frameworks.

The challenges stem from the unique physical and socio-economic conditions that limit options within the commonly used "protect, accommodate, retreat" framework of climate adaptation (Few, Brown and Tompkins 2007). Thirty-five percent of the city's land area could be inundated by 3 feet of sea level rise (Harlem, unpublished), and if sea level keeps rising the ability of defensive infrastructure to protect the city in its current 
state is questionable. Being such a densely built urban area, there is little to no room to relocate assets, or to create flexible space to accommodate periodic flooding.

Conservation measures such as rolling easements that move with the shoreline are not practical for highly developed urban areas (Titus 2011). Even if barriers could be created to prevent inundation from tides and storm surge, the rising groundwater through the porous substrate will eventually saturate low-lying areas. Already old building foundations are having salt water corrosion problems (Business leader 1, interview April 3, 2013), and discussions are beginning over whether homes and roads should be raised (Resilient Miami Beach, meeting September 18, 2013). Whatever the options for adapting the built environment are, they will certainly be costly, and who pays those costs and how is an issue that has yet to be confronted.

In some sense these physical impacts and the limitations of current adaptation options, I argue, present an existential challenge for Miami Beach, threatening the very things that make it "Miami Beach." Activists who campaigned for the preservation of the historic Art Deco District which led to the economic revival of the area now face the daunting challenge of preserving, perhaps raising, somehow adapting these architecturally significant buildings. With tourism a major part of the economy, the prospect of building barriers such as sea walls that cut off access to water is unthinkable. Part of the threat is a discursive threat, with the city becoming a symbol of coastal sea level rise impacts in local and national media. A 2012 article in Rolling Stone magazine declared "Goodbye Miami” (Goodell 2013) depicting a scenario of sea level rise and hurricanes leading to disasters and chaos, and plummeting real estate prices plummeting. With real estate another major part of the economy, the specter of falling values is also 
interpreted as a crisis, fed by the perception of the magnitude of adaptation challenges and limited options.

Perhaps the biggest challenge is time. Most climate adaptation planning takes an incremental approach, based on the assumption (perhaps the hope?) that changes to the built environment can be phased in gradually over time without major social or economic disruption. But as flooding and the discourse about climate impacts has evolved rapidly in the last two years, the conflicting logics of government officials, residents, businesses, and activists over what makes Miami Beach vulnerable, what constitutes quality of life, and what is the best course for adaptation point to the need for a different approach. I analyze how these different groups have interacted in my case study in order to understand the coming conflicts of climate adaptation, which I argue are important for understanding how Miami Beach is vulnerable, not just physically, but socioeconomically as adaptation and the debates around it proceed. I further argue that these conflicts point to the need for a transformative approach (O'Brien 2011), rethinking the values and priorities that guide adaptation, and centering human security (O'Brien 2006).

In what follows I will first review the scholarly literature on socio-ecological vulnerability to environmental hazards, drawing also on political ecology and the sociology of disasters, and then turn to the climate change adaptation literature, focusing on decision making and the emerging interest in transformational adaptation. I will then provide a brief background on the region's historical development and environmental challenges, and describe the emergence of a regional climate governance network. Next I will present a case study of one municipality in the region already experiencing and planning for impacts, Miami Beach, in two chapters. The first offers empirical evidence 
of the impacts of flooding in Miami Beach on urban life, the drivers of the flooding, and the perceptions of residents and businesses of the flooding and what this means for their decision making about the future. In the subsequent chapter I describe the controversy over the City's storm water master planning process, and analyze the logics of the City, resident activists, and business interests over decision making with regards to adaptation approaches to sea level rise. Finally, I draw conclusions about the challenges my case study highlights for adaptation planning and the nature of vulnerability in urban, coastal communities. The findings demonstrate the contributions of the new method I have developed to integrating social and physical science approaches to climate change and contributing to an improved understanding of socio-ecological vulnerability. 


\section{CHAPTER II - THEORY AND METHODS}

In this chapter I will provide the theoretical basis for my research and describe my methodological approach. I will review two main areas of literature, firstly theories of vulnerability to environmental hazards focusing on the human dimensions of vulnerability, and secondly the climate change adaptation literature with a focus on decision making. Finally I will note the particular urban challenges of climate adaptation. I argue that while location based approaches have provided important insights into socioecological vulnerability, vulnerability to climate change must have a broader view of impacts beyond the spatiality of first-order impacts such as flooding. Equally as important though not yet well studied are the "second order" impacts of adaptation to environmental change, as local governments begin to plan for infrastructure improvements, land use changes, and other measures, all under great uncertainty. I then outline how I approached my research topic, particularly how I integrated the physical and social dimensions of climate impacts, and finally I describe my research questions, data collection and analysis strategy.

\section{Vulnerability}

Vulnerability is a key concept in climate change research. It is the starting point for understanding how human and natural systems will be impacted by the changing climate and its impacts, extreme weather, sea level rise, drought, etc. and what can be done to minimize the impacts. Even so, the variety of approaches and definitions makes it difficult to identify a widely accepted usage of the term. In fact one recent prominent publication on climate change adaptation declared that it would avoid use of 
"vulnerability" wherever possible because of the lack of consensus on meaning (PROVIA 2012). Nevertheless, the term continues to be relevant to planners, policy makers and scholars for particular purposes. "Vulnerability assessments" are a ubiquitous step in climate change adaptation planning (Füssel and Klein 2006), and "vulnerable populations" is a legitimate and widely understood reference to those who are likely to suffer greater harm from disasters due to their socio-economic position.

One of the most important researchers in vulnerability over the last two decades, Susan Cutter, identified three themes in vulnerability studies (Cutter 1996). One is vulnerability as exposure to risk/hazard, which identifies the geographical distribution of biophysical or technological threats and the population exposed, and the degree of potential loss. The second is a social constructionist view, which highlights the society's resilience and the historical, cultural, and economic processes which influence society's ability to cope with disasters. The third theme is the vulnerability of places, in which vulnerability is both a biophysical risk and social response, but is grounded in a particular place. She attributed the discrepancies to different epistemological orientations, methodologies, types of hazards under study, and fundamental conceptual differences over whether the term refers to "the likelihood of exposure (biophysical/technological risk), or the likelihood of adverse consequences (social vulnerability) or some combination of the two" (Cutter 1996, 530).

The social vulnerability approach gained steam in the early 1990's as scholars began to place more emphasis on a dynamic and contextual understanding than traditional hazards models. As Blaikie, Cannon, Davis, and Wisner wrote in a 1994 book, 
Analyzing disasters allows us to show why they should not be segregated from everyday living, and to show how the risks involved in disasters must be connected with the vulnerability created for many people through their normal existence. It seeks connections between the risks people face and the reasons for their vulnerability to hazards. It is therefore trying to show how disasters can be perceived within the broader patterns of society, and, indeed, how analyzing them in this way may provide a much more fruitful way of building policies that can help to reduce disasters and mitigate hazards. (3)

They were among the growing number of researchers who argued that "natural disaster" was an inaccurate description of the harm caused by natural hazards such as storms, earthquakes, or droughts. This line of thinking held that the disaster did not come primarily from the physical event itself, but from social processes which placed people, some more than others, in harm's way.

This shift in thinking about disasters began with the work of political ecologists in the 1970's and 80's such as Michael Watts (1983) who challenged the idea that disasters occurred because cultures were maladapted to their environments, an idea which "reduced exposure and response to hazards to a series of purposeful choices by rational individuals, with little reference to social structural constraints or historically contingent conditions" (Neumann 2005, 24). Watts studied villages experiencing drought and famine in northern Nigeria, and found that the decrease in food production that had occurred during the drought was the result not just or mainly from the drought, but from the changes in the local food production system that had occurred under and as a response to colonialism. Villagers had decreased their cultivation of traditional food crops and increased cultivation of cash crops in order to pay taxes and participate in the market economy, and when the drought hit they were left with reduced food supplies, which resulted in famine. Watts and other researchers showed that vulnerability to disasters was 
due to more than just the choices made by individuals or cultures, but was the result of historical, social, and political forces such as globalization and colonialism.

A similar emphasis on structural constraints has been applied in urban, "firstworld" contexts by researchers in the sociology of disasters. Researchers studying Hurricane Andrew which hit Miami in 1992 similarly found that groups which are more marginalized and therefore have less political power and economic resources are more vulnerable to harm from "natural" hazards (Morrow 1999). Different population demographics including gender, class, race, and immigrant status have been shown to influence ability to cope with environmental hazards (Peacock, Morrow and Gladwin 1997). The most well-known example is the destruction wrought by Hurricane Katrina which struck New Orleans in 2005, which was widely interpreted as the result of the historic land use patterns, infrastructure development, and segregation (Flaherty 2010, Dawson 2010, O’Brien 2006). Over time land had been reclaimed in the delta city through levee construction and residential development had been encouraged in lowlying areas, exposing people to the risk of flooding if the levees were to fail and creating a "disaster waiting to happen" (Fischetti 2001, 77). Social factors such as age, income and race influenced who lived in higher risk areas and who was able to evacuate, producing differentiated vulnerability and outcomes in terms of survival and recovery (Finch, Emrich and Cutter 2008). New Orleans was a highly segregated city with troubled racial dynamics (Flaherty 2010) and the residents of the low-lying areas protected by levees were mostly Black, which resulted in the large disparity in deaths with fifty-one percent being black and the majority having been residents of the lower ninth ward (Brunkard, Namulanda and Ratard 2008). However despite calls for more of a 
focus on social vulnerability, "very little progress has been made in the handling of disasters beyond a narrow focus on technological preparedness" (Haque and Etkin 2007).

Writing concerned with justice in climate change has been mostly concerned with issues between nation states, involving complex treaties and legal ethical issues such as the rights of future generations and who should bear the cost of adaptation (Beckman and Page 2008). But as adaptation efforts begin to take shape at the local scale environmental justice has relevant insights for the spatial distribution of environmental hazards, particularly in urban areas. Through the 1980's and 1990's in Texas, Louisiana, Alabama, Florida, and other states residents protested against Locally Unwanted Land Uses (LULU's) such as hazardous waste disposal sites, lead smelters, and petrochemical producers which disproportionately burdened communities of color with environmental and health impacts (Bullard 2000). The environmental justice framing of the environment links nature with human welfare by declaring the environment to be "where we live, work, and play" (Turner and $\mathrm{Wu} 2002$ ) and places human welfare at the same level of importance as the well-being of nature. As my work and that of many others shows, climate change has significant impacts for "where we live, work, and play." Because environmental justice is grounded in the experiences of marginalized communities, justice and equality are central to how environmental justice frames environmental issues (Taylor 2000).

A few scholars have applied an environmental justice framework to climate change vulnerability research, seeking to understand the spatial distribution of minority residents across hazardous areas (Montgomery 2013). This work uses GIS to correlate elevation or flood zone data with variables such as race, ethnicity, and poverty. However 
as purely quantitative analysis this work suffers from a lack of context, and as a consequence produces mixed results. Although it claims an environmental justice perspective, it analyzes only the outcome state of unequal proximity to hazards, and ignores the processes which produce such outcomes such as the unequal or negligent enforcement of laws and protections from environmental hazards, which are a central concern of environmental justice (Bullard 2000). In particular, decisions that located toxic waste dumps, chemical plants or other hazardous facilities disproportionately in low-income communities or communities of color, termed "environmental racism" (Bullard 2000) negatively impacted quality of life and property values (Bullard 2000, Checker 2005). This environmental justice research showed how local governments are capable of making decisions that disadvantage certain communities over others, and must be taken as a lesson for climate adaptation decisions as infrastructure investments and land use changes are considered.

This focus on process, history and context parallels the "human security" framing (O’Brien et al. 2007) and the "vulnerability as produced" (Dooling and Simon 2012) approach. They stand in opposition to locational-technological-systems approaches in which the human dimensions are less visible, although they are not necessarily in conflict and may even be complementary (O’Brien et al. 2007). Over the last two decades attempts have been made to develop "integrative" approaches that combine the biophysical and social dimensions of disaster vulnerability, and despite criticisms this approach remains highly influential (Rothman and Robinson 1997). Aided by improvements in the ability to map large datasets, the integrative approach has been used particularly in examining vulnerability in a particular place. Cutter developed a "hazards 
of place" model that combines biophysical and social indicators to assess vulnerability in a local area (Cutter, Mitchell and Scott 2000, Cutter 1996). This work was aimed at improving an emergency preparedness model developed by several federal agencies in which vulnerability was treated merely as the presence or absence of hazard risk. Cutter's model included indicators of physical hazard risk such as the location of toxic waste sites, and the probability of storms or fires, among other things, and demographic indicators of social vulnerability established in the literature such as poverty and minority status. These indicators were applied to a local area using GIS to create an index of "overall hazard vulnerability" that varied across a local area (Cutter, Mitchell and Scott 2000).

The fact that this model can be mapped with readily available data gives it utility as a practical tool for planning purposes. In fact Cutter recently deployed a version of this tool in 2013 as a Social Vulnerability Index for sea level rise, through the website Climate Central. However the conceptual model is a fairly simplistic two-dimensional combination of equally weighted variables that even by Cutter's own account doesn't take into account "the root causes of the antecedent social vulnerability, larger contexts, and post-disaster impact and recovery" (Cutter et al. 2008, 601), factors which are critically important if the model is to be used for assessing and ultimately reducing vulnerability. Further attempts to develop a conceptual model of vulnerability by Turner et al. (2003) and Cutter et al. (2008) include temporal dynamics, social learning in the form of preparedness and mitigation, and the interactions between natural systems, social systems, and the built environment.

The integrated models have been criticized for their inadequacy to address the root causes of vulnerability however. O'Brien et al. (2007) argue that integrative models 
represent an attempt at merging two different framings that doesn't quite work. They identify two opposite approaches to vulnerability: a "scientific framing" which sees vulnerability as an outcome or end-point after adaptation has taken place, and a "human security framing" which sees vulnerability as contextual, as a present inability to cope with external pressures or changes. The contextual approach reflects a concern with the vulnerability of individuals and groups, rather than a systems theory perspective (Berkes 2007) which doesn't account for the differential impacts of disasters on differently situated people or communities within the system. Thus where the integrative models fail is that in attempting to integrate opposite approaches to vulnerability as both a starting and an end point they obscure or ignore the processes that create it (O’Brien et al. 2007). Further, the systems approach leads to offering solutions that are technological rather than people-centered (Cannon 1994, O’Brien et al. 2007), which has important implications also for how adaptation and resilience are conceptualized. The contextual approach, on the other hand, assesses the present capacity of groups or communities to cope with change in more general terms of poverty, capacity, culture, and history, and looks for adaptations that reduce vulnerability and increase resiliency now (O’Brien et al. 2007).

Contextual conditions, of course, are never static but dynamic. Dooling and Simon (2012) see vulnerability as "sets of dynamic conditions produced from historic interactions across economic, cultural and social processes" (5). Understanding the dynamics of the production of vulnerability allows for an understanding of the root causes and the ways that responses to environmental change can reduce or increase vulnerability. "A production-oriented framework provides conceptual space for analyzing 
how interactions between political economies of resource use and normative planning and management interventions - at both global and local scales - influence which places and populations are made vulnerable, and the intensity and persistence of conditions of vulnerability" (Dooling and Simon 2012, 5). This shift to a focus on process and interactions rather than static variables that determine vulnerability may prove to be particularly valuable at this stage of climate change research, when we are just beginning to understand the impacts on communities and the responses and adaptations that follow.

\section{Adaptation and Transformation}

Most of the concern surrounding climate change vulnerability has centered on the effects of climate change impacts, and the potentially unequal effect of those impacts on vulnerable communities. But comparatively little attention has been paid to the impacts of the efforts to deal with climate change, that is, adaptation. As with any other changes in infrastructure, policy, governance, and use of public resources, the potential exists for unequal distribution of risk or burdens. Therefore studying the processes and impacts of adaptation actions is an important part of a full picture of vulnerability to climate change.

Adaptation broadly refers to actions taken to adjust to the impacts of climate change. It is often juxtaposed with "mitigation," which in climate change research refers to efforts to reduce greenhouse gas emissions. Research on adaptation is relatively recent, coming mostly in the last 10 years since the failure of international negotiations to significantly reduce GHG's began to make it apparent that some degree of impacts could not be avoided. In fact talk of adaptation was considered something of a "taboo" until the mid-2000's for fear that effort spent on adaptation would take away from efforts at 
mitigation (Pielke et al. 2007). Indeed adaptation is still considered to be a less preferable option for some, because "mitigating climate change helps to reduce impacts on all climate-sensitive systems, whereas the potential of adaptation measures is limited for many systems" (Füssel and Klein 2006, 304). But as the impacts of climate change are increasingly felt and recognized, adaptation is becoming no longer a choice but a reality for local areas.

Adaptation, according to the IPCC is "the adjustment in natural or human systems in response to actual or expected climatic stimuli and their effects, which moderates harm or exploits beneficial opportunities" (Parry et al. 2007, 27). Adaptation to climate change can be either by collective action or individual action, and it can be proactive, reactive, or neither (Adger et al. 2006). Proactive steps can reduce negative impacts "while facilitating a more rapid and efficient response to changes as they happen" (NCA 2011b, 984). It has been often observed that adaptation is local, since "there is no one-size-fitsall adaptation solution to the challenges of adapting to the impacts of climate change, as solutions will differ depending on context and scale as well as on local culture and internal capacity" (NCA 2011b, 993, also Grothmann 2011). For this reason adaptation has fallen especially to local areas, and it presents a significant challenge for local governments which must mediate between different interests and determine priorities for limited resources. Attempts to plan collective, proactive adaptation strategies have had mixed results so far, such as a case of a coastal New Zealand community attempting to plan for likely significant future erosion due to sea level rise by limiting coastal development, which prompted a backlash from owners of coastal properties (Hayward 2008). Indeed a study by Few, Brown and Tompkins (2007) in the U.K. suggests that in 
the absence of immediate impacts of climate change public support for proactive strategies cannot be assumed because of concerns about the cost and consequences of such actions.

The first step for local proactive adaptation planning is usually a vulnerability assessment which looks at the projected climate impacts for a particular area and assesses the structures and populations likely to be vulnerable to those impacts. Füssel and Klein's (2006) review of climate assessments finds that assessment models evolved from estimating solely climatic impacts for a particular area to incorporating non-climatic indicators and the potential for adaptation, and finally becoming full-fledged 'adaptation policy assessments' which "aim to contribute to policy-making by recommending specific adaptation measures" and which are

characterized by the intensive involvement of stakeholders, by a strong emphasis on the vulnerability of a population to current climate variability, by the formulation and evaluation of response strategies that are robust against uncertain future developments, and by the integration of adaptation measures with existing policies. (324)

Still, as noted above, vulnerability assessments conducted with integrative models mostly lead to technological solutions, and this is evidenced by planning processes under way in many urban, developed country settings. Plans from San Diego, New York, and South Florida (Nordensen et al. 2011, ICLEI 2011, SFRCCC 2012a) focus on infrastructure, transportation, and ecosystem restoration, with some consideration given to planning policy but scant or non-existent mentions of social vulnerability factors.

Adaptation presents large decision making and management challenges, given uncertainties about the spatiality and temporality of climate impacts, lack of knowledge and capacity on the issue, and difficulties in aligning planning time frames and competing 
interests (Sharma and Tomar 2010, Few, Brown and Tompkins 2007). These challenges mean that adaptation actions may even increase vulnerability in some instances, such as when tradeoffs emerge from temporal and scalar conflicts. For example pumping against sea level rise can protect an urban coastal settlement from flooding, but may increase greenhouse gas emissions. Some have called these actions "maladaptive," and additional types of maladaptation include encouraging development in vulnerable areas, the reduction of incentives to adapt, high opportunity costs and disproportionately burdening the most vulnerable (Barnett et al. 2013, Kates, Travis and Wilbanks 2012). Social justice concerns have also been noted, such as when unequal access to decision making exacerbates impacts on vulnerable populations. Adger et al. (2006) note that often "collective adaptation decisions made at the local and national levels end up protecting vested interests.... and marginalized groups remain vulnerable because they cannot participate in and influence decisions and structures that create their vulnerability" (13). The result is that "actions taken to adapt to climate change can themselves have important justice implications because their benefits and costs are frequently distributed in ways that consolidate or exacerbate current vulnerabilities rather than reduce them" (Adger et al. 2006, 4), such as when reconstruction funds after a disaster flow to areas that already have some capacity rather than those that were the most vulnerable beforehand (Eriksen and Silva 2003).

The current approach of many local governments is one of "mainstreaming" adaptation planning into existing government operations and planning processes (Kates, Travis and Wilbanks 2012, Benzie, Harvey and Miller 2011, Sharma 2010). In development contexts climate change compounds existing challenges of urbanization, 
e.g. lack of housing, transportation, water and sewer infrastructure, and additional rural migrants (Sharma 2010). In developed country urban settings, mainstreaming climate adaptation takes the form of incorporating adaptation into infrastructure upgrades, hazard mitigation, and other existing functions (NCA 2011b) such as in the U.K. where researchers found that "the key issue in current approaches to adaptation is the ambition to mainstream climate change into different policy areas; the ambition is to address the risk of climate change in a way that enables 'business as usual' as much as this is possible" (Benzie, Harvey and Miller 2011, 236). But whereas these functions rely on well-established methods of planning and projecting future need or risk based on historical data for a particular location, climate change introduces considerable uncertainty into future projections, complicating decision making (Moser and Boykoff 2013).

In light of this uncertainty new frameworks for decision making have emerged that "promote options that allow reversibility, preserve future options, can tolerate a variety of impacts, and are flexible, such that mid-course adjustments are possible" (NCA $2011 \mathrm{~b}, 999)$. One of these cited approaches, adaptive management, developed as a strategy for managing natural resources in an integrated human-natural systems framework. It accommodates uncertainty by emphasizing social learning and traditional knowledge for interacting with the ecosystem, resulting in practices which improve resilience (Berkes, Colding and Folke 2000). In areas at risk of climate impacts such as coastal environments, it has been found to enhance adaptive capacity by "building networks that are important for coping with extreme events and by retaining the resilience of the underpinning resources and ecological systems" (Tompkins and Adger 
2004). Adaptive management promotes flexibility that is critical for dealing with uncertainty by putting in place "institutions that incorporate adaptive management to assure that decisions can be updated as one gains experience and as new scientific information becomes available" (NCA 2011a). However it has also been criticized for allowing regulatory institutions to avoid criticism by claiming that plans are continuously subject to change (Clark and Dalrymple 2003).

The iterative approach is central to accepted climate adaptation planning approaches (Moser and Boykoff 2013), including the one recommended by the National Resource Council (NRC), "iterative (or adaptive) risk management." The NRC defines iterative rise management as "an ongoing process in which the potential but uncertain consequences of climate change and climate policy are identified, assessed, prioritized, managed, and reevaluated in response to experience, monitoring, and new information" (NRC 2010b, 92). In contrast to other decision making frameworks such as ad-hoc decision making, which fails to address the time lag between actions and consequences, or a precautionary framework which avoids harm but is less able to deal with competing goals, the iterative risk management framework is a more holistic process that considers multiple options and priorities. It recognizes that decision making in adaptation "does not constitute a single set of judgments at some point in time but rather ongoing assessment" (NRC 2010b, 103). The iterative process consists of a cycle of steps from identifying objectives and criteria/values to assessing options, implementing strategies, and finally regular monitoring and reassessment of system inputs which allows decision makers to "learn from experience and respond to new information to reduce, control, or manage negative outcomes" (NRC 2010b, 100). Information on trends in population and the 
economy, physical impacts, costs, policy changes is monitored and re-assessed in order to make adjustments and to make sure strategies are effectively addressing the objectives and respond to new problems and opportunities (Willows and Connell 2003).

An example of developing iterative adaptation options is the conceptual framework proposed by Felgenhauer and Webster (2013), which addresses one of the key challenges of adaption planning, the uncertainty over the timeframe of climate change impacts. Particularly for sea level rise many of the options for adaptation are infrastructure investments such as dykes, barriers, raising roads and bridges, which are costly and have a life span of decades or more, limiting the opportunities for adjustments and course corrections based on new information. Felgenhauer and Webster's framework "explicitly treats the problem as a multi-stage decision under uncertainty" (1556) by assessing options in terms of lifetime and cost, allowing for decisions to be made that address near-term needs while considering long-term scenarios and delineating decision points for a change in strategy. The options are grouped in three types. The first is shortlived flow spending, such as beach renourishment or irrigation. These investments have low sunk costs so the potential for over-investment is limited, and they can be started or stopped relatively quickly. The second group is committed adaptation stock, such as sea walls and sewer improvements, which are long-lived, high cost investments dependent on current technology. The third group is "option stock" which is less costly and allows for later upgrading if needed. An example is over-building the foundation for a dyke, which adds some amount to current costs but reduces future costs by laying the groundwork that will allow it to be enlarged later if conditions warrant. The authors argue that 
given the uncertainty, there should be greater emphasis on option stock adaptation in the near-term, and that an optimal hedging strategy will consist of a balanced portfolio with enough adaptation investments to reduce the uncertainty in their effectiveness and some mitigation investment because adaptation may turn out to be less effective or more costly than expected. (1561)

Such frameworks provide a method for decision making when a suite of options exist. But one of the major emerging issues in adaptation research is what happens when locations or systems come up against limits of adaptation. While incremental frameworks such as adaptive management seek "to avoid ecological thresholds at scales that threaten the existence of social and economic activities" (Berkes, Colding and Folke 2000, 1260), the potential magnitude of impacts such as sea level rising three to five feet this century is raising serious questions about the impacts on settlements in particularly exposed locations (Nicholls et al. 2008). Indeed several communities in low-lying coastal areas have already been relocated or are planning for relocation due to sea level rise, which presents a host of challenges including employment, shelter, negative cultural and psychological impacts (de Sherbinin et al. 2011). So scholars have begun to consider scenarios for some places and systems where "vulnerabilities and risks may be so sizeable that they require transformational rather than incremental adaptations" (Kates, Travis and Wilbanks 2012).

Generally transformation is understood to denote "paradigmatic and systematic changes" (Moser and Boykoff 2011,32) and as such is differentiated from the more common notion of adaptation as incremental, iterative approaches that "maintain the status quo or only make minor adjustments to 'business-as-usual' governance and management processes" (Moser and Boykoff 2013, 12, also Benzie, Harvey and Miller 2011). Those considering transformation question how fundamental and large scale 
change could be "mainstreamed into existing structures of society" and whether this is even "oxymoronic" (Moser and Boykoff 2013, 12). But transformative adaptation is still poorly understood (Moser and Boykoff 2013), particularly how planned, anticipatory, transformation might be implemented (O’Brien 2011). Kates, Travis and Wilbanks (2012) assess existing adaptation efforts and identify three classes of adaptations as transformational: "those that are adopted at a much larger scale or intensity, those that are truly new to a particular region or resource system, and those that transform places and shift locations" (7516). Examples they give are the London plan to build higher barriers around the Thames estuary, desalinization where it hasn't been used before, and the relocation of species. In most cases the examples are collective adaptations but some are autonomous actions that cumulated in transformative adaptation, such as the re-greening of the Sahel which was begun by farmers cultivating trees to protect crops from wind and evaporation, and has grown into a green belt of 5 million hectares.

The socio-ecological processes driving (or blocking) transformative adaptation is an important emerging area of research. Kates, Travis and Wilbanks (2012) list some of the key factors in planned, anticipatory transformation,

Implementing transformational adaptation requires effort to initiate it and then to sustain the effort over time, and frequently long periods of time. In initiating transformational adaptation, it seems likely that external drivers in the form of focusing events and multiple stresses are important combined with local leadership. In sustaining transformational adaptation, it seems likely that supportive social contexts, especially if they are combined with incentives, and the availability of acceptable options and resources for actions are key enabling factors (7156).

Karen O'Brien (2011) argues that the key challenge is the social and psychological shift, and that a "deliberate science of transformation" is needed that engages "with the real 
'adaptive challenge' of climate change, i.e. a questioning of the assumptions, beliefs, values, commitments, loyalties and interests that have created the structures, systems and behaviours that contribute to anthropogenic climate change, social vulnerability and other environmental problems in the first place" (668). She argues that research on adaptation should "consciously create alternatives" for transformation, given that neither mitigation or adaptation will likely be sufficient to avoid suffering.

Many scholars have argued that the road forward for climate change adaptation lies with participatory and transdisciplinary processes, or "boundary processes," for epistemological, practical, and ethical reasons. Transdisciplinary research and processes "go beyond science" to include "mutual learning among scientists and society" (Sholz 2010, 73), with a key component being joint problem definition. Joint problem definition allows for scientific research to be conducted that bears on practical problems, and adaptation research at its heart is about solving practical problems stemming from environmental change. Similarly, boundary processes "facilitate the flow of information and sharing of knowledge between decision-makers and scientists/technical experts" (NCA 2011b, 930) by bringing scientists and stakeholders together in a decision making process. Because adaptation is a complex problem with needs and options that vary by location, sector, and affected populations, an interactive process that incorporates different knowledge bases and perspectives produces more practically useful knowledge (NRC 2011b). It also promotes engagement, which is needed for effective implementation (Brown 2012). The National Climate Assessment's review of decision making support mechanisms for climate mitigation and adaptation concluded that these processes "better enable decision-makers to apply complex information to decisions, 
consider uncertainties associated with climate variability and change, assess the wide range of possible human responses, and engage institutions and individuals who are potentially affected" (NCA 2011a, 925). Participatory processes have also been shown to increase public support (Fung and Wright 2001).

A number of transdisciplinary efforts at addressing climate change are already underway or have been tried in various forms, at local, regional and national levels (Renn 2004, Fung and Wright 2001). Local areas are the ones who will ultimately be responsible for adaptation (Moser 2005, Sharma and Tomar 2010), and given the magnitude of the potential impacts and changes that may be required, a successful plan will need to have public support. Participatory processes have been shown to increase public support, such as Fung and Wright's “empowered participatory governance” (2001). However success at the local level has been mixed. Few, Brown and Tompkins (2007), who studied the feasibility of participatory processes for anticipatory planning for climate change in the U.K. found that there was not enough consensus on the need to do anticipatory planning at all, so that any process with a defined goal of anticipatory planning would need to "limit the ambitions of inclusion and be explicit from the outset about the true scope of public involvement" (56). Even with this limitation the experience of New Zealand (Hayward 2008) points to the need for community participation in adaptation planning because otherwise more powerful citizens or interest groups can dominate local decision making. Indeed with the lack of experience, precedents and laws for dealing with climate change impacts such as rising sea level, the potential for conflict is significant and proactive, and community involved planning is necessary to avoid 
intimidation of policy makers into leniency in implementation and making decisions that create more problems down the line (Moser 2005).

Participation is also important for ethical and justice considerations, as decision making cannot be left to science alone. Adaptation is inevitably normative, as it involves choices between sometimes conflicting interests, values, and options, and though science can help define adaptation options, risk, goals, and processes, it cannot decide what is "right" or "good" (Moser and Boykoff 2013). In addition, since the outcomes of adaptation may not be known for some time, then "evaluating the adaptation process.... becomes at least as important as the question of success in outcomes" (Moser and Boykoff 2013, 20). Given the potential for adaptation actions to produce externalities for distant temporalities, spatialities or other social objectives, decision making processes should consider equity and vulnerability (Adger, Arnell and Tompkins 2005, Ericksen et al. 2011).

\section{Urban Challenges of Adaptation}

Using an iterative risk management strategy for sea level rise, the National Climate Assessment suggests that "decision criteria might include minimizing long-term costs and maximizing public safety. The relevant information might involve using scenarios to frame uncertainty in sea level rise and to understand how to translate that information into identifying property and ecosystems at risk" (NCA 2011a, 928).

Political ecological attention to urban contexts is rising, which is important because climate change impacts, particularly sea level rise, will have a profound and perhaps unprecedented impact as urban areas which are major centers of population, 
investment, industry and therefore power (Hodson and Marvin 2009) risk the loss of some of their most valuable assets (Nicholls et al. 2008). Urban political ecology theorists assert that "the urban process fundamentally constitutes a political-ecological process, one that shapes the process of production of urban natures" (Swyngedouw and Heynen 2003, 901). This is because

cities are dense networks of interwoven sociospatial processes that are simultaneously local and global, human and physical, cultural and organic. The myriad transformations and metabolisms that support and maintain urban lifesuch as, for example, water, food, computers, or movies - always combine physical and social processes as infinitely interconnected. From these perspectives, there is no such thing as an unsustainable city in general. Rather, there are a series of urban and environmental processes that negatively affect some social groups while benefiting others. (Swyngedouw and Heynen 2003, 901)

This means that the urban geographic dimension has different implications for first and second order effects of climate change. For first order effects, research on the geography of opportunity has shown that factors which contribute to social disadvantage such as low income and low education, tend to be geographically concentrated and to perpetuate states of low investment and low opportunity (Benford et al. 2009). So if a household or community in a low opportunity area experiences hazards associated with climate change, it is vulnerable beyond simply its socio-economic situation but also because of the reduced adaptive capacity in its surroundings.

\section{Methodological approach}

Current models and approaches to studying vulnerability have significant gaps in their ability to meaningfully assess vulnerability to climate change and to point a way forward to effective and fair adaptation in local areas. In particular there is a need to 
integrate data on the biophysical changes associated with climate change with the socioeconomic responses in order to understand the interactions between the two and the types of adaptation appropriate for a given situation. Not finding a method in the literature for studying the early impacts of sea level rise in urban communities from a ground-level perspective, I developed an innovative method that combines sociological methods with physical observations in order to assess the social impacts of urban flooding. The method fits within a political ecology approach which typically combines historical analysis, discourse analysis, ethnography and ecological data analysis (Neumann 2005). My research explores the physical and human dimensions of climate impacts and how they interact to produce vulnerability. I will first elaborate on the principles underlying the methodological approach, then describe the research design including definition of concepts, operationalization, data gathering methods and analysis.

As discussed previously, political ecology has been influential in infusing a critical perspective into disaster research and for emphasizing the contextual nature of vulnerability to environmental hazards. Goldman, Nadasdy and Turner (2011) differentiate political ecology from other social science fields concerned with environmental politics, such as environmental sociology and cultural ecology, by outlining three characteristic features which I will address in turn:

1. A commitment to incorporating understandings of the biophysical processes that underlie environmental change and the availability of natural resources

2. An emphasis on understanding environmental politics as geographically and historically situated (i.e. the "case-study" approach)

3. Strong commitments to social justice. (7) 
First, as I will describe in more detail below, my work engages substantially with the biophysical dimensions of climate change impacts and vulnerability in the study area. More than just a "backdrop to social conflict," in political ecology "the nature, rate, and spatial extent of ecological change are seen to matter in the unfolding politics surrounding the environment" (Goldman, Nadasdy and Turner 2011, 7). While the established models and theories I have discussed in the literature on vulnerability to environmental hazards could have suggested a research project that focused solely on assessing social vulnerability indicators, I felt the nature of ecological change due to climate change, specifically the onset of sea level rise, was a sufficiently different type of urban-ecological change as to require an investigation of its nature as a starting point for understanding social impacts. For one thing, accelerated sea level rise causing increasingly frequent flooding in an urban area is a new phenomenon that does not have any ready parallels. Secondly, South Florida's geology and topography are a unique ecological context. And lastly, there existed no studies of the physical impacts of sea level rise in the study area. In order to understand how vulnerability is produced, I needed to understand what that vulnerability was in relation to.

The second point, the "case-study" approach, is characteristic of political ecology because of its heritage both in the social sciences and ecology fields, which have as a method deep examination of relationships in a particular place. A good list of the characteristics of case studies is given by Billick and Price (2010)

Case studies "focus in depth on phenomena in their real-world context; rely on non-random selection of one or a few cases whose unique characteristics facilitate meeting research goals; use multiple types and sources of information about each case to answer the research question evaluate theory by whether it can be successfully modified to fit rich patterns in data associated with one or a few 
cases rather than on a simple falsification criterion; use a logic of analytical rather than statistical generalization--that is they predict how a phenomenon is manifested in particular cases, rather than summarize frequency of occurrence across cases; and they require multiple-investigator teams to carry out a multifaceted research design. (5)

Though my research was not conducted by a multiple-investigator team, I did consult with researchers outside of my field for background information on hydrology and tides so that I could design research a physical-ethnographic research strategy that would be feasible and productive. I also consulted with storm water engineers so that I would be able to ask knowledgeable questions and properly interpret the data I was gathering for that component of the study. I found that combining these multiple sources of information was critical to achieving my research goal of a dynamic and complex understanding of vulnerability.

The third point, a commitment to social justice, is regarded as a liability in more positivistic science research, but since the post-modern era self-reflection about one's position in the research and acknowledgement of oneself as part of the construction of knowledge is a norm for the humanistic social sciences. I have chosen to conduct research in the community where I live and work, and the potential benefit of sharing my findings with the community was a key reason for choosing this research topic. My concerns with social justice have influenced my approach to the research design, including the questions I have raised and the theoretical perspectives I have drawn from. But in contrast to more activist research projects, I have generally limited my activities as a participant observer to non-activist roles, and where I have acted as an activist I have done so for specific reasons and kept note of those activities, which I will describe here. 
In my case study of Miami Beach, I was a participant observer in neighborhood association meetings and City committee meetings. During those meetings, and in conversations with participants of those groups, I refrained from mentioning my interest in climate change, identifying myself instead simply as a graduate student studying "urban sustainability." My primary participation in the meetings was listening and occasionally offering comments that were not related to climate change or flooding. This was because I wanted to observe when and how climate change was discussed in these settings, if at all, in order to understand the discourse and what impacts it had on different aspects of urban governance. Only after attending several meetings would I then reach out to select participants for interviews. After more than 6 months of participating and researching in this way, I began to identify opportunities to use the knowledge I was acquiring in a way that put forward new ideas which I felt would be beneficial to the community, such as creating a blog and sharing it with neighborhood activists and City officials. By this point my data was mostly gathered and where I believe this had an impact on my research findings I have noted it.

My approach reflects a pragmatist approach, as articulated by qualitative researchers Corbin and Straus (2008),

What is discovered about 'reality' cannot be divorced from the operative perspective of the knower, which enters silently into his or her search for, and ultimate conclusions about, some event. This does not lead to radical relativism.... Instead the Pragmatists, like any practicing scientist in their day or ours, must make a couple of key assumptions. One is that truth is equivalent to 'for the time being this is what we know - but eventually it may be judged partly or even wholly wrong.' Another assumption is that despite that qualification, the accumulation of knowledge is no mirage. (4) 
Since discovery cannot be separated from the "discoverer," that knowledge is constructed, and research is designed to construct it. The constructivist viewpoint is that "concepts and theories are constructed by researchers out of stories that are constructed by research participants who are trying to explain and make sense out of their experiences and/or lives, both to the researchers and themselves. Out of these multiple constructions, analysts construct something that they call knowledge" (Corbin and Strauss 2008, 10). There is a fine line between positivistic and post-modern approaches in this research project. Climate change is real -- yet any understanding of how people perceive, interpret, and react to it, is constructed.

So far this is not very different from other social science research projects. But for a project on climate change vulnerability, which is a relatively new field for the social sciences, has a strong interdisciplinary bent and a strong applied arm, and a contentious political history to boot, the construction of knowledge begins with the very decision to select a topic called "climate change," and to select a study area as a location being impacted by climate change, and further to try to talk to the people who live there about it. My selection of this topic was in many ways a response to the construction of natural science researchers and government planners who voiced concerns based on scientific data that Miami Beach was vulnerable to sea level rise and that this was related to recent flooding events. But I was aware that the people I would be interviewing might not, and in fact probably did not, share this understanding. Throughout the research I was very conscious of negotiating a path between maintaining enough structure so that my results would be meaningful, but still allowing for responses that elicited the thought patterns of my informants in ways I did not expect. For example, by probing residents' views on 
changes they had seen in Miami Beach I found that residents who did not necessarily believe in human caused climate change still showed concern for the long-term viability of the City.

I did not assume that residents and businesses would have thought about climate change previously, and so I avoided use of the term initially in the interviews. I recruited participants to talk about the impacts of flooding, and only if they mentioned sea level rise did I ask if they connected the flooding to climate change. By allowing this flexibility and avoiding the suggestion of politics that the term climate change carriers, I was able to elicit alternative perspectives on the flooding, such as the perspective that it was not increasing, and even alternative perspectives on sea level rise, i.e. that it is "nature." If, during the interview, a respondent mentioned climate change or sea level rise, then I would probe further with questions about how they connected the flooding to climate change and what they felt that meant for their future decision making. Or if he/she asked me questions about the flooding, sea level rise, or adaptation planning I would answer as directly as possible, providing honest answers but trying not to overwhelm my interviewee with information. Especially in these moments, the interviews were more like a conversation and we learned from each other.

Also, the open structure of the interviews was critical in allowing me to capture what is my main theoretical focus, which is that vulnerabilities are produced, not just by the physical phenomenon of sea level rise but by a host of social, economic, and historical factors interacting with a changing environmental. One example of this was when I learned from the grocery proprietor that three years ago he purchased some planks as an adaptation to the flooding, but only after a competing grocery moved in several 
blocks away, and he was afraid his businesses would suffer when customers now had an option to go elsewhere when his store was inaccessible due to the flooding. Qualitative work is designed to be flexible enough that many of these nuances can appear. Yet it is impossible to be comprehensive enough to account for every aspect, and I don't claim to have achieved that here.

This is one of the key reasons why more qualitative research is needed in climate change research. Models and indexes abound but they cannot readily illuminate the complex interacting factors that go into decision making. They have been criticized for use as policy tools such as by Barnett et al. (2008) who write "we question the very possibility of reducing complex social-ecological processes to numbers, or a number, given the diversity of spatiotemporal processes involved" (115). Although their critique is directed at the use of indexes for large scale units of analysis such as inter-country comparisons, I believe this critique is also valid at smaller scales, because vulnerability factors can vary greatly even neighborhood by neighborhood. This critique is relevant to my study area because the vulnerability analyses currently available for the region are models based on quantitative date-elevation. Although South Florida has as sophisticated an understanding of our biophysical impacts as any area due to work by water managers and local scientists from universities, there has been little research so far on socio-economic factors of vulnerability to climate change in South Florida.

Füssel and Klein's (2006) analysis of the evolution of vulnerability assessments found that second-generation vulnerability assessments, which include assessment of adaptive capacity along with traditional vulnerability factors, require the involvement of social scientists and make heavier use of qualitative data. They argue that qualitative 
approaches allow these types of assessments to produce more realistic estimates of society's risk due to anthropogenic climate change by

identifying a number of ways to maximize the utility of vulnerability analysis, including more recognition of vulnerability as a product of coupled humanenvironment systems; identifying the 'complexity, interconnectedness, and iterative nature of the components' that generate vulnerability; situating the vulnerability of a particular place in a larger spatial and historical context; [and] including both quantitative and qualitative data. (320)

This approach which highlights the complexity and the importance of context in producing vulnerability is in essence what I have attempted.

\section{Research Design}

My study consists of two components which will be used to produce an analysis of social vulnerability to climate change. My primary concern with climate impacts is with sea level rise, both the current impacts of flooding and the long-term reshaping of the landscape. I define vulnerability as "a state of well-being" which is "not the same for different populations living under different environmental conditions or faced with complex interactions of social norms, political institutions and resource endowments, technologies and inequalities" (Adger 1999). Also of critical importance is how vulnerability is produced (Dooling and Simon 2012) through the interaction of contextual conditions and actions taken at different scales, including particularly adaptation actions. My focus is on the individual, household, community, and county level factors, as little apparent action is being taken at the state, national, and international levels on adaptation as of yet. 
Research Question 1: What hazards do the early stages of sea level rise pose for the urban ecology and how does this impact urban life? What are the perceptions of urban flooding among residents and businesses who experience significant flooding and how does this impact their decision making?

The first component of the research is an urban ecological analysis of the potential hazards related to sea level rise in Miami Beach. The existing vulnerability analyses are based on predictions of sea level rise measured in static feet and analyzed spatially with Geographic Information Systems (GIS) to produce include "inundation maps" which show the extent of flooding in an urban area at high tide for a given stage of sea level rise. But this method has many limitations because the maps do not take into account the variation in water level due to tides, which is important for understanding the true impact on urban life during the early stages of sea level rise. Nor do the maps take into account physical barriers, drainage systems, or other built environment features that control the flow of water. So it is not clear from these maps how low levels of sea level rise actually impact the daily lives of urban residents, and therefore a better understanding of the impacts of tidal flooding is important for understanding what the early of stages mean for South Florida.

I began by conducting observations in the study in the study area during times of flooding under varying conditions of rain and high tides in order to map the extent of flooding and to identify sites that experience severe flooding for more extensive focus. Over a period of eighteen months I conducted ethnographic observations on thirty-two different days, mostly concentrated during a period of four months in the fall of 2012 when flooding was unusually severe. I took photos and noted flood depths and times 
which I later matched with National Oceanographic and Atmospheric Administration (NOAA) tidal data from the Virginia Key tide station, which is the closest station to Miami Beach that records water levels, to produce an analysis of the extent and changes in flooding in Miami Beach over the last fifteen years, as far back as data from the Virginia Key station is available.

I also conducted interviews with ten residents and nine businesses in the areas surrounding the selected sites. This is theoretical sampling (Corbin and Strauss 2008) designed to recruit a sample of people with direct experience with flooding. I recruited interviewees mainly through contacts I had in the neighborhood, asking people I knew if they would help me to arrange an interview with someone they knew who lived in the area. Most contacts arranged one interview, with two being the most interviews I had from the same source. I also recruited three interviews from knocking on the doors of residences I saw that experienced flooding. The interviewees came from a range of socioeconomic statuses, genders, ages, and ethnicities (see chart below). I interviewed five homeowners (including one couple) and five renters, and seven small and two large businesses. The purpose of the interviews was to elicit the impacts the flooding has on the lives and businesses of the interviewees, their perceptions of the flooding and its connection with sea level rise, and how the impacts and perceptions influence their decision making about the location of their home or business. The interviews were semistructured, and ranged from thirty minutes to one and a half hours. The interviews were recorded if the subjects would allow, and if not then detailed notes were taken during the interview and immediately afterward the notes were typed up to allow as much recall as possible. The interviews and the flood observation data were imported into NVivo and 
coded for themes under major categories including disruptions, adaptations, and perceptions. Findings in these major categories are reported in chapter four, as well as further analysis of the connection between disruptions and perceptions in an attempt to assess correlation between experiences with flooding and decision making.

Table 1.

Miami Beach Resident Interviews.

\begin{tabular}{l|c|l|l}
\hline Tenure & Socio-economic status & \multicolumn{1}{c|}{ Age } & Gender \\
\hline Owner 1 & middle class & Elderly & Female \\
Owner 2 & middle class & Middle aged & Female \\
Owner 3 & middle class & Middle aged & Male \& female \\
Owner 4 & middle class & Middle aged & Male \\
Owner 5 & middle class & Middle aged & Male \\
Renter 1 & middle class & Middle aged & Female \\
Renter 2 & middle class & Young & Female \\
Renter 3 & low income & Elderly & Female \\
Renter 4 & low income & Elderly & Female \\
Renter 5 & low income & Elderly & Male \\
\hline
\end{tabular}

Research Question 2: What are the different "logics" of climate adaptation are emerging in the South Florida "climate governance network" and how is this expressed in planning actions so far?

The second component of the research design seeks to understand the different "logics" of various stakeholder groups in the emerging climate governance network, including government officials, scientists, and activists, and how those different logics shape beliefs about adaptation strategies and South Florida's future. Documenting this emerging governance network is important for understanding how decisions are made that shape adaptation planning and influence the vulnerability of different communities in Miami-Dade. My goal for this step is to shed light on important questions including: How 
are climate change vulnerability and adaptation conceptualized? What are the relevant timeframes? What actions are being taken on adaptation, and what is driving those processes? What knowledge or experiences support decision making? These questions were designed to understand the dynamics of adaptation planning and the key conflicts, which will point to how vulnerability is produced. This component also serves as baseline research for future documentation of Miami-Dade's adaptation planning but I do not seek to be comprehensive, rather to focus on the specific question of construction socioecological vulnerability.

The research consists of two main parts: the first is a case-study of planning for climate change adaptation in Miami Beach. I interviewed ten city officials, which I arranged by calling and requesting meetings, six local activists and two business leaders who I established contacts with through participating in neighborhood meetings. I also attended fourteen city meetings, and attended seventeen neighborhood association meetings. The second part of this research question describes the emergence of the regional governance network and its approach to vulnerability and adaptation planning. I conducted interviews with eight local government officials who were leaders in the emerging climate governance network of county and regional level officials. I attended nineteen local or regional forums on climate change adaptation and took extensive notes. The interviews and selected meeting notes were transcribed and coded, using for discourse analysis. Taylor et al. (2014) use discourse analysis in a study of urban planning debates to "identify in everyday policy and planning debates how diverse urban realities are framed, and reasoned, in the language of different actors" and to "uncover how these meanings intersect with and influence the political and material outcomes of 
the policy process" (7). The interviews and meeting notes were coded for language that revealed major concerns about flooding and climate change, varying definitions of the problems, and views of how problems ought to be dealt with. The coded responses were analyzed to ascertain the underlying "logics" that unified the various groups of actors. The findings from are reported in chapter five.

The final chapter of the dissertation brings together both components of the research to draw conclusions about how vulnerability to climate change is produced in South Florida. Through this framework my research, which more precisely detects the relationship between physical hazards and socio-economic context, contributes to an improved understanding of vulnerability and risk from sea level rise by integrating physical factors into their social, historic, and economic context. 


\section{CHAPTER III - BACKGROUND AND CONTEXT}

In this chapter I will describe the context of South Florida's vulnerability to climate change, touching on its history of development into a major metropolitan region and the status of current socio-economic vulnerability indicators. I will also provide background on the emergence of regional climate governance and explore some of the aspects that point to vulnerabilities.

\section{South Florida's Development}

South Florida's environment has always been intertwined with its economy. Agriculture, tourism, and real estate are three major climate-dependent sectors of the economy, and these sectors have driven the region's economy since urbanization began. At the end of the $19^{\text {th }}$ century northern investors began buying land to establish plantations for tropical crops such as cocoanut and avocado. Later this land became prime real estate for development as the area became desirable as a winter resort for the wealthy. Henry Flagler was at this time building his railroad down Florida's East Coast and decided to extend it to Miami, according to local legend, after an early Miami booster sent him an orange blossom that had survived a harsh frost in the rest of the state in 1894 (Muir 2000). Four years later the railroad arrived, Flagler built his Royal Palm hotel south of the Miami River, and Miami grew quickly thereafter, attracting famous visitors including U.S. Presidents and wealthy industrialists.

Accomplishing the vision of these early developers meant changes to the landscape happened quickly in the urbanization of Miami. Early settlement was concentrated along a limestone ridge that ran along the east coast and fresh water flowed 
from the Everglades to Biscayne Bay through natural channels in the ridge called "transverse glades." In 1907 the State of Florida began dredging canals in order to drain the Everglades for agricultural land. These canals reduced the water levels in the Everglades, altering a delicate ecosystem which depended on cycles of wet and dry to support its unique habitat (Carter 1974). The rapids on the Miami River were dynamited, which allowed salt water to flow further up the river, turning it brackish.

Development on Miami Beach followed very soon on the heels of Miami. As historian Howard Kleinberg (1994) relates, in 1904 a ferry service was started from Miami to "Ocean Beach," the early name for the barrier island in Biscayne Bay, so that visitors could take day trips to the sandy beach. The island was covered with mangrove forest, although the southern end had been cleared for a cocoanut plantation which ultimately failed. As Miami grew developers started to pay more attention to the island, and in 1913 Carl Fisher arrived and bought up the old cocoanut plantation land for real estate development. That same year he received his first dredging permit from the state. Fisher filled the swampy land on the western side of the island through "bulkheading," which meant building sea walls, dredging from the bottom of Biscayne Bay and pouring the muck to fill in the land. More dredging to create a channel deep enough for yachts led to the creation of an entirely new small island, Star Island, in Biscayne Bay, on which Fisher built exclusive residences. Other developers followed suit resulting in almost a dozen man-made islands in the Bay.

With real estate a large part of its economy, Miami Beach has had its share of ups and downs. The City was incorporated in 1917, encompassing approximately seven square miles of the barrier island and man-made islands. Real estate development and 
urbanization picked up speed, and developers financed and built infrastructure such as bridges for cars, canals, and donated land to the city for parks and schools. Miami and Miami Beach benefitted from the 1920's boom time all over the nation, and the wealthiest Americans came to spend the winter in Miami Beach. Apartments filled to capacity in the winter, and the wealthy built mansions. Fisher and others built grand hotels and casinos, and by 1925 Fisher had made $\$ 50$ million from his Miami Beach enterprises (Kleinberg 1994). Despite the interruption of a devastating hurricane in 1926, development rebounded and continued through the 1930's, 40's and 50's. During the 1970's Miami Beach entered a slump, and became known for large numbers of elderly residents and a high crime rate. In the 1980's renewed interest in preserving the historic Art Deco buildings of the 1920's and 1930's led to the revival of the area's tourism economy based on arts and entertainment, and of course climate.

Miami Beach is a major economic engine of South Florida due to its popularity as a tourism destination. According to figures published by the City's Economic Development Office, in 2010 Miami Beach had a Gross City Product of almost $\$ 7$ billion annually, five million overnight visitors and seventeen million beachgoers annually. About a quarter of Miami Beach's economy is hospitality, and forty-four percent of the jobs in the city are in accommodation and food services. Approximately 30,000 people commute to Miami Beach daily for work, increasing the City's daily population by onethird (Miami Beach Economic Indicators 2010).

Although Miami Beach's economy is very integrated with Miami Dade County and the region, its population has somewhat different characteristics. Miami Beach is Whiter, slightly older, and has more wealthy households than the County as a whole (see 
Table 1). The racial disparity reflects historical patterns of segregation in Miami Dade and Miami Beach, which despite early attempts at building housing for Black laborers generally discouraged Blacks from living in the City until at least the 1960's (Kleinberg 1994). The Hispanic population began growing in the 1980's as Cuban immigrants moved in, and today Cubans are the largest Hispanic group but are not as dominant as in the County. Miami Beach has increasing numbers of South American residents who tend to be more affluent and have been buying properties as investments or second homes (Campo-Flores and Dougherty 2013), and also increasing numbers of Central American residents who tend to be less affluent and work in low-wage service sector jobs, construction and grounds keeping.

\section{Table 2.}

Selected Miami-Dade County and Miami Beach Demographic Indicators.

\begin{tabular}{c|c|c}
\hline & Miami Beach & Miami-Dade County \\
\hline Percent White non-Hispanic & $40.3 \%$ & $15.7 \%$ \\
Percent Hispanic & $52.3 \%$ & $64.6 \%$ \\
Percent Black & $3.6 \%$ & $17.3 \%$ \\
Percent foreign born & $52.0 \%$ & $51.2 \%$ \\
Percent of Hispanics who are Cuban & $52.6 \%$ & $36.4 \%$ \\
Mean household income & $\$ 86,688$ & $\$ 65,799$ \\
\hline
\end{tabular}

Source: American Community Survey 2008-2012

\section{Social Vulnerability}

Traditional social vulnerability indicators include age, race, income, and gender (Cutter, Mitchell and Scott 2000). Miami Beach has many residents who would not be deemed vulnerable by these measures, but also a significant number who would be. The City has a large population of elderly residents, many of whom live in single-person 
households, and are significantly more likely to live in poverty than their U.S. peers. According to data from the U.S. Census Bureau, ${ }^{2}$ over half the city's residents are foreign-born, most from Latin America, but there are also significant numbers from Europe, Russia, and Canada. Three-quarters speak a language other than English at home, and forty percent speak English "less than very well." Miami Beach also reflects the transient character of the larger Miami metro area. More Miami Beach residents lived somewhere else in the U.S. or abroad in the past year than did in the U.S. as a whole. Miami Beach has a gap between socio-economic groups reflected in the skewed income distribution. The median household income is $\$ 42,330$, lower than the U.S. median of $\$ 51,222$, however the mean household income is higher than the U.S. mean by about $\$ 8,000$. More residents have college degrees or advanced degrees than the national average. High rents and property values and a recent come back in the housing market reflect the high desirability of the City as a place to live and the influx of investor owners particularly from Latin America. A majority of residents, sixty percent, are renters, and half of renters pay more than thirty-five percent of their income in housing costs. The urban character of the city is reflected in transportation options--a quarter of households don't have a car, and higher percentages walk or bike to work than the national averages.

The South Beach area, specifically the census tracts between $5^{\text {th }}$ Street and $15^{\text {th }}$ Street, and between Alton Rd. and Meridian Ave, is a diverse neighborhood including long time elderly residents, recent immigrants, low-income renters, single family homeowners, and luxury condominium owners. This neighborhood is about $60 \%$ foreign born, the vast majority from Latin America, with about sixty percent non-citizens, over

\footnotetext{
${ }^{2}$ Data from the American Community Survey 5 year estimates 2006-2010.
} 
half arrived after the year 2000, and about sixty-five percent speaking English "less than very well.” Forty-five percent of households earn less than $\$ 25,000$ per year, and nearly half the labor force is employed in the tourism industry. Many live in small rented apartments in relatively poor condition. Rent prices have risen dramatically in Miami Beach in the last decade, from $\$ 632$ per month in 2000 to $\$ 1059$ in 2012 according to the U.S. Census -- an increase of sixty-seven percent compared with sixty-three percent in Miami-Dade County as a whole and forty-seven percent in the U.S. The fact that the median rent in the County is nearly as high as Miami Beach, at $\$ 1057$ in 2012, means that there is little refuge for those who can ill afford the rising rents on Miami Beach. Moreover, for those who work on Miami Beach, the added time and expense of commuting from outside Miami Beach likely negates any savings in housing cost. One important difference is that rental units on Miami Beach tend to be older and smaller than elsewhere in Miami-Dade County, with relatively few two or more bedroom units available. This plus the high rents mean that overcrowding is more of a problem on Miami Beach. Eight percent of Miami Beach renter households have 1.51 or more persons per room, compared with three percent for Miami-Dade County. For Miami Beach owner occupied households the figure is only 1.5 percent.

\section{The Emergence of Regional Climate Governance}

As I described in the introductory chapter to the dissertation, the immediate impacts that are associated with climate change in South Florida are not new to the area. But climate change will exacerbate these phenomena, speeding up sea level rise and salt water intrusion, increasing the number of hot days and the strength of hurricanes. The 
decades of experience that government, NGO's, and scientists have in studying, planning for, and adapting to our unique environment provide a strong foundation of knowledge for understanding and dealing with climate change impacts already exists in South Florida. But there is considerable anxiety around what the impact will be from the acceleration or amplification of these phenomena under climate change, and whether technology and policy innovations will be developed quickly enough to preserve a way of life that in any way resembles the current urban development. To answer this question it is important to look at how governance of climate issues is emerging.

Governmental action on climate change in South Florida goes back to the early 1990's when concerns about climate change impacts centered around hurricanes, as South Dade had just been hit by Andrew in 1992. Miami-Dade County was early to the climate change conversation in becoming a founding member of ICLEI - Local Governments for Sustainability (ICLEI) through the leadership of Harvey Ruvin, known to many locals as the "father of the contemporary environmental movement" in MiamiDade (CLEO Anniversary Celebration 2012). ICLEI came about through the efforts of Ruvin and other members of the National League of Cities and National Association of Counties who were concerned with global climate change and who recognized that local governments were critical to developing solutions due to their ability to limit sprawl and dependence on automobiles (Governance Leader 5, interview August 24, 2012). As part of the first ICLEI campaign "Cities for Climate Protection" Miami-Dade adopted in 1993 an Urban $\mathrm{CO}_{2}$ Reduction Plan which "led to the reduction of approximately 34 million tons of carbon dioxide (CO2) equivalent emissions" (Seijas et al. 2010, 505). 
Over the next decade Miami-Dade County continued to participate in ICLEI initiatives such as ClimateWise and the Cities 21 Project, and also passed resolutions urging state and federal action on climate change. According to a Miami-Dade County official by 2005 it had become clear not only that the County's CO2 emissions had not fallen, but that global failure to curb emissions meant that local areas would have to start preparing for climate change impacts (Governance Leader 5, August 24, 2012). A Climate Change Task Force (MDCCTF) was created in 2005, chaired by Ruvin, with six committees and 150 participants from academia, planners and architects, local activists, government and non-profits (MDCCTF 2008). A science committee reviewed recent literature on thermal expansion of the oceans and ice melt, and settled on a prediction of three to five feet of sea level rise by 2100 for South Florida (MDCCTF 2008). Over the next three years the MDCCTF produced recommendations in six areas: science, greenhouse gasses, built environment, natural systems, economic, social and health, and intergovernmental affairs. The recommendations covered a broad range of areas from requiring that all county departments include goals for greenhouse gas reduction in their strategic plans to establishing a green collar jobs task force to restricting land uses in areas at risk from sea level rise to a county-wide education and outreach program on climate change (MDCCTF 2010).

Many of these recommendations were included in the sustainability plan released in 2010 by the mayor's office called GreenPrint. But the MDCCTF process did not result in the kind of action by the County that many hoped for. A status update of the MDCCTF recommendations compiled in 2010 showed that while progress had been made on some recommendations, particularly those on energy efficiency which could draw on funding 
from the Energy Efficiency and Conservation Block Grant that came as part of the American Recovery and Reinvestment Act (ARRA), few recommendations addressing adaptation planning had seen much progress (MDCCTF 2010). In particular recommendations for large scale response and public education went unfulfilled. For example the status of a recommendation that "the County bring together all agencies and entities involved in economic development and planning in order to develop a unified and comprehensive response to the challenges of climate change, housing, economic development, and quality of life" was listed as "This recommendation will require County Commission action. No action has been taken to date" (MDCCTF 2010). Indeed there was a widespread perception that the County Commission did not want to deal with climate change. A county official indicated in an interview that he thought that some of the commissioners had been influenced by the builder's association which didn't want the county to release sea level rise maps because of the potential impact on the industry (Governance Leader 8, interview July 7, 3013). Although the MDCCTF had recommended that the County produce maps of areas that would be impacted by sea level rise, and had projected up to twenty-four inches of sea level rise by 2060, the County's Department of Environmental Resource Management website devoted to the MDCCTF cited an EPA projection of eighteen to twenty inches by next century, and stated that "the areas most susceptible to impacts due to changes in sea level rise are the areas already subject to flooding by major rain events and storm surges. These areas are called flood zones and are shown in the FEMA maps" (Accessed August 28, 2011). The MDCCTF sunsetted and a new mayor took office, a fiscal conservative who downsized the sustainability office. Activity then shifted to the four-county Compact, 
which drew heavily on the work of the MDCCTF, and worked to build momentum regionally for climate change adaptation.

Although Miami-Dade County and the SFRCCC received assistance from several federal agencies including NOAA and the U.S. Geological Survey, I found the lack of direction or specific guidance on adaptation planning from the federal level meant that progress was stop-and-go. The hands-off approach means that that adaptation is left up to the state and local governments, and although the number that are developing climate adaptation plans is growing, progress on implementation activities is still limited (NCA 2011b). Adaptation planning typically follows several steps: assessing potential impacts specific to the area, creating planning strategies for dealing with those impacts, implementing the plan, and doing on-going monitoring of environmental changes leading to revisions to the plan (NCA 2011b). Plans typically focus on infrastructure elements raising bridges and road, storm water, etc. and planning elements on land use, zoning, and building codes.

At the state level in Florida there was a brief period of action between 2007 and 2009 when the Governor, moderate Republican Charlie Crist, appointed a climate action task force. In an interview, a regional governance leader explained that the task force published a state adaptation plan in 2008, with the help of a research group from Pennsylvania State University that had a template for doing climate change impact assessments and a Florida Atlantic University applied research center that had been doing some work on coastal adaptation at the urging of the National Energy Commission, a privately funded research and advocacy group with IPCC connections (Governance Leader 3, interviewed August 13, 2012). The legislature created the Florida Energy and 
Climate Commission (FECC) in 2008 and the Governor's office organized two summits in Miami in 2007 and 2008 that were well-attended, including by elected officials, according to an interviewee. But in the third year of the Crist administration the political situation changed as the governor started thinking about running for the Senate. The third climate summit was cancelled. In 2010 the new administration of Rick Scott, a conservative Republican, together with a more conservative state legislature repealed the FECC legislation.

Just as the state was pulling back and climate change became intensely politicized at the national level, the southeast Florida region began serious efforts to assess and plan for impacts to the region. A SFRCCC member described it this way

The same thing happened at the federal level, congress imploded and I think the administration's done a lot but they've been doing it sort of stale-mated because they couldn't get anything out of congress. So there wasn't anything happening at the state level, there was retrenchment, the federal level was becoming much less clear, and the four counties down here, especially one county commissioner in each of the counties said this is too important to our region. (Governance Leader 3, interviewed August 13, 2012)

With the state pulling back, localities in Florida were left on their own to plan for adaptation.

The first SFRCCC Climate Leadership Summit was held in 2009, coordinated by elected officials representing each of the four counties of Monroe, Miami-Dade, Broward, and Palm Beach. The initiative grew out of the recognition of common interest and geography shared by the four counties with respect to climate change. The story of the founding, often repeated at SFRCCC meetings and written in the Regional Action Plan, is that representatives from several of the counties were in the Capitol visiting their Congressional representatives to advocate for climate policy, but each county brought 
slightly different information on sea level rise planning scenarios for the region. They realized that having consistent information and speaking with one voice as a region of 5.6 million residents would be much more powerful than working as separate counties, and resolved to return home and work to establish a joint effort. The first summit was held later the same year, to serve "as a platform for broader discussion among county and municipal elected officials and the community as to the pressures and challenges that climate change poses for Southeast Florida" (RCAP 2012). An agreement was drawn up which acknowledges that South Florida is one of the most vulnerable regions of the country to climate change, and agrees to developing joint policy positions, an adaptation action plan, and committing staff resources. Within four months all four county commissions unanimously ratified the SFRCCC agreement. The major commitments of the SFRCCC were to developing joint policy statements on state and federal legislative priorities that would urge action to mitigate climate change, and that would recognize "the unique vulnerabilities of Southeast Florida to the impacts of climate change" and would "further a joint policy position that includes specific recommendations regarding the allocation of federal climate change funding based on vulnerability to climate change impacts" (SFRCCC Agreement 2010).

The SFRCCC is unique and important in several ways. While individual cities or counties in the U.S. such as San Diego and New York City had begun creating climate adaptation plans, the Southeast Florida Regional Climate Compact was the first "megaregion" to do so. This was especially remarkable for a region that, despite its integrated economy, common environmental issues, and similar history of development, had seldom valued regional planning and mostly actively worked to maintain distinct identities for 
each of the counties. One SFRCCC member called it an "an unnatural act for county commissioners" to agree on a regional Compact of this type (Governance Leader 3, interview August 13, 2012). But it came at an appropriate time. The SFRCCC is a unique reflection of the complicated geography of climate change. While adaptation approaches vary from local area to local area, even from street to street in some instances, it also is impossible for a local area to go it alone, as my Miami Beach case study later will show. Addressing adaptation for coastlines and watersheds requires viewing an entire region as an integrated system, which will only accelerate a trend to regional collaboration.

The SFRCCC has a steering committee composed of two staff members from each county, one municipal representative from each county, and a non-voting member of the South Florida Water Management District. Additional staff from each county plus the SFWMD and one environmental non-governmental organization (NGO) form a technical support team. There is also a joint policy advisory team composed mostly of county staff, some of the same people who are on the steering committee, and a science advisory team that completed the consensus paper on Sea Level Rise. Each fall since 2009 the SFRCCC has convened a Climate Leadership Summit, with each county rotating as host. Outside speakers from academia, private research groups and federal agencies serve as panelists on climate mitigation and adaptation topics, the SFRCCC steering committee provides an update of activities, and county and municipal government representatives share plans and strategies for mitigation and adaptation. The summits draw around 200 participants including academics, local government staff and elected officials, NGO's, private engineering firms and federal agency scientists. In 2011 the SFRCCC released a Regional Climate Action Plan (RCAP) as a framework for climate adaptation and 
mitigation for the region's local governments. The RCAP included a vulnerability analysis for sea level rise which used LiDAR data to show the areas impacted by one to three feet of sea level rise, and over 100 recommendations on mitigation and adaptation activities (SFRCCC 2012c). The RCAP provides information and recommendations for South Florida counties and municipalities to understand the impacts of climate change and begin their own planning processes.

The RCAP was designed to be a framework that counties and municipalities can tailor to their own needs and different contexts. It is non-binding on any government, and endorsement by a county or municipality does not commit that entity to any particular actions or recommendations, which are instead implemented through standard processes such as capital improvements or grant funded programs. Because of this the Compact has to rely on "soft power" to advance its agenda, by educating and involving like-minded government officials and members of the public. Below I will describe some of the factors in the SFRCCC's successes to date as well as some of its limitations, based on my interviews with members and observations of public meetings. I argue the success of the SFRCCC so far has been due to steering committee members with strong personal commitments to the work and to the focus on increasing regional collaboration and expanding and sharing resources. The limitations stem from narrowly conceived vulnerability and lack of public involvement.

\section{Personal commitment}

From my observations and interviews I found that, with the absence of a mandate from the federal or state level for climate adaptation, the SFRCCC exists largely due to the efforts of local government officials who were personally committed to the work 
because of a belief that addressing climate change is absolutely critical to the future of South Florida. Some of these staff members have science backgrounds, including PhD's in natural sciences. Others had no science background or particular interest in environmental issues but learned about the potential impacts from those who did, such as one local official who recalled

I remember the first meeting I said... "do we really have to accept that it's changing and that we can't do anything about it and that we have to adapt?" And so that got me started on really studying, at least doing some studying about it to understand that no it's probably too late to just forestall it, we really have to adapt. We have to consider that too. (Governance leader 4, interview August 14, 2012)

That sense of urgency about the need to address climate change has created a culture of commitment and determination among SFRCCC members to moving forward adaptation planning within local government. One local official who became convinced about the need to act on climate change official remembered eagerly sharing anything available with coworkers

....at that time in 2005 there really wasn't a lot out there that was talking about impacts.... information was kind of hard to come by at that time because nobody was really talking about it, and at the state it wasn't an issue, so you just kind of had to get it as you could. I was so hungry, whenever I saw anything about climate change I was so excited because you never saw anything, and I would treasure it and I would send it out to everybody. And now I can't possibly keep up. (Governance Leader 6, interview August 31, 2012)

That commitment translated to personal choices as well, such as in the case of one official who, when sustainability initiatives were downsized by a new administration, went to work for a different government altogether in order to keep working on climate issues, saying, "They had a green team when I got here.... they had a sustainability action plan that they did also with the energy grant. But I've just given it a little more structure 
and attention. I've elevated the issue too. And everybody kind of knows that it's my thing" (Governance Leader 4, interview August 14, 2012).

For some steering committee members the belief in the importance of working on climate change led to an emotional connection to their work, and to each other. This was evident at the third annual summit when SFRCCC steering committee members honored a member who was retiring. She teared up upon receiving the recognition and talked about how much the work had meant to her, saying "This is so important to me, after my family. [SFRCCC facilitator] is my newest best friend for the last 4 years" (SFRCCC $4^{\text {th }}$ Climate Leadership Summit, December 2011).

The SFRCCC is therefore not simply another task force appointed to work on an issue of ordinary significance. It is a personal commitment from those who believe that climate change will have significant impacts on South Florida and that local government must move to address them. This commitment drives them to look for opportunities to persevere even in unfavorable political climates, and it helps create bonds of friendship between steering committee members that is an important source of support for those working on an extremely complex and politically charged issue.

\section{Widening the Circle}

But SFRCCC steering committee members also recognize, and often repeat, that to make progress on adaptation others need to be brought into the conversation beyond the core group. Referred to as "widening the circle" this is an important strategy both for creating momentum for adaptation activities within government and for public outreach. As one official put it, "It's important that we widen the circle. We can't just keep talking to each other. We need to bring in the others, we need to bring in the police, fire, public 
works, the planners, and say this is the information, so how is this going to change the way you do your job?" (Governance Leader 4, interview August 14, 2012). Educating local government staff is seen as a crucial step in mainstreaming climate adaptation into how government operates, and something that with Compact agreement functioning as political cover can be furthered by professional staff without political debate.

Also as a public outreach strategy, Compact steering committee members are reaching out to different audiences. One staff member told about attending a public forum on transportation.

This was an audience that all of a sudden I was informing them with the science and they probably didn't even know that was going to happen. We need to do more of that. We need to, when it's a homeowner's association... and they have breakfast once a month, go to them and inform them. And the message is, this is what we're learning, this is what the science is telling us now, what does this mean to you? If you're going to go back and you're going to run a transportation agency, right? Or if you're going to go build a new development what does that mean? That's what I'm trying to do. (Governance Leader 4, interview August 14, 2012)

Thus far moving forward on adaptation has been a process of education and inclusion, rather than directives and policy which may be as yet too politically and technically difficult to achieve.

\section{Building more regional collaboration}

Despite being neighbors with similar environments and a fairly integrated economy, the four counties of Southeast Florida have historically worked to maintain distinct identities and do not have a significant history of cooperation on regional issues. Initially, Miami-Dade and Broward each had their own climate change task forces and each of the counties was using different projections of sea level rise. But once the 
benefits of acting together as a region were realized, a few environmentally minded county commissioners worked together to establish a process for regional collaboration on climate change. As one founding member of the SFRCCC described it, the four counties had previously seen each other as competitors, but through the Compact have "built relationships and trust" (SFRCCC $4{ }^{\text {th }}$ Climate Leadership Summit, December 2011).

Building relationships and trust are key to how the Compact functions because it is not a legal entity with authority for governing the region, but a regional framework for collaborating and an agreement to work together. The reason for this structure, according to one of the steering committee members, is that with four counties and over 100 municipalities, the framework can be adjusted and adopted to the needs of each jurisdiction. "You have to know your audience and know your constituencies. That's the good thing about the regional plan, that if we have the framework then we can all kind of go out and do our thing the way it's best for us" (Governance Leader 4, interview August $14,2012)$. Another steering committee member put it in the language that a separate, more comprehensive regional planning process is using, the language of "subsidiarity," to mean decision making happening at the smallest level practical for an issue. For example in transportation, highways should be a regional issue but sidewalks could be designed at the block level (Southeast Florida Regional Partnership 2013). In the words of this steering committee member, subsidiarity is the "idea that decisions have to be made at the correct level in order for there to be appropriate buy-in. That idea can be expanded to talk about climate resiliency and adaptation. There are things that we have to do at the 
regional level that will require regional support and regional cooperation" (Governance Leader 7, interview June 24, 2013).

The idea of subsidiarity fits with the nature of climate change adaptation, in that an entire region may experience similar impacts and certain actions can be taken regionally, but many actions are much more locally specific because of differing socioeconomic and physical contexts. For example water is managed in South Florida on a regional level through the South Florida Water Management District, which manages flood control and water supply for the entire watershed south of Lake Okeechobee. But counties and municipalities have their own storm water, waste water and water delivery systems which will need to be adapted. A county level official explained,

The [South Florida] water management district is sixteen counties on the peninsula of Florida and they're certainly going to be taking on some big engineering activities to deal with that, come down a little bit smaller you're looking at beach renourishment programs that provide for shoreline protection, you may find that cities are looking at sea wall ordinances or storm water retrofits, maybe you come down to a given neighborhood where cities are petitioning to try and get certain types of adaptation work done - that happened in the Riviera Isles area of Ft. Lauderdale where they petitioned the city to put in back flow preventers as a pilot. So again I think this idea of subsidiarity can be applied here because you can see that every level has to start thinking about what the next steps are that are going to help deal with the issues. (Governance Leader 7, interviewed June 24, 2013)

But having a framework for regional cooperation on climate change adaptation is important then because infrastructure is connected across county borders and the changes that one government makes can affect the others "upstream" or "downstream." As the official went on to say, 
There are certain things that can't be done locally. Regional transportation issues have to be dealt with regionally. Ft. Lauderdale's not going to go out and raise I95 because they're concerned with adaptation. But they can work with state DOT, they can encourage these kinds of things but certain kinds of things have to be done regionally and certain things have to be done locally. And not every municipality is going to choose the same set of solutions. (Governance Leader 7 , interview June 24, 2013)

Some cooperation has already been happening, for example with some eastern municipalities buying water from municipalities further westward due to the salinity of the eastern well fields (Sonenshein 1995). But officials have cited increasing collaboration in other areas as well such transportation. As one official described it,

For things to work effectively, they need to be coordinated. So that's why we talk about trying to better regionally connect and coordinate our transportation systems. Because there's all kinds of movement across county borders from Monroe on up. So anything we can do to make that more efficient and effective will impact quality of life, will impact emissions, you name it. (Governance Leader 6, interview August 31, 2012)

The SFRCCC contributes to this increase in regional collaboration by setting an example

and framework. As one official said,

I think that the compact helped people make the recognition that it was possible to work across these lines. And I think that we started making connections across these lines which made it easier to do more of that type of work. It's not that it wasn't happening before, but I think that the existence of the compact has expanded people's thoughts about their ability to collaborate and their ability to accomplish more by working in a collaborative setting. Certainly since the compact started the Sustainability Stewards is a great example - we had not worked with the cities that way previously. I mean there were examples of pockets of it, but this was a bigger effort to try to work collaboratively with the cities. And I think that's very true on the county level. It's a big scale effort, and the counties hadn't really worked together that way in the past, and so it's changing the nature of the relationships. (Governance Leader 7, interview June 24, 2013)

The collaboration has also led to expanding and sharing resources. For example Miami-Dade had early leadership with the work done by its Climate Change Task Force, 
which was used extensively as a basis for the RCAP. Broward County, which had a more supportive County Commission, created a climate change division within the Department of Natural Resources Management staffed with hires from federal economic stimulus spending (ARRA), and supported the work of the SFRCCC by compiling the report and convening the science committee. The contributions are made according to available resources and expertise, as one member described,

Early on in the development of the Compact staff steering committee there was a survey that we put out to determine what resources each group had to address the issues. And so early on we had an understanding that each of the counties had a different level of resources available, and they've made different levels of progress towards dealing with these issues in general. So we were aware from early on that each member of the Compact was in a different place relative to each other and relative to the region. And so I think that some of our first couple years especially when we were dealing with the technical aspects were to try and get us on the same place. And if you read the compact, our compact charter, the compact clearly states that each of the counties will provide what resources they have available that area reasonably available. That's not the exact language, but it says to the extent we have the resources available we will participate and help. If there are times when different members carry more of the load, but that has to do with their interest in a particular issue as well as their expertise and the availability of those resources. (Governance Leader 7, interview June 24, 2013)

By sharing resources and demonstrating the ability to develop regional collaboration, the SFRCCC has attracted more outside resources particularly from the federal government and large environmental NGO's. NOAA assisted in preparing the RCAP vulnerability analysis and USGS provided technical support as did the SFWMD. The Union of Concerned Scientists and World Resources Institute have attended SFRCCC meetings, and the Kresge Foundation provided a grant to support the coordination and moving forward with implementing the adaptation plan. The Broward MPO recently received a federal grant to look at regional transportation impacts of climate change. 


\section{Focus limited to physical vulnerability}

Although the SFRCCC has been fairly successful at building momentum for climate change adaptation in South Florida it also has limitations that are important to recognize. So far the focus of its work - evidenced by the vulnerability assessment and RCAP — has been on the physical environment, i.e. the built environment and natural systems. The RCAP did not contain a section on health, housing or social equity, and discussion of the economy was limited to the value of exposed real estate. One steering committee member explained this was a matter of the expertise on the steering committee.

Well they had three working groups, and one was transportation, one was natural systems, and one was built environment. And I think that's where the staff felt comfortable that they could take the work from. The people involved don't have the background in these other issues, and so the reason health and agriculture are coming up in the next wave of work is because they realized that they didn't get attention. So I think in that sense, I don't think there's any resistance to it as much as they didn't probably feel comfortable that they could manage the outcome and deliver it in a product that they could get commissioners to go along with. Governance Leader 3, interview August 13, 2012)

Another staff member saw it as a matter of priorities, that certain actions needed

to happen first in order to address the most pressing adaptation concerns, saying

We've got to get stuff into our planning documents now, in order to start dealing with some of these issues, and because climate change and sea level rise are slow activities and on a longer time horizon, then those issues just haven't been brought to the tippy top of the priority list yet. And that being said I don't think they're being ignored.... we are in the infancy of these kinds of conversations and so some of the bigger issues are some of the ones we're trying to address now, but that's absolutely a conversation that needs to be had and it's likely to be had in the next for example the next version of the RCAP where we'll bring in the public health aspect and we'll try to work more on some of those kinds of issues. But we need to get the big stuff done first. (Governance Leader 7, interview June 24, 2013) 
However SFRCCC members did recognize the potential for additional benefits of adaptation, termed "co-benefits" (NCA 2011b). They cited the Florida Department of Health's study on climate change impacts, and Broward County's regional health planning council initiative as ways of creating opportunities to adapt to climate change and improve air quality, reduce greenhouse gas emissions, and encourage bicycle riding. A "Coalition of the willing"

As mentioned the SFRCCC is an agreement between the four southern counties to collaborate but it does not require any particular action. Since action is voluntary, it is also uneven, particularly among municipalities. Although the steering committee includes a few of the most active municipalities, SFRCCC members recognize that much education remains to be done with municipalities. As of 2014 only 24 out of 112 municipalities had signed the Mayor's pledge, most in Broward County. Since municipalities have a lot of responsibility for infrastructure development, services, and land use regulations, their participation in adaptation action is key to success in the region.

\section{Limited public involvement}

The SFRCCC's purpose is to steer collaboration among local governments, but steering committee members recognize that public involvement is also important. However opportunities for public involvement with the SFRCCC are limited. The annual summits are open to the public but there is a cost to attend, they are held during the working day, and generally not geared towards a general audience. Very few members of the public attend the summits, and media coverage has been scant. However the 2013 summit included an evening town hall meeting with congressional representatives, which 
was standing room only. SFRCCC steering committee members are all county staff, with one non-governmental representative on the technical support committee. This is in contrast to the Miami-Dade CCTF which involved many more citizen stakeholders and had meetings open to the public, although here too there was a lack of widespread public communication about the initiative and few members of the public actually attended.

\section{Conclusion}

South Florida's environment and economy have always been intertwined, and the climate has closely shaped the major industries that dominate the economy. Miami's socio-economic profile indicates significant areas of vulnerability according to traditional vulnerability indicators such the gap between income and cost of living. The region has a long history of dealing with environmental challenges, many of which prefigure the challenges of climate change. The region also acknowledged its vulnerability to climate change early on, and has recently taken the lead in the state on adaptation planning, leading to increased cooperation among local governments and the development of a local plan. The current efforts benefit from the experience of long time leaders who have remained committed to environmental issues and who have inspired newly committed leaders in spite of political obstacles. Despite the absence of state leadership, these local and regional leaders have formed an innovative regional compact and are linking scales across political divides. They have created momentum for the process by building relationships and sharing resources.

However as a comprehensive adaptation effort, it is limited by its largely technical approach which doesn't fully account for the socio-economic dimensions of 
vulnerability, and by the limited participation of the public and municipalities. Whether the effort will be able to provide long-term leadership remains to be seen. 


\section{CHAPTER IV - IMPACTS AND PERCEPTIONS}

As explained in previous sections of this dissertation, Miami Beach is predicted to experience a variety of physical impacts associated with global climate change, including sea level rise that will likely result in a reshaping of the urban landscape. I have argued that the increasingly frequent urban flooding that Miami Beach is currently experiencing can be seen as the onset of perceptible, accelerated sea level rise and that studying this phenomenon provides insight into the physical and social challenges that Miami Beach will face in dealing with this problem. In this chapter I will describe and analyze the impacts of urban flooding that Miami Beach is currently experiencing, and how residents and businesses are perceiving, reacting and adapting to these impacts.

\section{Biophysical Impacts of Sea Level Rise in the Study Area}

As described in the introduction, the predictions for sea level rise made by local scientists and officials for South Florida indicate that over the next fifty years sea level could rise by as much as two feet (SFRCCC 2012a). So-called "inundation maps" are an increasingly common tool for visualizing the impacts of sea level rise on a local area (NOAA Digital Coast). For areas where the data is available, these maps are produced using LiDAR data ${ }^{3}$ which allows a very detailed representation of elevations. The image below left for example shows Miami Beach's current topography. The image below right

\footnotetext{
${ }^{3}$ LiDAR (Light Detection and Ranging) is a remote sensing method for measuring land elevations. An aircraft is flown over a large area collecting measurements from a light beam bounced off the ground. The data points are $1.5 \mathrm{~m}$ apart and are vertically accurate to within 6 inches. Trees, buildings, and other nontopographical features are mathematically eliminated from the dataset. LiDAR data for Miami-Dade County were collected from 2002-2004 by a joint FIU-UF research project and area available for download from the Florida Department of Emergency Management. (IHRC)
} 
was produced using the same elevation data and adding a layer that shows the locations which would be inundated during high tide in scenario of two feet of sea level rise.
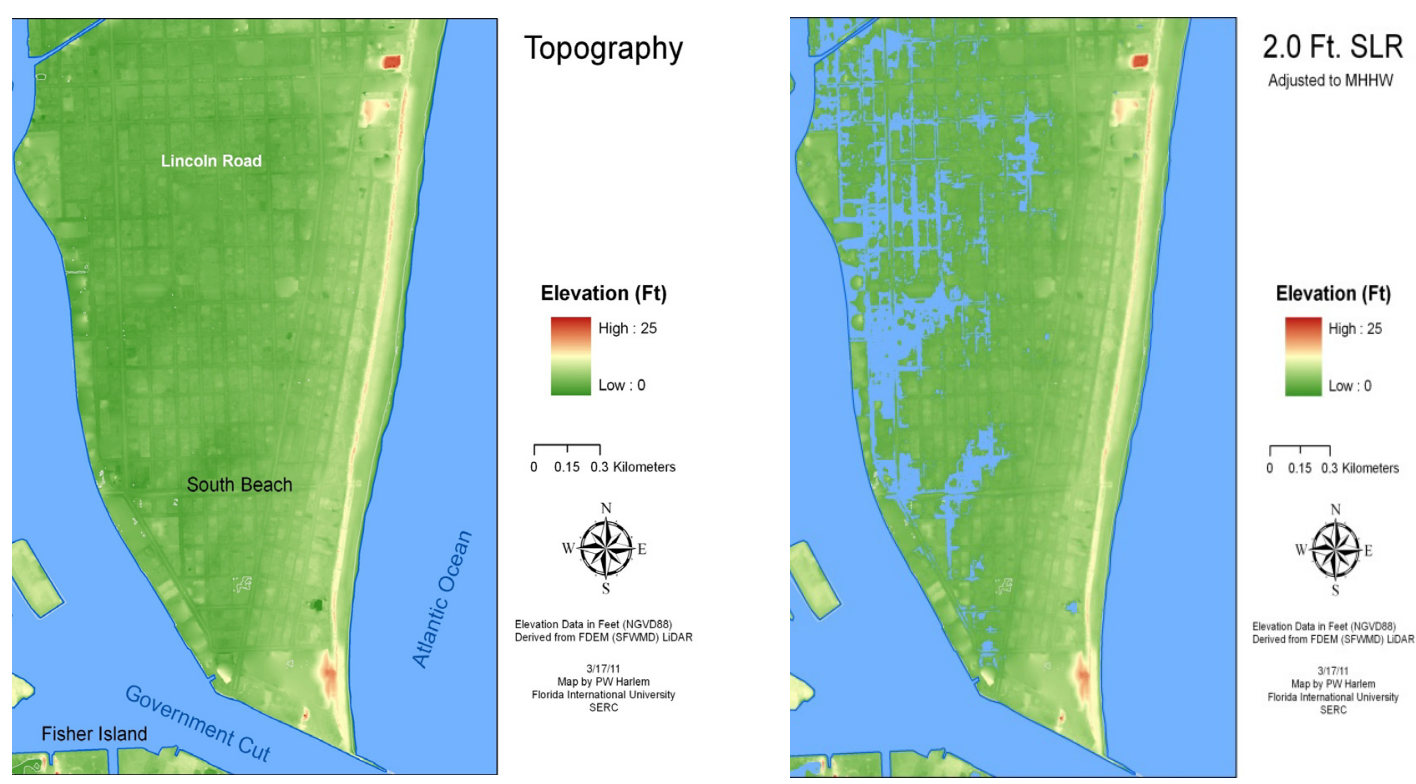

Figure 1: Inundation maps of southern Miami Beach (Maps by Peter W. Harlem, used with permission)

What these maps show is that relatively low-lying and "flat" areas such as Miami Beach could be significantly impacted by just a few feet of sea level rise. Miami Beach's maximum elevation is twelve feet NAVD and minimum is 0.5 feet, with an average of six feet (CDM Smith Inc. 2012). The higher elevations are on the east side of the island where the sand dunes are, and the western side of the island is lower, having previously been mangrove forest which was bulkheaded and filled with material dredged from the bottom of Biscayne Bay in the early decades of the $20^{\text {th }}$ century (Kleinberg 1994). Analysis of LiDAR data shows that with two feet of sea level rise approximately seven percent of Miami Beach's land area would be inundated, but with three feet that rises to 
approximately thirty-four percent, and with four feet approximately sixty percent (Harlem 2011).

However these inundation maps are limited in their ability to accurately represent future sea level rise scenarios. The maps are nicknamed "bathtub maps" because they represent a simple visual layering of inundation on top of current elevations and are not true hydrologic models. The maps do not take into account how water flows over a landscape, nor the composition of its geologic substrate which determines conductivity between bodies of surface water, nor coastal changes such as erosion (Harlem 2011). They are also static, whereas tides are dynamic. The inundation layer is based on the Mean Higher High Water datum which is the higher of the two daily high tides South Florida experiences. This means the scenario depicted in the maps does not represent a permanent state of inundation but rather a high in the tidal cycle with water levels varying throughout the day.

Importantly, they also do not take into account the built environment, particularly drainage infrastructure. My research looks at the connection between the biophysical impacts of climate change and the built environment on Miami Beach, as a basis for understanding the ecological and social impacts that sea level rise may have on the urban area. How Miami Beach is experiencing climate change and sea level rise has everything to do with its drainage system. The existing drainage system is driven by gravity, with water generally flowing from higher elevations in the east through underground pipes westward and out into Biscayne Bay (Kleinberg 1994). However given the low land elevations, the slope or "head" in the system is very small. This means that if the water level in Biscayne Bay is higher than the outfall, water can flow back up through the pipes 
and into streets, producing flooding that is not associated with rain events but instead due to extremely high tides or storm surge.

Water level and tidal data indicate that this is a growing problem for South Florida. The National Oceanographic and Atmospheric Administration maintains a network of 3,000 tide stations across the U.S. for the purpose of predicting and monitoring tides. For the Miami area the Virginia Key tide station is the primary source of tidal predictions and data. Data is only available for this station going back to 1996 , when it was moved from a location in Government Cut. The station with the longest history in South Florida is the Key West station which has data going back to 1913. Key West data indicate that mean sea level has increased by 0.73 feet or 8.76 inches over the past 100 years. This increase has been cited by the South Florida Water Management District as a primary cause of worsening drainage conditions in South Florida, as the drainage infrastructure was built in the 1930's when sea level was lower and did not interfere as frequently with draining water from the urban areas during storms.

Tidal flooding is also becoming more frequent. South Florida has a semidiurnal tidal cycle with two high tides and two low tides per day, with a tidal range of about two feet. The tidal range, heights and timing vary with seasonal lunar and solar orbital cycles, so that several times per year tides are higher than average due to the position and proximity of the sun and the moon. The phenomenon known as "perigean spring tides" occurs when the moon is closest to the earth (perigee) and during the full moon or new moon when the moon and the sun are in alignment and the gravitational pull of both on the earth's oceans produces slightly higher tides (NOAA 1998). During these times of the year, which occur in late fall and late spring in South Florida, high tides are higher than 
in other months. Tide predictions are based on models that take into account these astronomical cycles, as well as hydrodynamic, topographic, and other factors particular to a local area.

However the actual tide heights and times experienced on any given day in a local area are influenced by weather conditions, ocean currents, and other non-periodic factors which are not included in the model predictions and are not part of NOAA's regular prediction services (Ehret 2012). For short term tide predictions, it is the National Weather Service which monitors marine conditions and issues tide predictions and flood warnings for up to a one-week period. If a significant enough tidal event occurs, NOAA will conduct an analysis and issue a report such as a report released in January 2013 analyzing water levels during Hurricane Sandy (NOAA 2013). The report indicates that the maximum storm surge reported at Virginia Key was 1.44 feet on October 28 as the storm was passing by Jacksonville, and the maximum storm tide (highest water level recorded during the storm) was 2.17 feet NAVD.

But Hurricane Sandy was not the only thing causing elevated water levels in South Florida that year. Further analysis reveals that water heights were above predicted levels for most of 2012 (see Figure 2). The cause of this discrepancy is not clear however, and pinpointing the reason for such variations is complex. According to a NOAA researcher I spoke with, "Sea level fluctuates several inches on a routine basis, and those small fluctuations can last for a few days to a few months, sometimes years. There is no easy way to identify what causes these variations, there are any number of contributing factors which cannot easily be accounted for" (Ehret 2013). Possible explanations include seasonal cycles, Gulf Stream fluctuations, El Niño/La Niña, or sea level rise itself in the 
twelve intervening years since the benchmarks were last updated. ${ }^{4}$ In 2012 the Virginia Key station recorded more than 7348 hours where water levels were above predicted, which is eighty-three percent of the year. The maximum water height and the maximum difference were both recorded while Hurricane Sandy was passing offshore.

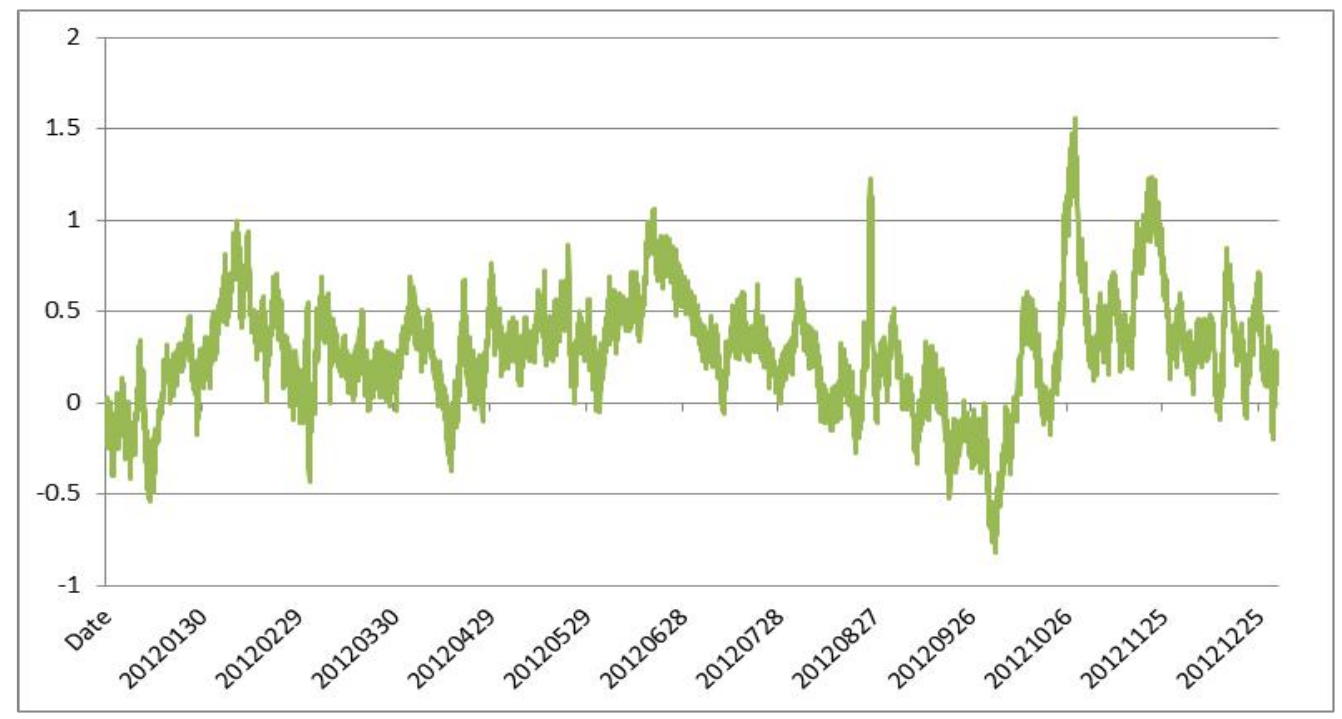

Source: NOAA Virginia Key tidal station historic water data hourly water levels

Figure 2: 2012 Verified minus predicted hourly water height values, Virginia Key, FL

Table 3.

2012 Virginia Key water height statistics (All values in reference to NAVD88)

Average predicted water height: -0.876 feet

Average verified water height: -0.592 feet

Average difference: 0.284

Maximum verified water height: 2.12 feet (recorded 10/28/2012, 18:00 LST)

Maximum difference: 1.56 feet (recorded 10/29/2012, 9:00 LST)

Source: NOAA Virginia Key tidal station historic water data hourly water levels

\footnotetext{
${ }^{4}$ NOAA tide predictions are based on benchmarks called "datums" which are calculated by averaging water height over a period of 19 years. The current datums in use are from the 1983-2001 epoch.
} 
This analysis of available tidal data for South Florida demonstrates the difficulty of relying on established datums and traditional benchmarks for gauging the impact of tidal events and isolating oceanographic and weather related drivers of urban flooding in areas with very low grade elevations such as Miami Beach. As I will show in the following section, a few inches of water height can mean the difference between a "birdbath" on a street corner and an impassible street crossing, or between a flooded sidewalk and a dry sidewalk. Yet the tools currently available for measuring and analyzing the impacts of changes in water level on an urban environment are not well developed for such small variations. As sea level rises along the coast it will be important to derive new measures that are relevant to a particular urban environment for the purposes of planning and preparation for extreme events. The following is an exercise in developing such a measure.

\section{Field Observations and Data Analysis}

In order to understand the current drivers of flooding in Miami Beach and the effect that rising sea level may have on urban life, I conducted observations in the Flamingo Park neighborhood in Miami Beach, which has several of the areas most susceptible to flooding in the city (CDM Smith Inc. 2012). I collected data on the height

and extent of flooding under varying conditions, and on the timing of human responses to the flooding. Using an ethnographic approach I noted the adaptations made by residents and businesses and engaged in conversation with persons at the sites about their responses to and perceptions of the flooding. I correlated this data with water height data available from NOAA to produce an analysis of the incidence and duration of flood 
levels that were associated with particular responses, as a way of gauging the impact that flooding currently has on urban life in Miami Beach. This method also provides a way of gauging how perceptions of flooding compare with actual incidence of flooding over the last fifteen years. In total I conducted observations on thirty-two different days over a period of eighteen months, mostly concentrated during a period of four months in the fall of 2012 when flooding was by most accounts unusually severe.

When I began my research the only information on urban flooding in Miami Beach that was available was a map of "flood prone areas" from the Public Works Department. This map did not distinguish between areas that tended to flood due to rain events and areas that flooded solely due to tidal events, so my first step was to identify and distinguish the two. I began by observing flooding during the perigean spring tides in October - November 2011, and noted locations where water appeared to be coming out of drainage inlets. Next May-June, when tide was relatively high and the summer rains had started, I canvassed the neighborhood after several rainstorms to see where water was ponded, and sketched a map of the areas where water was ponded. I found they did in fact correspond to the LiDAR map of low-lying areas, and to the map the city had already identified of flood-prone areas based on their observations. From these maps I selected ten sites that represented a variety of elevations and built structures for further observation. After further observations during conditions of tidal flooding I selected two areas for detailed ethnographic observations of response and adaptation activities.

From August to November 2012 I conducted forty hours of observations during two tropical storms and the perigean spring tides. I documented at least one full high tide cycle at each of the study spots, arriving at the location 2.5 hours before high tide and 
remaining at least 2.5 hours afterward. I took more than 500 photographs of flooding conditions, responses and adaptations, and recorded detailed observations of the type of responses and adaptations I saw, and the times and locations they occurred. For the analysis I linked these time recorded observations to water height data available from Virginia Key and used the NOAA inundation analysis tool to estimate the amount of time that water height was at or above the level that triggered a particular response to flooding on Miami Beach. Below I will present the results of two attempts to quantify the impacts of flooding on urban life in terms of the reactions and adaptations it triggers and their social cost.

\section{Results}

Inundation map ground-truthing

Inundation maps such as those shown above come from Digital Elevation Models (DEM) which visualize LiDAR data to present an overall picture of the elevation in an area. Inundation is depicted on these maps by changing the colors of data points below a certain elevation to blue, to mark the areas that would be below tide level given a certain amount of sea level rise. However the maps are only an estimate, because they do not represent the way water flows over land, through land, or through connections such as drain pipes. Therefore even though an area may be indicated as vulnerable to sea level rise at a certain level, without ground-truthing the maps we cannot know whether any particular location would in fact be inundated in an actual flooding event. In order to assess the degree of correspondence between the inundation models and actual flooding, I mapped the extent of flooding over an approximately seventy block area of South Beach 
during an extremely high tide event and layered this information on to an inundation map in a DEM using GIS.

On October 29, 2012, high tide was observed at 9:42 a.m. at 2.02 feet NAVD. No rain had been observed in the last six hours. It took me approximately four hours from 8:30 to 11:30 a.m. to cover the entire area, noting on a street grid map the locations where water was pooled. Because time was limited to cover such a large area I did not take any measurements but merely noted visual observations on a street grid map. I then created a line layer in GIS from my notations, using a street grid layer as a guide. The line layer was added to the DEM on top of a two feet NAVD inundation scenario. The results are shown in Figure 3 below.

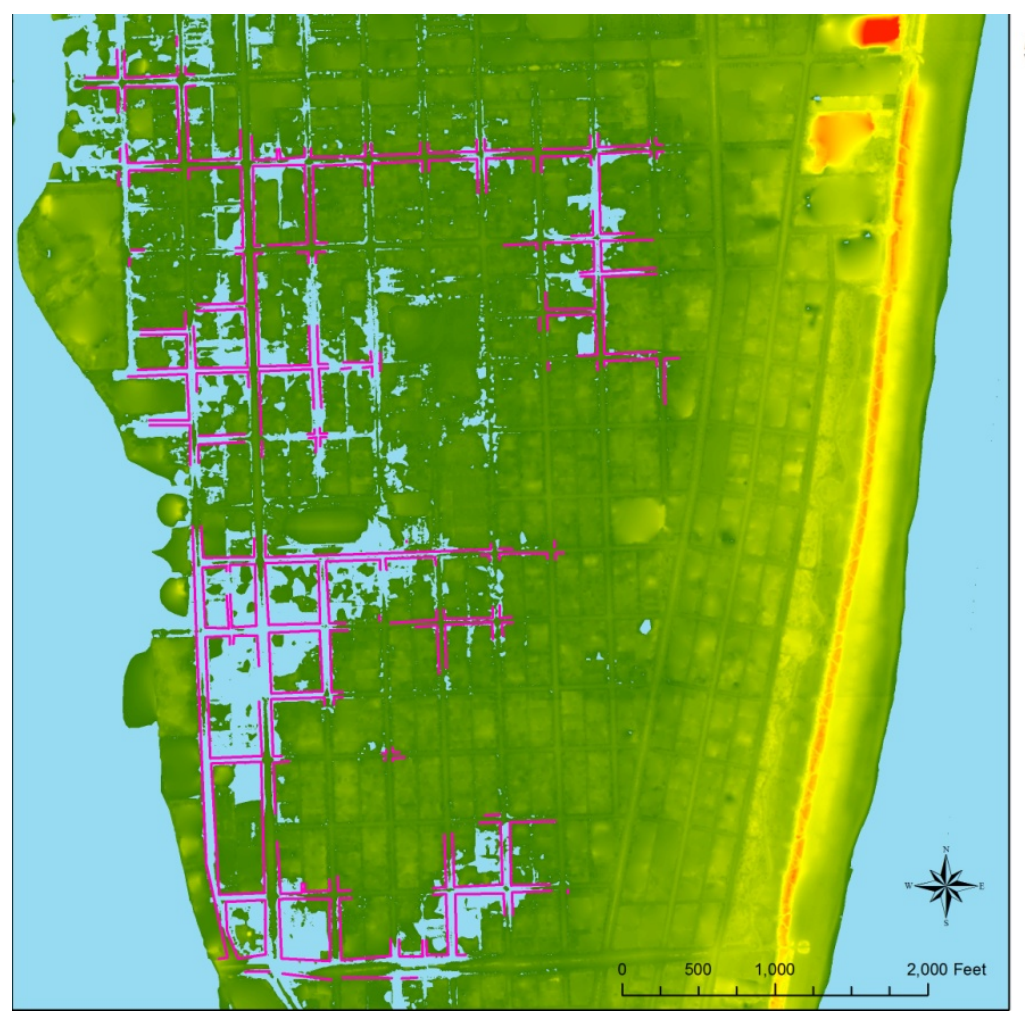

5th St. to Lincoln Road Miami Beach

Comparison of LiDAR inundation mapping and actual extent of flood high tide scenario. Mapped Oct. 29, 2012

\section{Legend}

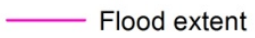

Elevation

High : 20

Low : 0

Map by Emily Eisenhauer

Figure 3: Ground-truthing $5^{\text {th }}$ Street to Lincoln Road with 2 feet Inundation Scenario 
The correspondence between the observations and the DEM is quite close, with a few exceptions which are noted below. This is somewhat surprising because the main conductor of flood waters is the drainage system, and in such situations water height in the streets is not at the same level as the actual tide level because of hydrodynamics. Nevertheless, the inundation map appears to be a reasonably accurate depiction of an actual inundation scenario at low resolution.

The exceptions come for locations in which the street is not level and so water cannot easily flow over high places to get to lower places. This is shown in the chart below of the variance in elevation over one street which appeared inundated in the DEM but was not observed to be inundated during the flooding event. The street contains high points up to 2.2 feet over which it appears there was not enough water to flow to reach the lower points on the other side and cause the street to be fully inundated.

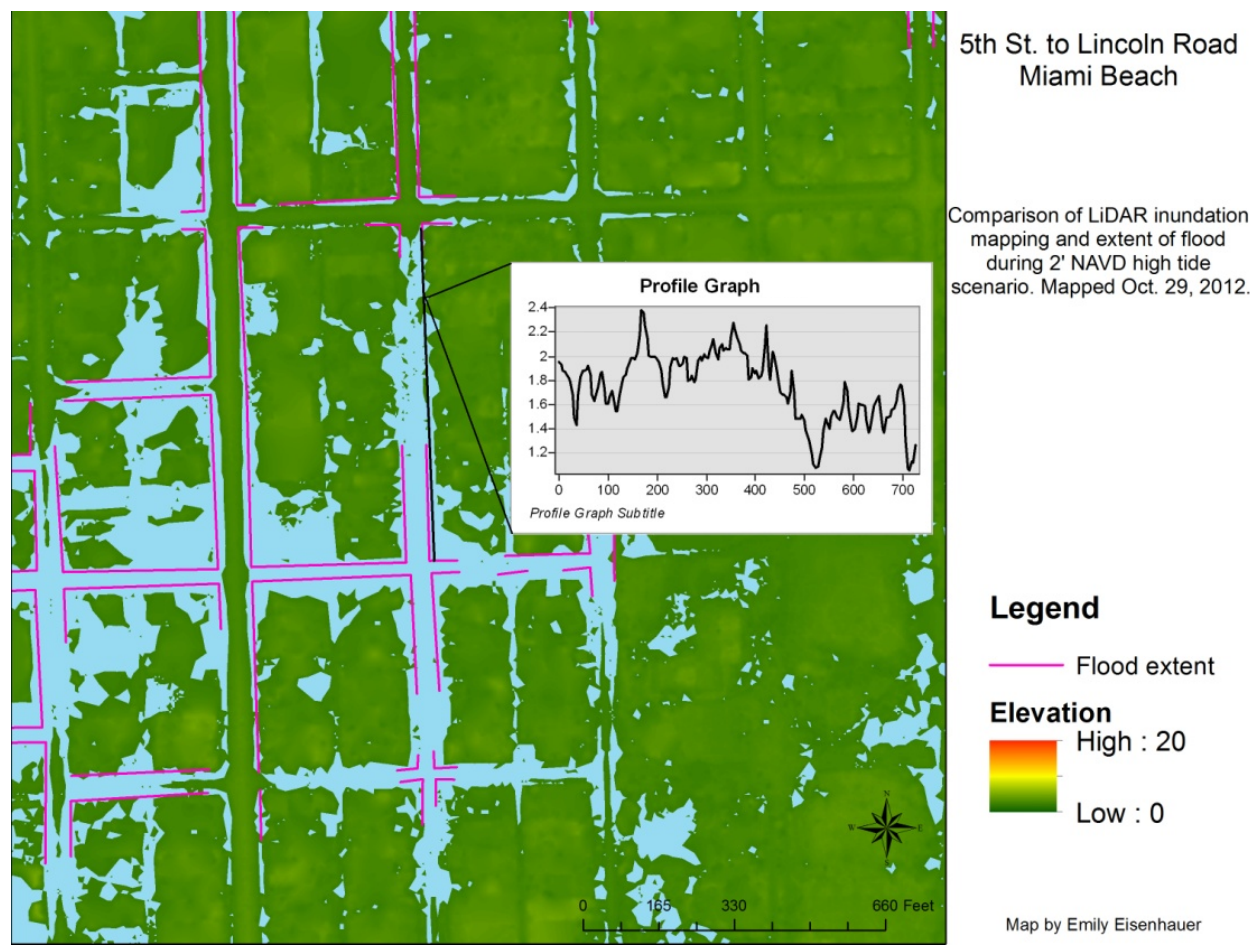

Figure 4: Ground-truthing 2 feet inundation scenario with street elevation profile graph 
Site 1

One area which experiences particularly obstructive and frequent flooding is $6^{\text {th }}$ Street between Jefferson and Meridian avenues. South Beach has been heavily gentrified over the last couple decades, but this neighborhood still has a lot of subsidized and lower rent housing. On this street is a community center which houses Miami-Dade County social services outreach program and a non-profit elderly services program. Several subsidized housing developments for elderly are located within a few blocks. There are a small grocery store and laundromat on this block that serve the mostly low-income and immigrant residents of the surrounding area. The owners are also immigrants and have been in this location since 1992. The grocery is very busy, and the owners say it is a great location for the business, except for the flooding.

On days when the tides reach approximately $0.68^{\prime}$ NAVD water emerges out of a drainage inlet on the southeast corner of the intersection and flows west down the gutter in front of the grocery. When the water begins to overtop the sidewalk, workers bring out metal planks about eight feet long and place them perpendicular across the sidewalk and into the street so that customers can enter the store from the street when the sidewalk becomes impassable. On this day, October 16, 2012, I observed these men putting out the planks at 9:00 a.m. The planks remained there for three hours until the water receded and the workers removed them, shown in Figures 5 and 6. 


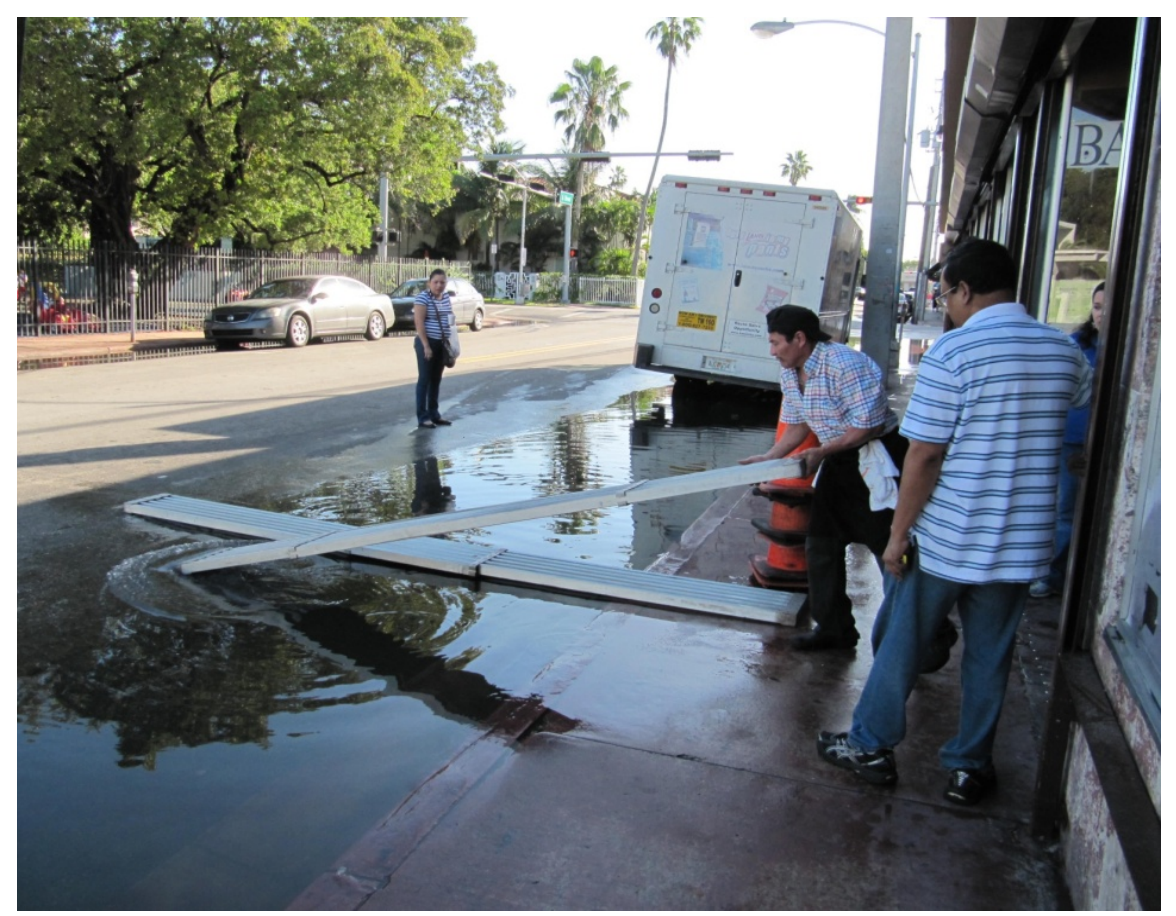

Figure 5: Deploying the sidewalk planks, October 16, 2012. Photo by author.

I observed people crossing these planks with wheelchairs, high heels, and strollers to get into the store. When I spoke with the owner he said that he stood outside to help people across so no one would fall, but on this day I observed no one outside for most of the time. They have not discussed this with the City, although I saw two City trucks drive by the store. On this day the water kept rising and half an hour after they put the planks out the sidewalk was completely submerged and the planks were not enough for people to completely avoid getting their feet wet. The picture below of two women crossing over the planks to enter the store with a baby carriage was taken at 9:30 a.m. High tide was predicted for 10:06 a.m. and the water continued to rise until there was about four inches of water on the sidewalk. However the store did not sustain any damage because the floor slopes up about two feet immediately inside the entrance, minimizing the risk of flooding. 


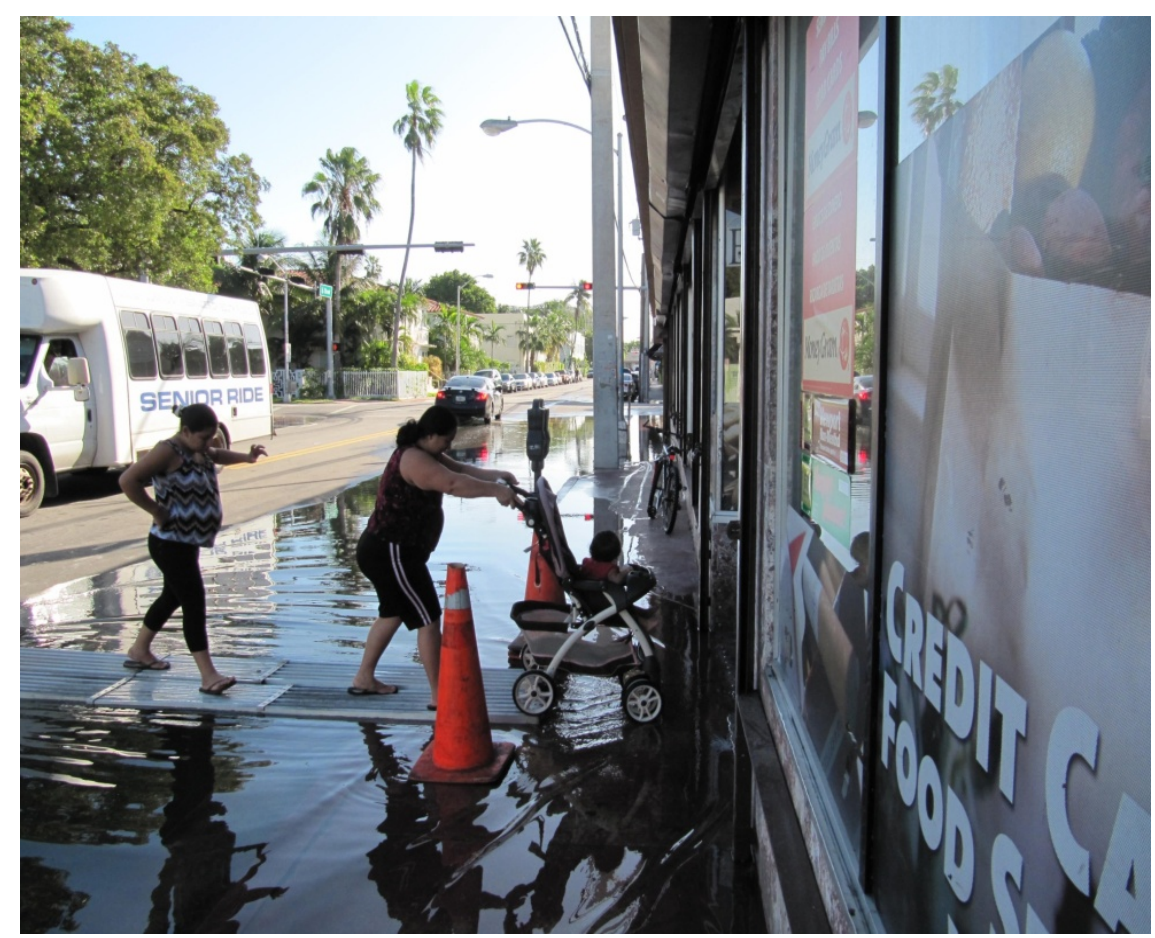

Figure 6: Crossing the flooded sidewalk, October 16, 2012. Photo by author.

The flooding disrupts commercial activity by interfering with the ability of potential customers to enter the store, and the planks represent a planned adaptation to the flooding that is based on repeated experiences with flooding as well as a level of knowledge about the conditions and drivers of flooding that allow the adaptation to be efficiently deployed. A conversation with the store manager revealed that they are aware that the flooding occurs when the tides are extremely high, and that this usually happens during full moons and is worst during the fall months. The planks were first purchased three years ago during a time when tides were high and the manager feared that instead of waiting for the water to recede customers would go to a large grocery chain that had recently opened four blocks away. The planks cost several hundred dollars and are heavy to carry around to the back of the store where they are stored when not in use. But even 
with this adaptation, the store owner claimed he lost $\$ 4000$ for every two hours the store was impacted by the flooding.

The planks are an adaptation that represents a new cycle of human behavior which runs in concert with a cycle of the natural world. They are usually deployed when the water reaches the top of the sidewalk, and removed when the water recedes to about the same level. Although the human cycle is not as precisely regular as the natural cycle, it is regular enough that measuring it provides a way of quantifying the disruptions to urban life and potentially the social cost of urban flooding. I used this cycle to develop an index to measure the social cost of the flooding in this location, called the "Sidewalk Index." On October 16, 2012 I observed that the planks were brought out and placed in position at 9:09 a.m., when the water had just overtopped the sidewalk. At 11:50 a.m. the water had receded to just below the level of the sidewalk, and the planks were removed ten minutes later at 12:00 p.m. Table 4 contains observations and corresponding ocean height at Virginia Key tidal station.

Table 4.

Street Observations, Times, and Water Heights, October 16, 2012

\begin{tabular}{l|c|c}
\hline \multicolumn{1}{c|}{ Event } & Time & $\begin{array}{c}\text { Virginia Key } \\
\text { Observed Tide }\end{array}$ \\
\hline Planks placed in position & $9: 09$ a.m. & 1.22 \\
High tide & $10: 24$ a.m. & 1.57 \\
Water receded below sidewalk, first plank removed. & $11: 50$ a.m. & .99 \\
Second plank removed & $12: 00$ p.m. & .84 \\
\hline
\end{tabular}

The Virginia Key tide station is on the ocean side of the island whereas the flooding at this location is being driven by the tidal cycle along the Biscayne Bay side of Miami Beach. Since no tidal data is available at that location we do not know what the 
exact time lag is between when high tide is recorded at Virginia Key and when actual high tide occurs in this section of Biscayne Bay. Further, there is also a lag between the time when water level rises in Biscayne Bay and when the water emerges from the inlet onto a city street. So it is not possible to determine the precise time lag between an observed tide height at Virginia Key and the corresponding water level at any given location. For the purpose of estimating the amount of time when the planks are deployed I assume that they are placed and removed when water heights are at equal levels. I take the average of the two water heights (1.22 and (.84/.99)) and use a water height of 1.0675 feet to denote the tide level at Virginia Key which triggers the deploying of planks at the grocery. Using the NOAA inundation estimator I find that in 2012 water height exceeded this level sixty-one times for a total of 152.7 hours. I further refine this total by eliminating the times when the water height is exceeded while the store is closed, which is from midnight to 7:00 a.m. I conclude that grocery experienced significant impacts from flooding for 113.3 hours in 2012.

The furthest back that tidal data is available for Virginia Key is 1996. Performing the same analysis with this historical data reveals that the instances of extreme water levels appear to have increased in the last six years. The chart below shows the number of hours that water height was at least 1.0675 feet NAVD going back fifteen years, which is the furthest back that tide data is available for this location. Since 1996 three years have exceeded 100 hours of flooding at this level, all three since 2008. 2012 was the most extreme with 153 hours of tide level above 1.0675 feet NAVD, shown in Table 7. 


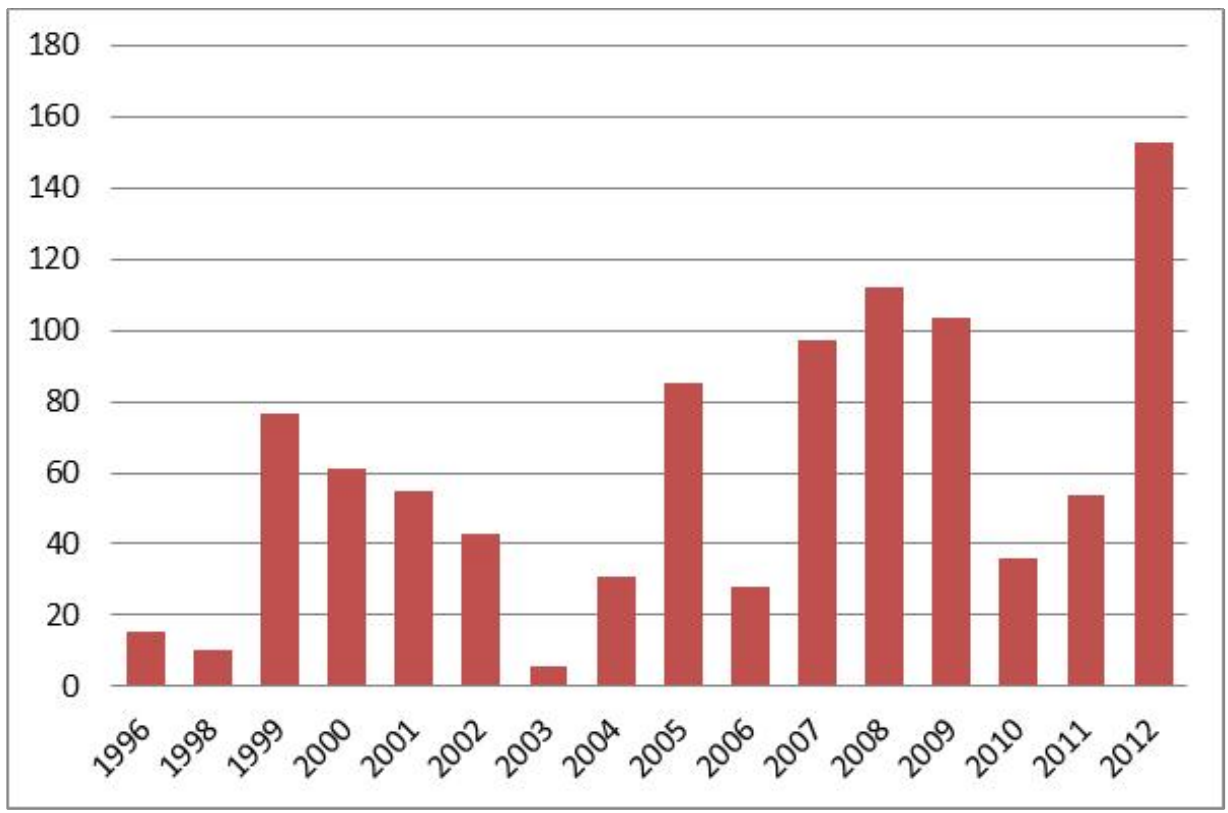

Source: NOAA Virginia Key tidal station historic water data hourly water levels

Figure 7: The Sidewalk Index

Site 2

Another site of significant urban tidal flooding which I observed is the intersection of Alton Road (SR 907) and 10th Street. Alton Road is a main artery on Miami Beach, approximately 100 feet wide, with two lanes of traffic, a center turn lane, and parallel parking on each side. Bus stops just north of the intersection on both the northbound and southbound sides serve two routes connecting Miami Beach with downtown Miami and northern Miami-Dade County, and busses stop approximately every twelve minutes during rush hour. The intersection is in the center of a busy commercial district with a Walgreens drugstore on the northeast corner, a Whole Foods grocery on the northwest corner, an office building on the southwest corner and an advertising school on the southeast corner. This intersection is heavily used by pedestrians as a connector of two major South Beach neighborhoods: Flamingo Park, 
with approximately 13,500 residents, and West Avenue with approximately 10,000 residents ${ }^{5}$

During some of the worst days of flooding this intersection was featured in local TV news reports. On at least fifteen days during October and November the City placed cones blocking the two outside travel lanes where the water was highest, shown in Figure 8. According to City officials, the lanes were blocked off when water levels were predicted to be high or when they observed significant flooding, shown in Figure 8.

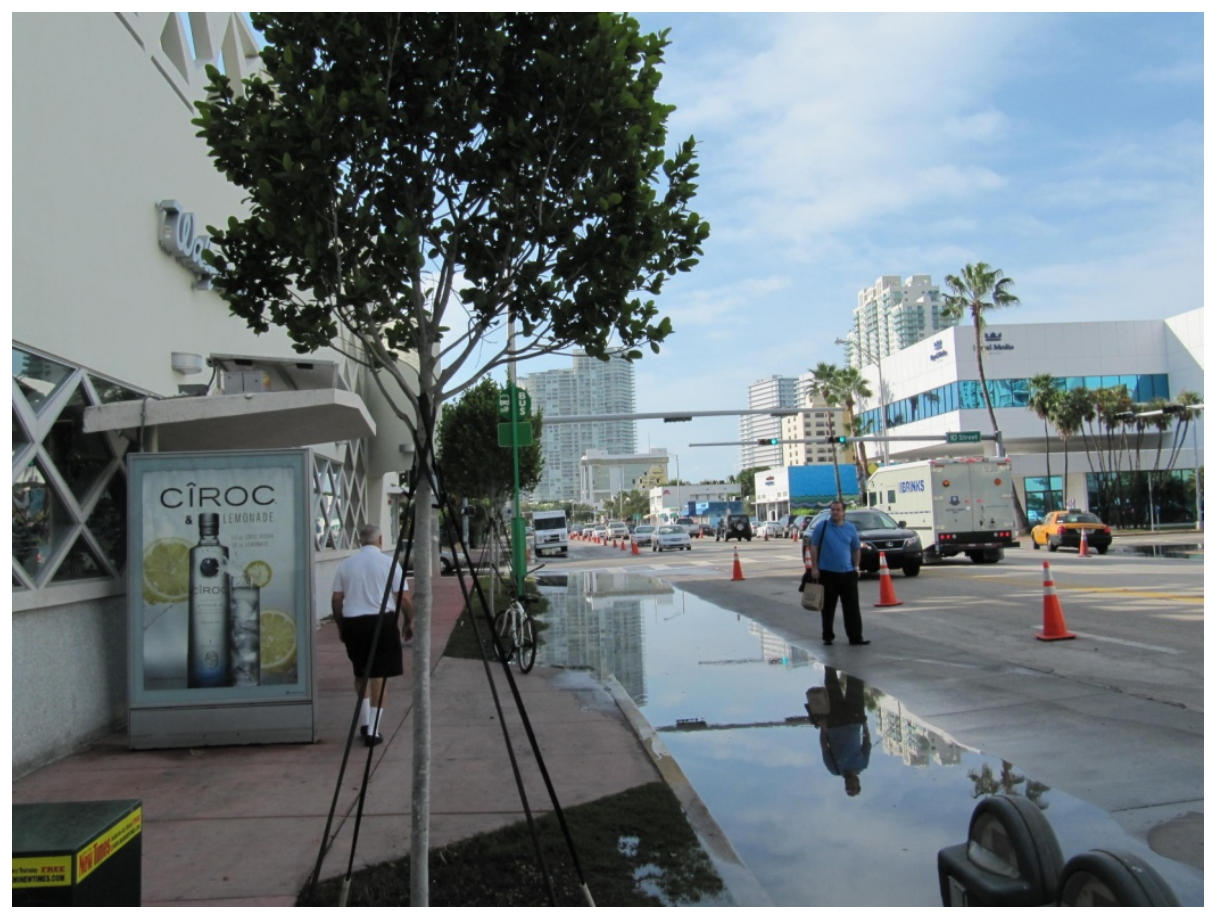

Figure 8: High Tide Flooding on Alton Road, October 17, 2012. Photo by author.

But at no time was the intersection completely closed, and cars, pedestrians and transit users continued to navigate the flooding. I observed this intersection on twentyfour different days, making notes about the impacts and disruptions caused by the flooding, such as sidewalks becoming impassable, bus riders having difficulty embarking

\footnotetext{
${ }^{5}$ West Avenue neighborhood population per West Avenue Neighborhood Association Chair. Flamingo Park population estimated by author from 2010 Census block group estimates.
} 
and disembarking, and store entrances being blocked. These urban disruptions are described in further detail in the second part of the chapter.

On November 2, 2012 I arrived at the intersection at 9:30 a.m. to observe the high tide cycle and its impacts. High tide was predicted for 11:48 a.m. and according to the Virginia Key data the tide was running about 0.5 feet above predicted levels. There had been no rain in the last five days. As an indicator of the disruption caused by the flooding I chose to observe the point at which pedestrians had to step outside of the crosswalks in order to cross the intersection. When water levels are high enough water emerges from the drainage inlet on the northeast corner of the intersection, which is inside the crosswalk crossing Alton Road. According to my observations on previous days, pedestrians will typically step or "hop" over the ponded water until it extends three to four feet into the street. Once the water extends beyond this distance they will look for places to cross where they can step over the water, which often means walking in the street around the water instead of waiting on the curb, as the man in Figure 9 is doing while waiting to cross the intersection.

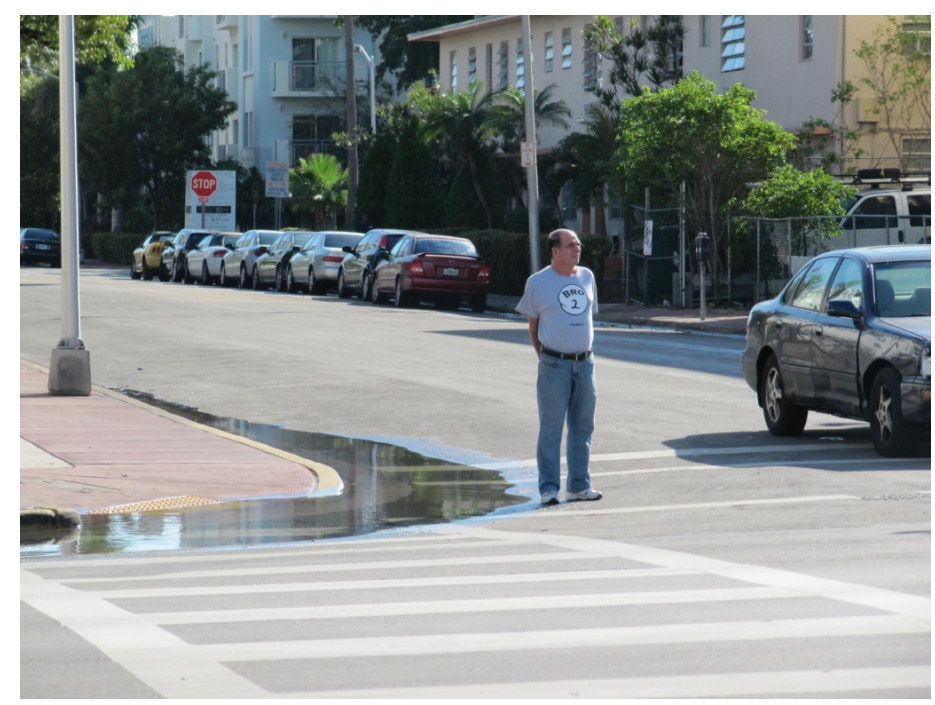

Figure 9: Man Waiting to Cross Alton Road, November 2, 2012. Photo by author. 
At this crossing on this day, I observed a pedestrian walk around the water outside of the intersection at 9:51 a.m. I measured the extent of the water which reached about 4.5 feet out into the street, and was 4 inches deep in the inlet. As the water continued to rise I noted the times when similar behavior occurred at the other crossings. These times are shown in Figure 10 below. As the tide was receding, I noted the times when pedestrians were again able to cross while remaining in the crosswalks. These times are noted in Figure 11 below.

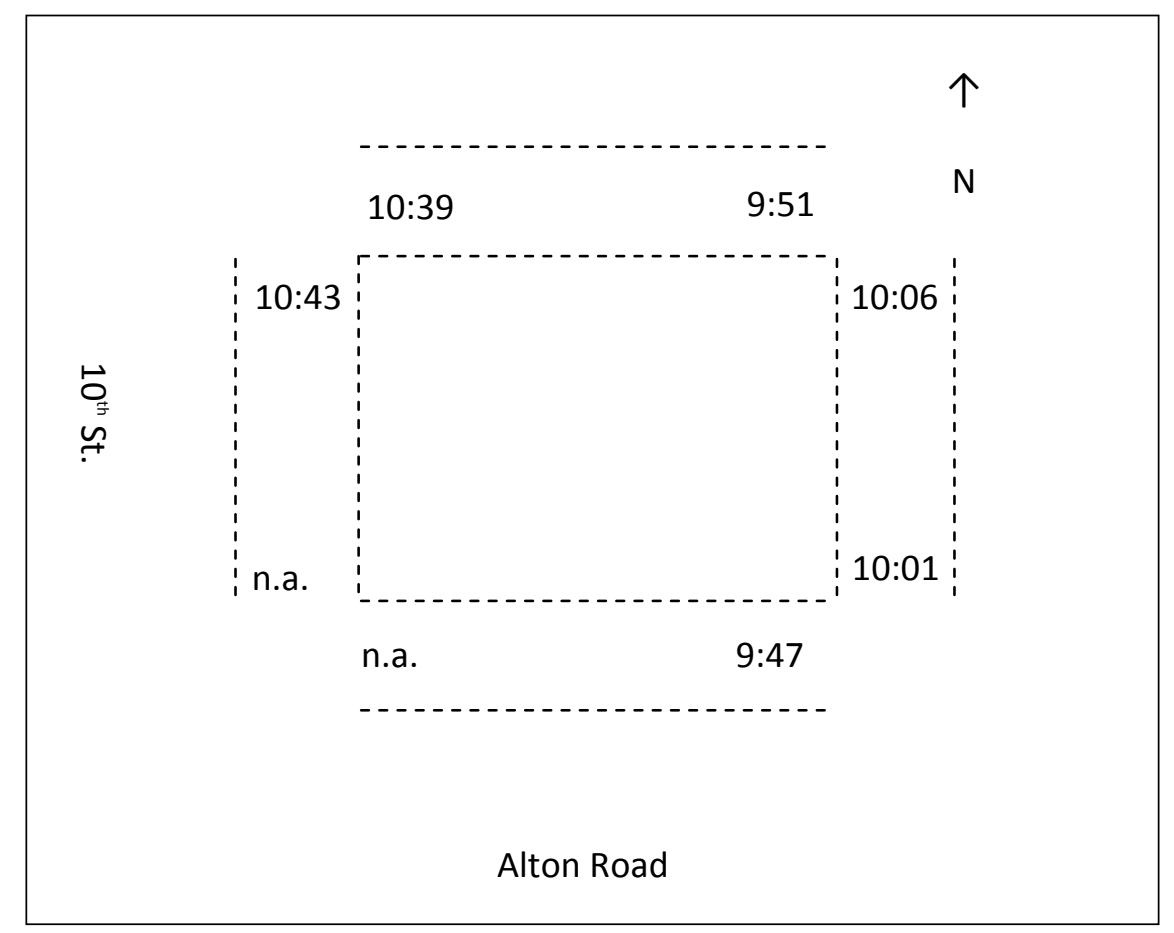

Figure 10: Alton Road and 10th Street: Times when crosswalks observed to be no longer usable for pedestrians as tide rises. November 2, 2012. Illustration by author. 


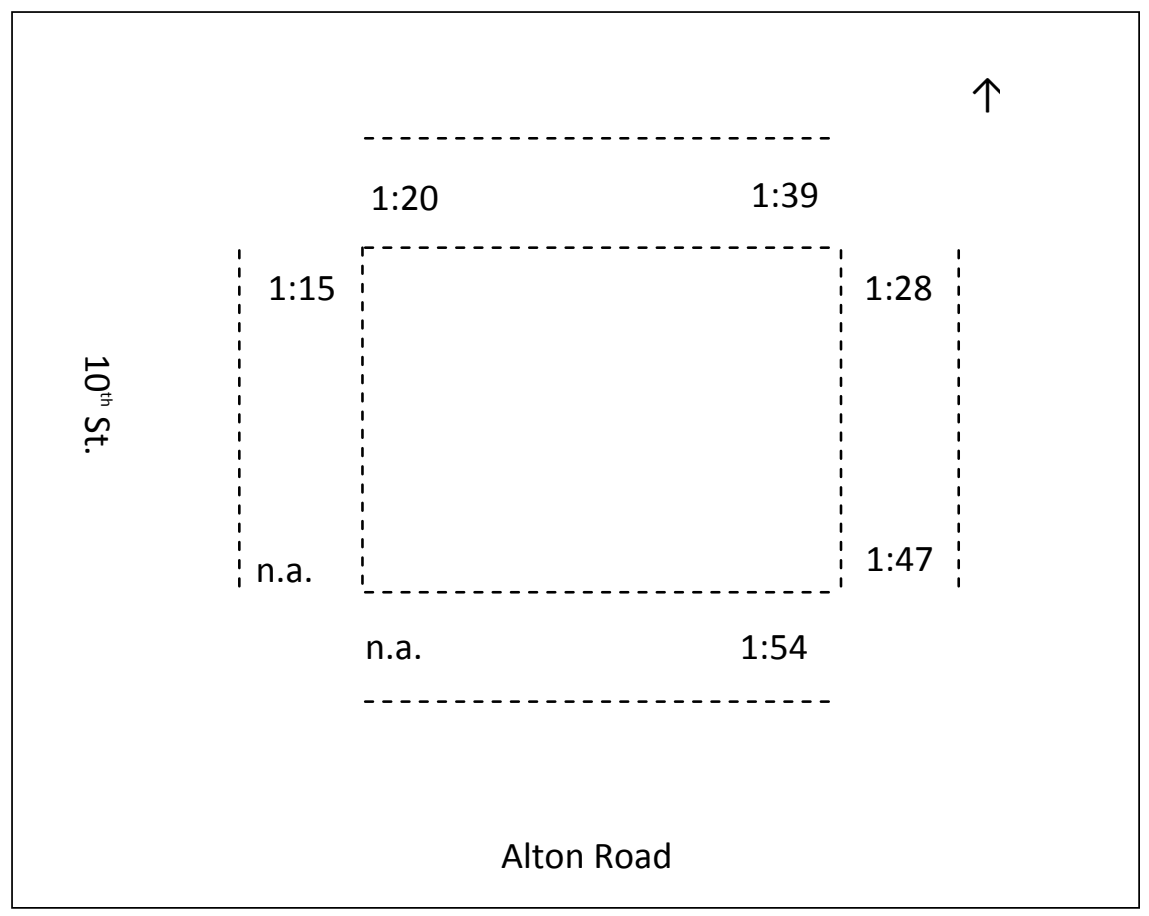

Figure 11: Alton Road and 10th Street: Times when crosswalks observed to be usable again for pedestrians as tide recedes. November 2, 2012. Illustration by author.

For the analysis of the timing of the disruption of this intersection, I chose the northeast corner which was the first to flood of all the corners. I have used the actual observed behavior of pedestrians because there is a relatively steady stream of pedestrians using this crossing and therefore it provides a fairly reliable time stamp. However it is not a perfect measure because some individuals are more able to step across wider distances than others, particularly those with less mobility. It is therefore a conservative indicator. For the analysis I take the average of the Virginia Key water height level at 9:51 a.m. (0.42 feet) and at 1:39 p.m. (0.48 feet) which is 0.45 feet. Below is a chart showing the number of hours that water levels were above 0.45 feet from 1996 to $2012 .^{6}$

\footnotetext{
${ }^{6}$ The water heights used in the analysis as benchmarks for urban disruptions do not correspond to actual elevations in the observation locations. For example, in Site 2 the inlet from which water flows into the
} 


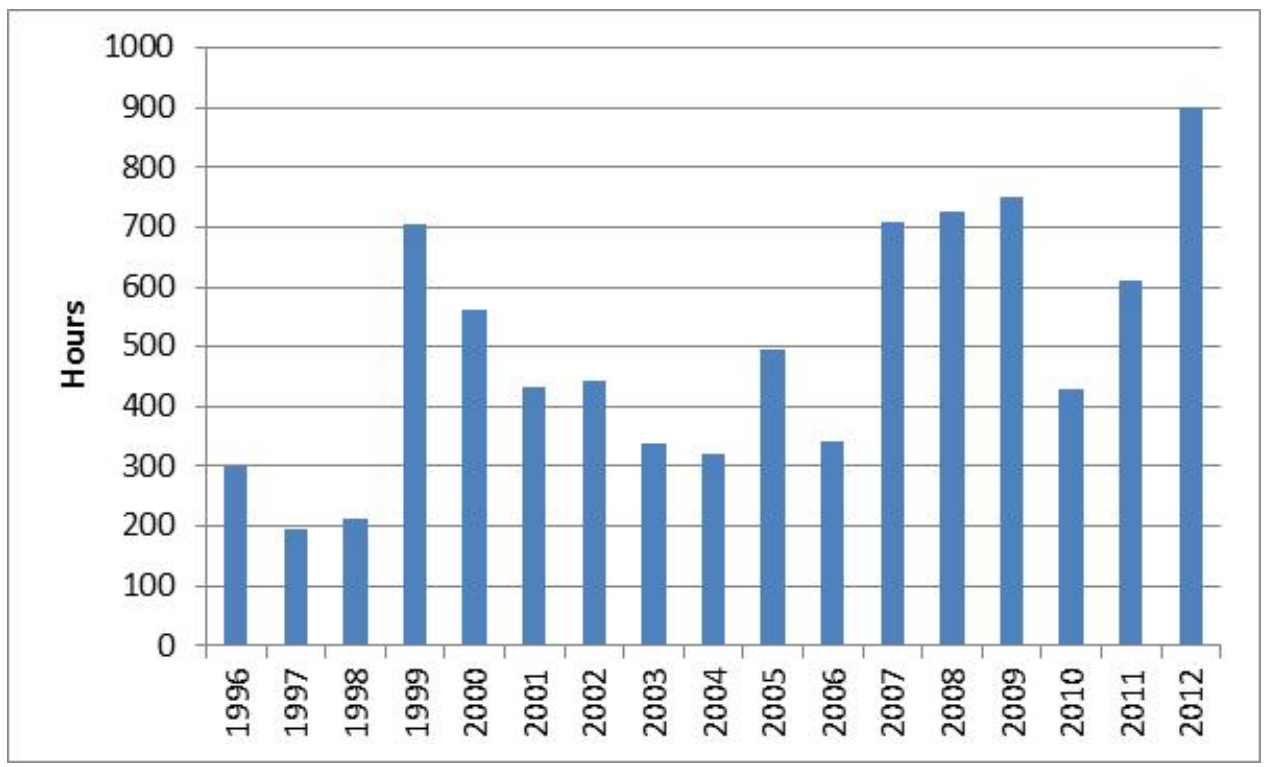

Source: NOAA Virginia Key tidal station historic water data hourly water levels Figure 12: Tide Hours above 0.45 feet NAVD, 1996-2012, Virginia Key, FL

The chart shows a similar pattern to that from the first observation site. 2012 recorded the most hours of water height above 0.45 feet with nearly 900 hours, or ten percent of the year. Four of the years with the largest number of hours occurred in the last six years. The longest period when the tide was observed above this level was October 28, 2012, corresponding with Hurricane Sandy passing offshore. Water levels were above 0.45 feet for eight hours from 8:48 a.m. to 4:48 p.m., and the highest water level recorded during this time was 2.14 feet NAVD at 12:48 p.m.

This analysis demonstrates that small changes in water level, on the order of inches, can have significant urban impacts. As sea level continues to gradually rise, progressively more low-lying areas will begin to experience such impacts. This has

street has an elevation of 3.13' NAVD according to Roadway Plan drawings obtained from FDOT. The discrepancy is due to the pressure and velocity from wave action which pushes water into pipe outfalls, resulting in higher water levels in the street than in the tidal data. 
implications also for municipal infrastructure project design which will be discussed in the next chapter.

\section{Urban Life Impacts}

The previous examples demonstrate that tidal flooding in urban areas disrupts urban life and prompts the people who live and work in the area to react and to adapt. These behaviors can be classified as unplanned adaptations or on-the-spot reactions, or as planned adaptations or behaviors learned from repeated experiences with flooding. In this section I will describe the disruptions and adaptations that I observed through my ethnographic work and that were related to me in interviews with local residents and businesses.

\section{Damage and Disruptions}

The types of disruptions that flooding causes to urban life in Miami Beach range from relatively small, almost imperceptible inconveniences to more substantial damage to property and even danger to life. The most common disruptions are the inconveniences to pedestrians of having to walk around water ponded at crosswalks in intersections where storm drains are located close to intersections and street crossings. This inconvenience becomes a danger when pedestrians are walking along the crest of the road to avoid water, particularly for the elderly or disabled (see Figure 13). Miami Beach has made efforts in recent years to become more pedestrian friendly, but pedestrian accidents are still more common than they should be and Florida is notorious for its high rate of pedestrian fatalities. A 2002 FDOT report found that Alton Rd. is Miami-Dade's third worst "high crash corridor," and that only twenty-seven to forty-five percent of drivers 
yielded to pedestrians when turning at intersections. Thus flooding worsens an already dangerous situation, as the example in Figure 13 shows.

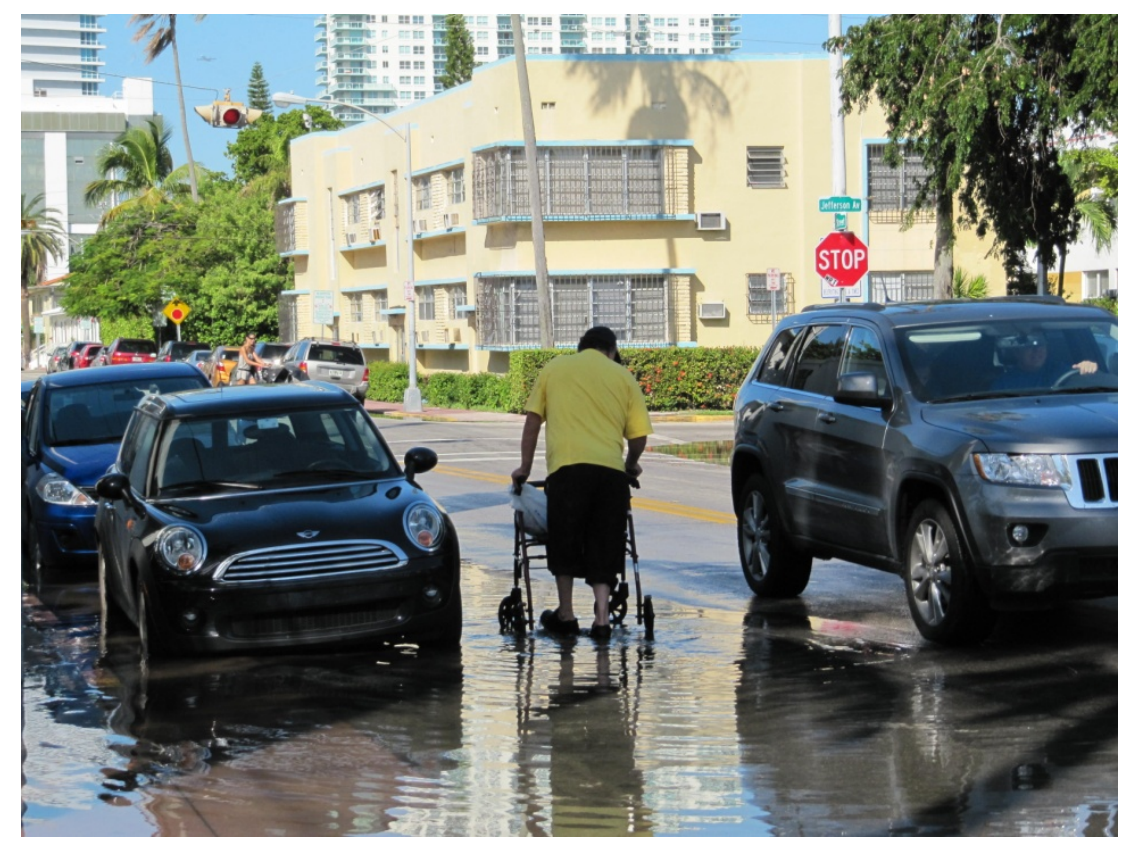

Figure 13: Man With a Walker in Flooded Street, October 16, 2012. Photo by author.

Bus passengers were another group affected by the flooding. When sidewalks became flooded people would no longer wait at the bus stop. Bus drivers would try to accommodate by picking people up or dropping them off in areas that weren't as flooded, perhaps half a block away, but this created confusion for people who were unsure where to wait for the bus. It also backed up traffic when the bus stopped to pick up people who were waiting in the street. I observed one woman nearly miss her bus because she had to walk half a block out of her way to avoid a flooded crosswalk, and had to flag down the bus so it would wait for her to cross. Agile people were able to jump over puddles, but I observed few elderly or less mobile people attempting to navigate the flooded streets to board a bus. The elderly and less mobile are a significant portion of transit riders, and 
their absence during this time leads me to suspect they may have decided not to attempt an excursion when there was significant flooding, perhaps altering their routine or depending on other means of transportation.

Many people I interviewed who lived in flood-prone areas reported having trouble getting to their destinations and either waiting to leave their homes until the water receded, switching routes, or using a different mode of transportation. One woman I interviewed who did not have a car said, "Now I don't have a car so I walk everywhere or bike, and it definitely impacted me a lot.... If flooding was too bad sometimes I would just opt not to go out..... for example, grocery shopping that day and I was like oh forget it, I'll wait until there's no flooding. Which at some point you just give up and deal with the flooding" (Renter 2, interview May 23, 2013). Another woman who was taking classes at Miami Dade College downtown told me she had trouble getting through the flooding on her scooter.

Last year I remember I missed two days of class because I couldn't leave my house. My car was broken and I was driving my scooter and I couldn't leave my house on my scooter or walking. So I was ready to leave to school and then-actually I left but I couldn't leave the beach, I couldn't get through either West or Alton. It was a really bad traffic also, then I got up to there like a few blocks away and then the water was really high and I couldn't, I had to come back home. (Renter 1, interview May 2, 2013)

A man told me that the flooding interrupted mail and deliveries, and that leaving the building was a challenge. "On foot it was impossible unless you wanted to get wet, so I left on bike or in car. People coming to visit was out of the question" (Owner 5, interview March 14, 2013).

The loss of business was the main concern for many businesses in the areas most susceptible to flooding. The grocery proprietor told me that before he bought the planks 
he wasn't as concerned if business dropped off for a few hours because people would wait to come later. But when a large grocery chain moved in a few blocks away he became worried that people would go to the other store instead of waiting, and so purchased the planks to try to make it easier for people to enter the store. He claimed he lost $\$ 4000$ of business for every 4 hours the store was closed. Another business manager I interviewed also felt the flooding prevented customers from coming into his store. I chatted with him outside of the store one day as the water in the street was rising, and he was starting to bring sandbags out. He was concerned because it was Halloween and he was counting on being able to sell his Halloween merchandise to last minute customers, since South Beach is known for being a popular spot for appearing in Halloween costumes. A gym manager I interviewed described having to be flexible with his classes since people would arrive late, and to alter his class workout routine which included running out around the neighborhood. An employee at another grocery told me about difficulties getting deliveries when the delivery area was flooded. He said the forklift can't drive in more than six inches of water, and deliveries won't come if they know it's flooded. The store gets daily deliveries in the mornings, and getting late deliveries affects tagging and getting items onto the shelf which can affect sales for a day and a half. Once, when they weren't able to get a delivery from a supplier before the supplier closed at $2 \mathrm{pm}$, the product was not available. On the other hand, the store manager commented that the flooding perhaps increased sales as people stocked up on items they were afraid they might not be able to get if they couldn't get to the store.

Many of these example show how flooding impacts businesses is based on their location in the commercial landscape. Another such example is a dry cleaner located in 
an area that experienced frequent flooding in fall 2012. Normally, according to the manager, dry cleaning picks up in November as customers come down for the winter and start bringing in more costly items. But when we spoke in early December he said that

Because of the flooding our income was the same as in the summer until last week. [Other nearby cleaners] weren't flooded as much, so I assume people went there. Loyal customers waited for us. But we saw the season wasn't picking up yet. In the season we make $\$ 55-70 \mathrm{k}$ a month, I'd say average $\$ 55 \mathrm{k}$. It's not just more clothes or more people, but in the summer people have regular shirts, which are cheaper. In the winter there are more dry cleaning clothes, dark clothes, colors, coats, etc. and they cost more. In the summer we make $\$ 42 \mathrm{k}-\$ 47$ a month, so there's a $\$ 10 \mathrm{k}$ difference that we didn't see till last week [when the flooding stopped]. (Small Business 4, interview December 3, 2012)

Other costs were associated with physical damage. The most common complaint was about damage to cars, which is a major concern in a neighborhood where most residences do not have parking facilities and thousands of residents and visitors park on the streets every day. Nearly every interviewee talked about seeing cars flooded, and many were concerned about the damage to their cars from driving through salt water. One interviewee said his mechanic told him he had rust damage under his car, but as the rust occurs gradually it is difficult to quantify. The salt water also does damage to electrical wiring in buildings and fixtures. After several days of flooding in late October I observed a city work team repairing some wiring in a light pole, and spoke with one of the workers who said "the wires get eaten out by the water, so we've got to replace them" (October 29, 2012). I said that that must have happened on 11th too because I noticed the lights were out last night. He said it was all over the city, and when I asked how often this happens, he said every time there's a high tide.

On the morning of October 27, as Hurricane Sandy was passing by off the coast and the low-lying streets were under a foot of water, I was out taking observations and I 
came across a high rise condominium with a crowd of about 100 people standing outside, appearing to be waiting. There was an alarm going off, so I asked a man sitting on the curb what was going on and he said they had evacuated the building but he didn't know why. Another man came over and said he heard the electrical room had gotten flooded because of the high tide. I asked another man standing next to me if he lived in the building and he said yes, he had gotten home at 7am after working the night shift at the airport with a cargo carrier. He didn't know why they evacuated either. Two firefighters walked by and told the building manager they could let people back in. I went around the side of the building, which is directly on Biscayne Bay, and there was a fire truck and two men guarding the entrance to the parking garage which sloped down under the building. They told me not to go in because they were safety issues. The garage had about one foot of water in it. I asked a man in a fire department shirt if this happened a lot and he said not that often but it does happen. Another firefighter said with the high tide and the full moon and the wind from the storm pushing the water on-shore, it made the water really high. No one seemed particularly tense or upset, the strong wind from the storm perhaps acting as a reminder that the damage could have been much worse.

\section{Adaptations}

Although occasional flooding has always been part of life on Miami Beach, the frequency with which flooding is now occurring, and the growing recognition that this is connected with sea level rise, means that responses to flooding are turning into adaptations - new, non-temporary behaviors and changes to the built environment that can be observed as people learn to adjust to the new reality. 
The most visible adaptations involve landscaping changes and physical changes to property or methods for preventing water from intruding into buildings. One store had installed new landscaping that was repeatedly inundated by the high tides, as shown in Figure 14.

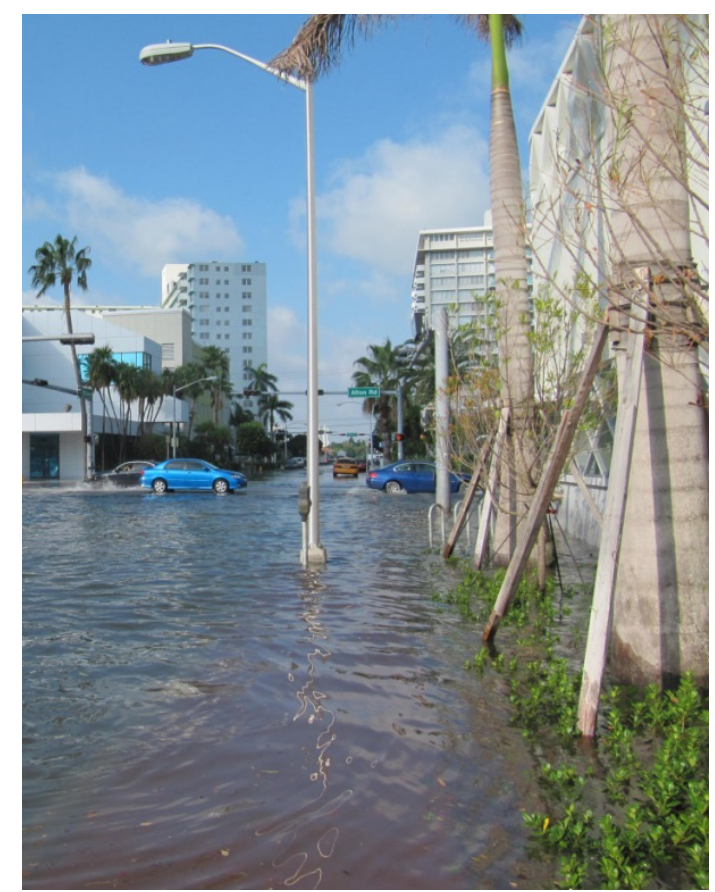

Figure 14: Flooded landscaping, October 28, 2012. Photo by author.

After the shrubbery and most of the trees eventually died, the landscaping was replaced with rocks, as shown in Figure 15. 


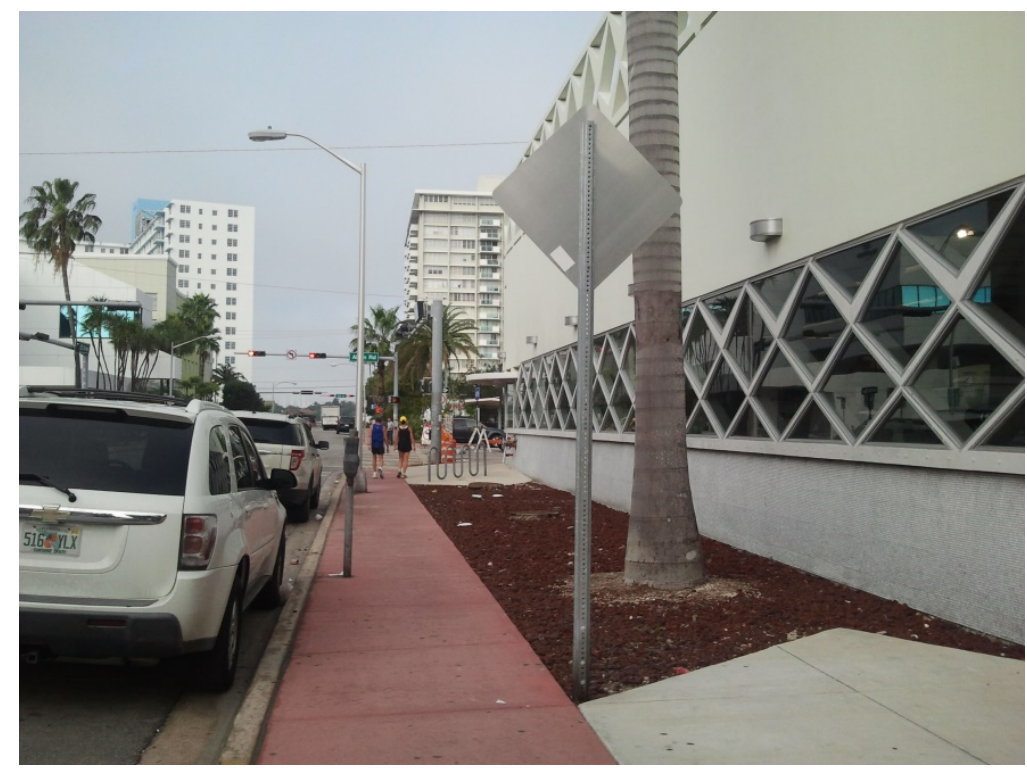

Figure 15: Flood-proofed Landscaping, February 9, 2014. Photo by author.

By far the most common adaptations were sandbags, which were seen in front of businesses and homes in areas susceptible to flooding and became more common as time wore on. Some interviewees said that their landlord had provided the bags, and others had purchased them or gotten them from the City. Some had them in storage and brought them out when they saw the water rising in the streets, others left them in or near entryways. I observed only two commercial buildings using metal flood barriers which according to the City they are required to have by the building code. These barriers are heavy and must be bolted down, requiring an electric drill. When I asked one small business owner if he had these flood barriers and used them, he said "it would be a lot to invest in something like that which fits on with a seal, and it wouldn't work well with the stucco" (Small Business 7, December 19, 2013).

As the days of flooding continued, some of these adaptations took on a more permanent character. Residents of the apartment building below initially placed a board 
over a place in the walkway that was often under water as shown in Figure 16. Later the building manager built a wooden step, shown in Figure 17.

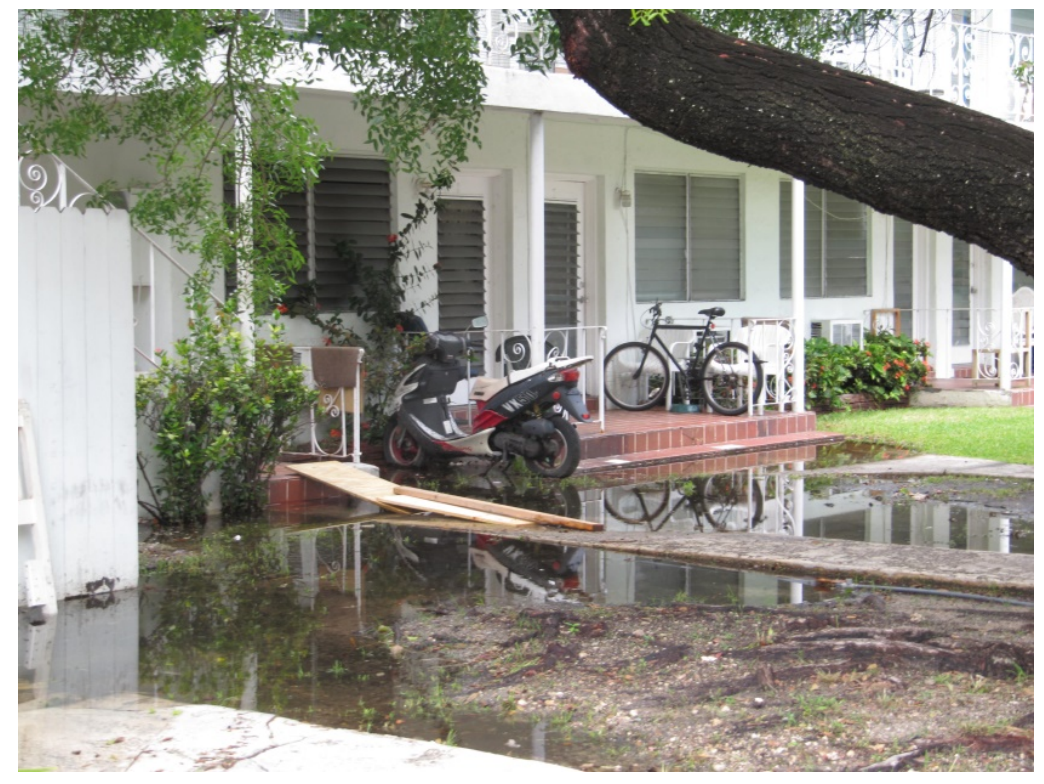

Figure 16: Board Over Flooded Walkway. May 23, 2012. Photo by author.

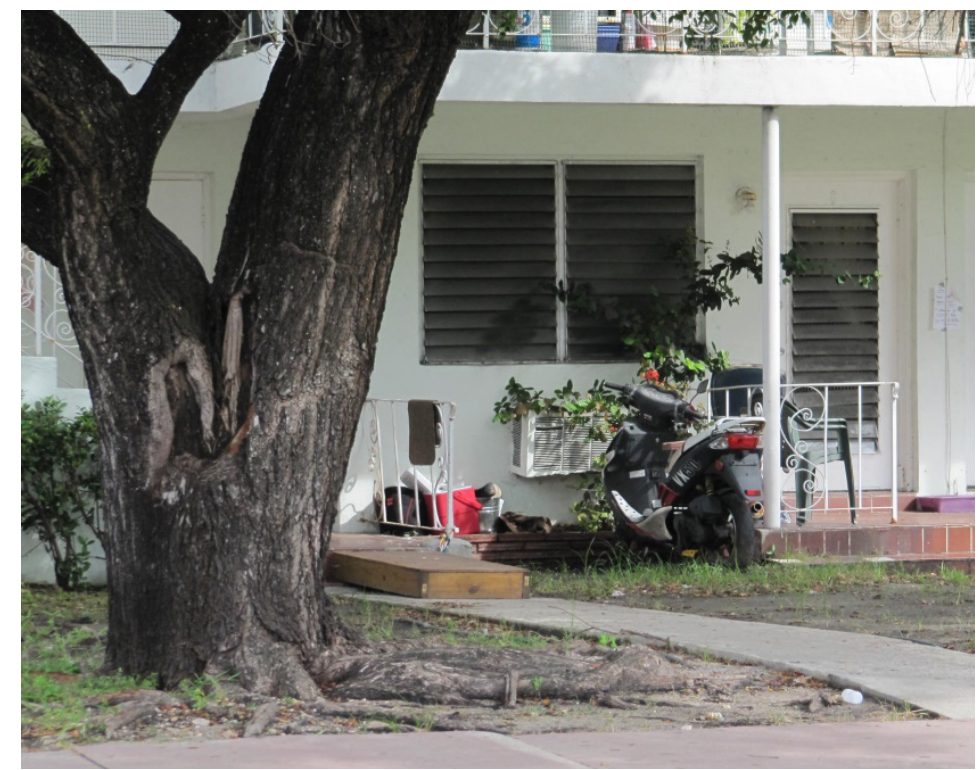

Figure 17: Wooden Step Over Walkway, October 17, 2012. Photo by author.

A store that opened in this location early in 2012 encountered its first flooding problems that June with rain storms and higher tide levels. They brought out sandbags 
which were piled rather haphazardly against the door to prevent water from hitting the base of the door, as in the photo below. By October they began arranging the bags in a circle in front of the entrance which made it easier for people to step over and also meant that the bags could be left in place between flood times. If the water rose higher they would add a second layer of sandbags, which didn't completely prevent water from reaching the doors, but worked fairly well to prevent the major problem which was the wave action created by cars driving by through the flooded street.

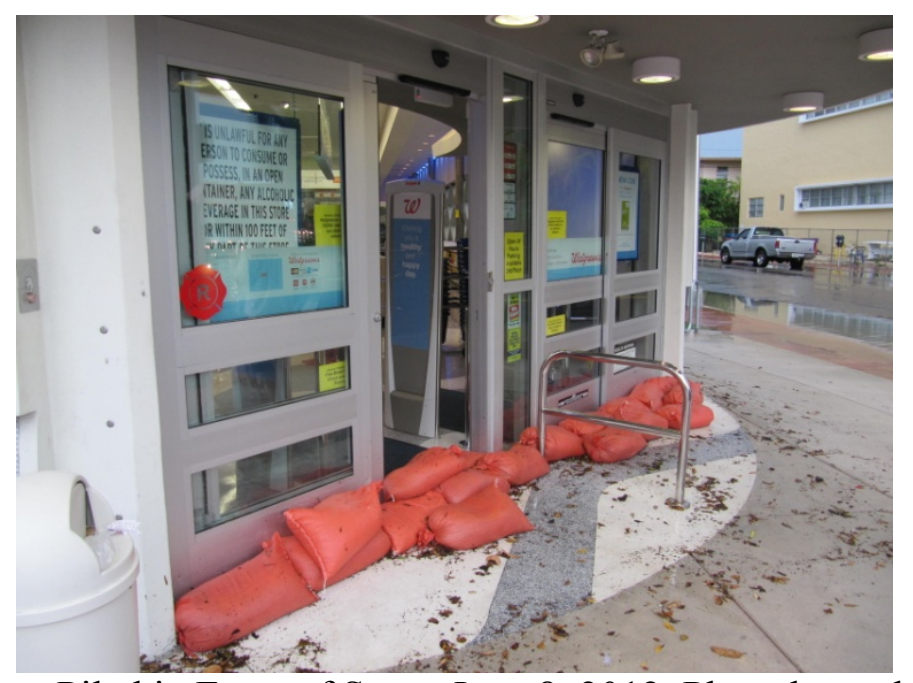

Figure 18: Sandbags Piled in Front of Store, June 8, 2012. Photo by author.

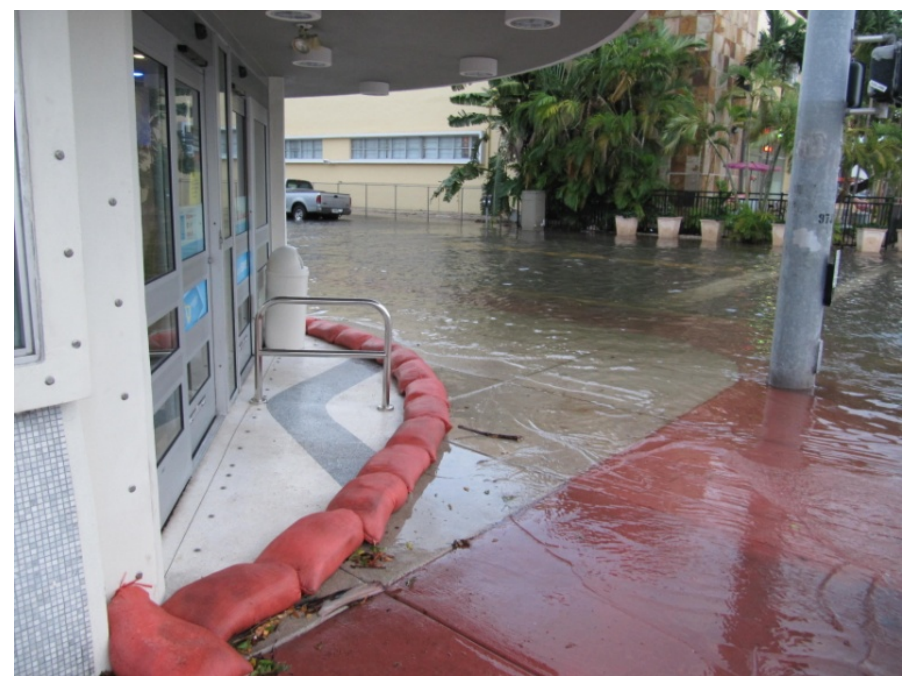

Figure 19: Sandbag Ring in Front of Store, October 27, 2012. Photo by author. 
Although these physical adaptations became less temporary, residents and businesses realize they are not really a permanent solution. Sandbags obviously interfere with wheelchair access, and the makeshift walkways were not constructed according to any code or permitting process. One owner recognized the problems with this, but felt he had no choice. I asked him if the City had ever said anything about the walkway he made for people to walk over, and he said no, never, and that he wouldn't make any money if he didn't have it. I ask if anyone had ever gotten hurt using it and he said no, and that "I'm taking a risk and I shouldn't, but otherwise I couldn't pay my bills" (Small Business 1, November 28, 2012).

\section{Perceptions and Decision Making}

In my interviews I also sought to understand how people perceive the flooding and how that impacts their decision making. I asked whether they felt there had been any change in the flooding they had seen since they had been on Miami Beach, what they attributed the changes to, and whether this would influence their decision making in the future about their business or residence. Given the small sample size I did not attempt to correlate perceptions with individual politics or demographics, but rather to understand how the flooding, its drivers and impacts were interpreted and the thought processes about future decisions.

Perceptions of the flooding

The most predominant view among the interviewees and people I spoke with while doing my observations was that flooding has always been a problem on Miami Beach, particularly when it rains, but that it has gotten worse in the last several years. A 
business owner on Alton Road for 15 years said, "It started about three years ago. It gets bad when there's a lot of rain, worse than just high tide" (Small Business 5, interview January 16, 2013). But in the last year the street flooding that came with the extreme high tides made it obvious to nearly everyone that something was different, and that rain was no longer the main driver of flooding. A homeowner who has lived in the same house in the Flamingo Park neighborhood since the late 1980's said,

The first rain - we would notice that the first rain of the season all the leaves would go into the sewers and then things would back up.... But it seemed the City would come around and clean all the sewers out, cause it was all the dead leaves, and then they cleaned all the sewers out and it would go right back down. That was the only time we noticed flooding back then.... If it rains at the same time as one of those high tides that's when you really have the problems. That's the way it was four, five, six years ago, but last year it seemed even worse, it was backing up even without rain. (Owner 3, interview March 9, 2013)

Similarly, a renter who has lived in the same area for 6 years said,

I definitely feel like it floods more around here, around 10th and Alton especially when it's not raining. Like rain no longer seems to be the indicator of whether or not it's going to flood. So it can be a perfectly sunny day and day after day there will be feet of water at that corner. (Renter 2, interview May 23, 2013)

Many recalled the June 2009 flood when most of the neighborhood was under two to three feet of water for several hours as the time when they first noticed the flooding, such as this condo owner who had bought in the early 2000's,

Well it seemed to jump to a new place then. A new kind of flooding that we hadn't seen before.... That flood was so big and then maybe there was 1-2 after that that had an impact, maybe not such an impact because that was sort of a shocker. But it's not like each time it gets worse and worse. I mean I haven't noticed that. We've already seen it so it's not a shock now. (Owner 2, interview March 31, 2013)

However this view was by no means a consensus. I spoke with people who insisted that the flooding had always been just as bad, some who claimed it had actually 
improved, and some who were hardly aware of it. One day when I was making notes in front of the grocery with the planks, a man crossed over the plank, looked at my rubber boots and said, "you're well prepared, did something break?" "No," I say, "it's high tide." "Really?" He says. "I've lived here seven years and I've never seen it like this" (October 16, 2012). Although that seems hard to believe that people would not have noticed the flooding or not understand where it comes from given the data on tide levels, it is possible that the intermittent and localized nature of the flooding, and residents general experience with the Florida climate may explain the apparent ignorance of flooding and its drivers. It is possible that the man who had lived in Miami Beach for seven years and not noticed the flooding lived on a street that does not experience significant tidal flooding, that he had not happened to be in flooded locations during high tide events, and if he did see water in the streets he may have attributed it to rain. In Florida's sub-tropical climate it is not an uncommon experience to enter a building when the street is dry and the sun is shining, and come out an hour later to find the sun still shining but the street wet because of a twenty minute rain shower.

There did not seem to be a correlation between perceptions of the flooding and how long someone had lived or worked in the area. Two people I spoke with who had worked on Miami Beach for over twenty-five years, insisted that it had always been like this, that it has not gotten worse. One actually stated that it had gotten better, due to improvements made by the City, and it is true that the City has completed projects which made significant efforts to improve drainage in several sections of the City. While another woman who has lived in the same apartment for fifteen years but had just returned after being away for the last four years, said she didn't ever remember the 
flooding in the past. These different perceptions point to the difficulties of perceiving gradual long term change, particularly for an intermittent phenomenon.

But with more experience with flooding, more media coverage and more conversation happening among locals, people were learning. Knowledge was spreading by word of mouth, and business owners were having conversations with their customers about the flooding. One business manager said, "At first we didn't know where it came from. The first couple days it was raining, and we thought it was the rain. But then there was no rain and the street was still flooded, and the customers were making comments" (Small Business 4, interview December 3, 2012). When I asked another business manager how he made the connection between the flooding and the tides, he said "We just figured it out. It will be flooded and there won't be a drop of rain. And it happens twice a day" (Small Business 6, interview December 14, 2013). People began to notice increased media coverage as well. I observed TV news trucks filming the flooded intersection of $10^{\text {th }}$ Street and Alton at least three times, but only one interview subject made reference to media coverage, in this exchange I had with a homeowner couple in an interview,

Homeowner 1: It's very recent that it's become common knowledge and perceptible.

Homeowner 2: Yeah last year was when people really started talking about it. Emily: How did you notice that?

Homeowner 2: Because we were part of it, everybody just started, all of us that live on the beach, we have a lot of friends here, Homeowner 1: Well also the Herald, the local paper is covering it more. (Owner 3, interview March 9, 2013)

But despite all the disruptions, somewhat surprisingly the majority of people I spoke with said the flooding didn't bother them very much, and very few expressed any 
strong emotions about it. The few who did express strong emotions felt that the City should be doing more, such as a woman who told me, "This is a rich city [gesturing at the buildings around] why don't they do something? They say it comes from the Bay but I don't believe it because it smells" (August 20, 2012). But the predominant attitude was one of "dealing with it." When I asked one resident if the flooding bothered her, she said "not really" and explained that she'd just walk down the sidewalk by the park, and jump over the flooding or take off her shoes if she had to (Owner 2, interview March 31, 2013). Another one said that when the tide is high "you have to wait a little to go out and it goes down. You relax. Every neighborhood has its problems. It doesn't bother me" (Renter 4, interview February 7, 2013). Several people explained this attitude as a feature of a Miami Beach mentality, as one business owner said, "Miami Beach residents are tough people, it reminds me the most of NY of any place I've been in the U.S. They're like yeah it's flooded (shrugs shoulders) but they still come in" (Large Business 2, interview February 5, 2013). A resident put it this way, “It's a Miami thing, people just deal with crap. It's not a very political city, not like San Francisco, because it's a transient place to live" (Owner 4, interview February 14, 2013). This reference to politics shows an ambivalence about what can be done about the flooding. One business owner said that you have to deal with it because "Well there's nothing else you can do. I got frustrated, it was like 3 weeks straight, and it seemed like forever. But what can you do?" (Small Business 6, interview December 14, 2013).

The link between perceptions of flooding and climate change or sea level rise is complex. Not everyone I interviewed connected the flooding with rising sea levels, and those who did had differing beliefs about what was causing it and what could be done 
about it on Miami Beach. Those who paid attention to science and politics immediately connected the flooding to sea level rise, like the business owner who said he "supported Al Gore 100\%" (Small Business 1, interview November 28, 2012) or the middle class condo owner who said that he "read a lot and listen to NPR, so I thought it could be related to sea level rise and climate change" (Renter 1, interview May 2, 2013). But for others the connection was not clear, due to lack of familiarity with the link between climate change and sea level rise or to doubt about the connection between sea level rise, tides, and the drainage system. I asked a business manager if he connected the flooding with climate change or sea level rise, and he said "It could be — but it hasn't rained and it's flooded more, and it doesn't make sense how a high tide could cause that much flooding. It's hard to know, it's not my area" (Small Business 5, interview January 16, 2013). A renter I spoke with, when I asked if she knew where the flooding was coming from, said "It's hard not to imagine that to some degree it's related to sea level rise, but also I know the drainage systems here are problematic" (Renter 2, interview May 23, 2013).

Concern about sea level rise meant that many were skeptical that the proposed projects to fix the flooding by improving the drainage infrastructure would work. When I told one business manager that that the city has plans to fix the street, she said, "last year the city installed a big pipe under the street. They've tried two to three times, but they can't do anything. The only solution would be to raise the buildings" (April 30, 2013). When I explained the pumping stations to a homeowner she said, "Where are you going to pump the water? If you pump it out it will just come back in." A resident said, "as little as I understand, the water is higher than the land, so I don't know what they're going to 
do" (Renter 3, interview February 6, 2013). Nevertheless many still wanted the City to do something, such as one condo owner who called the City and said, "That's it I've had enough of this. What are you guys doing about the flooding? You need to do something. We can't live like this. It's every day" (Owner 5, interview March 14, 2013). Business owners were particularly frustrated, such as one store owner who had been complaining to the City for years. "I'm a simple person. I pay a lot of taxes, property tax, federal, state sales tax. I create jobs. It's so frustrating. I can't fight the city. I can't get tenants. People see the water. I've been trying to sell this corner for two years but can't because of the water" (Small business 1, interview November 28, 2013).

Those who did not believe in sea level rise caused by climate change still frequently felt that the situation was ultimately not sustainable because development on the island was fighting "nature." One woman referred to the construction of the beaches by the Army Corps of Engineers in the 1980's and said, "In 1982-83 walking on Ocean Drive you could feel the ocean spray. Then the government fixed the beach, they pushed the water back, and that's not natural. When a problem comes the sand goes up and goes down again, its nature" (Renter 4, interview February 7, 2013). An employee at a business that closed its doors regularly when the streets were flooded said "its nature, and you can't do anything about it. It's the ocean. If a hurricane comes, it will take everything away. The city can't do anything about it, we just have to get used to it and if anyone doesn't like it they should leave Miami Beach. The only solution is to shut my door" (April 30, 2013). 


\section{Decision Making}

Given the disruptions caused by flooding, the concerns about sea level rise and doubts about the ability of the City to deal with these problems one might expect people to be thinking about leaving the area. However very few people I spoke with, particularly business owners, had considered the possibility of moving. Every business I interviewed said they had a terrific location and could not imagine relocating. "You couldn't make up a location this great," one store manager told me. When I asked about the possibility of relocating he said "We might make changes, but Miami Beach would have to be under water before we'd relocate" (Large Business 2, interview February 5, 2013). Even businesses that knew about the flooding beforehand still chose their location. A small business owner told me, "We get high foot traffic and high visibility. It's a great location." When I asked if they had known about the flooding beforehand, would they still have chosen this location, he said, "Definitely. The rainy season is only six months and how many times does it really rain that hard and flood? The other businesses around here are thriving and dealing with it, so we thought we'd be ok. We knew it was the lowest point on the beach and was susceptible to flooding." When I asked if he would consider relocating, he said, "No. Space like this is hard to find on Miami Beach. We've established ourselves and everybody recognizes us and knows where we are. It's cheaper to keep it here" (Small Business 6, interview December 14, 2013).

Similarly, a large national chain built a store on leased land even though they were aware that the parcel experienced flooding. The developer of the project said accommodating the flooding went into the design of the new store, which was raised as much as possible while still being ADA compliant. The store replaced an old apartment 
building which had been severely impacted by the flooding, which the new building was better able to handle. As for concerns about the future, he said

I have not spoken to one person who has based any investment strategy on rising tides. It's almost like there's no real consensus, there sort of a belief that the tides are rising but there's no real consensus in the business community about when it's going to happen and the effect it's going to have. So therefore people don't, they ignore it. (FIU School of Architecture Symposium, March 14, 2013)

For some, the type of business and business regulations played a role in their desire to stay put. When I asked the manager of a highly regulated business if he would consider moving he said no, because the location is great. "It could get worse and I still wouldn't move," he said. “[My business] isn't like a clothing store, you can't put them anywhere." I said to him, what if I told you the predictions were for two feet of sea level rise in fifty years would that impact your decisions any? "That's a lot," he said, "but what would that mean?" I said the water would be about two feet higher. "Sometimes it's that high now," he said. "It doesn't scare me, I can’t move" (Small Business 5, interview January 16, 2013).

For other businesses the amount of sunk costs involved in establishing the business means that moving is out of the question. One small business owner told me, "People ask me, with the flooding why stay? Because getting a business open on the Beach is a nightmare to consider moving. It took six months to open between the City and the County, the impact studies, they wanted to study traffic flow, etc. It took $\$ 60,000$ to open, six months rent with the doors closed" (Small business 7, interview December 19, 2013). Even the prospect of rising costs for dealing with the flooding didn't change his mind. When I said that the pumping projects might increases costs for water and 
sewer and asked if that would affect his decision making, and he said "No, I'm pretty much stuck here. I've just got to pay for everything."

But even the owner who was most concerned about rising sea level told me that he was sixty years old and didn't want to move. He came to the U.S. in 1982, to West Palm Beach and learned the grocery business. In 1989 he had a business on Collins Ave. and then he rented the space where the market is now, which was empty at the time. He rented for two years and then bought the building - the owner gave him a good price. “It's a great location," he said, "I'm doing fine, I'm supporting my family." But he sees the flooding getting worse and is frustrated by lack of action from the City. He owns several businesses and has been trying to sell one for two years, but can't, he says, because of the water. I ask if that's really the reason, and he says, "Yes, if people are going to buy they do research." He said, "We don't mind paying more taxes, but they need to fix the problem. These properties are my retirement plan. I'm in my sixties, I'd like to slow down but I have to support my kids and I don't want to sell for nothing." I tell him that some scientists have predicted for this area two feet by 2060 , and he says yes, that would be under water. I ask if that would change any decisions he makes about his business, and he says “I don’t know, I don't think too much about it. This is my home, I love it, my kids love it, I have no plans to move. It's beautiful here, who would want to leave?” (Small Business 1, interview November 28, 2012).

I found only two businesses who said the flooding might impact their decision making. One was a restaurant manager who did feel that his business had been impacted by the flooding, and said that if he had known about the flooding before renting the space he would still have wanted to rent but would have tried to bargain for reduced rent or a 
relief clause in case they can't open because of the flooding. The other was a young man who had just become manager of a business and had already spoken to the owner about buying it. I asked if the flooding would be a factor in his decision to buy, and he said no, it's a good business. Then I referred to a comment he had made earlier about a customer who had mentioned a newspaper article saying that Miami Beach would be under water in thirty years, but he said, “I haven't thought much about it. I'd have to look into it and think about how much I'd need to invest in order to sell in a few years, or if it would last longer" (Small Business 4, interview December 3, 2012).

For businesses, location is primarily about the economics of return on investment, but for residents it is more complicated. The economics are important, but so are quality of life, particularly ties to the community, being near the water, and being able to get around without a car. Having easy access to transportation, the supermarket, and work was important to people across the income spectrum. A low-income woman who had rented for fifteen years in a building that often experienced flooding said "I love it here, that's why I don't move. It's so easy because the bus is right there, the supermarket, and work. The only thing they should do is take care of the traffic, it's horrible" (Renter 3, interview February 6, 2013). A middle aged homeowner who had relocated from the northeast said, "We looked off the beach a lot when we were looking to buy and it just, we were so spoiled by living on the beach and being able to walk everywhere and having the water and so, I just didn't want to go back to commuting lifestyle again. But that said, I go off the beach to work but still" (Owner 2, interview March 31, 2013). A renter told me, "I love the location, I love being between Lincoln Rd. and I take the bus a lot too so 
it's nice to be a block from Alton. But it's also sort of a quiet neighborhood, it feels like a quiet neighborhood and I love being on the water" (Renter 2, interview May 23, 2013).

How economic considerations interplayed with other considerations was different for renters and homeowners. An elderly woman I interviewed had lived in the neighborhood since the early 1990's, and was now disabled and received assistance from her neighbors and friends who stopped by to visit her every day. "A long time ago it came in and flooded, a little, not too much. The manager cleaned the water out and came and helped me because my legs are not too good and I'm alone, so they look after me. I've been here fourteen years, it's a quiet neighborhood. I like it" (Renter 4, interview February 7, 2013). But she recognizes that because she has a housing subsidy through the Section 8 program she has to live "wherever the government sends me. Now prices are very high, one apartment is $\$ 900$, I can’t pay it." In 1993 she recalls, “a one bedroom just like this was $\$ 450 . ”$

A middle-class renter who loved much of what the neighborhood had to offer was also worried about being priced out of the neighborhood. For that reason she has thought about buying, but had concerns about sea level rise.

I have really mixed feelings about it, and part of it is because of sea level rise, the projections are daunting. So I kind of feel like, first of all I feel like I could very well get priced out of the neighborhood so that would be a smart reason to buy. But I'm not one hundred percent sure that I want to stay here long term, I think I probably will but I'm not convinced enough. And the problem is that if you buy and there's significant sea level rise then your investment won't be very good. So yeah that part of it definitely gives me pause. It's not the only reason I haven't bought a place but it's something I think about when I think about buying a place. (Renter 2, interview May 23, 2013)

But she also emphasized what she liked about living on Miami Beach and the changes that had been happening recently in Miami. 
I feel like Miami's becoming a more interesting place, and that the neighborhood's becoming more interesting. With the New World Symphony and the Wallcast, things like Panther Coffee on the beach, the kinds of things that people like me like... I like Miami Beach a lot, I like the City I think it's a good city and they do good things with their tax dollars. I love Flamingo Park and the great pool that I swim in, and stuff like that. So I just think it's a place that is very livable for me and I enjoy it, so I definitely think about that and I imagine that if I don't buy a place I'll end up getting priced out... but again, in ten years are the infrastructure problems going to be so significant that it becomes a much harder place to live? So it's definitely a question. (Renter 2, interview May 23, 2013)

But if rent went up too much on Miami Beach, she didn't feel like there were other options in the area. "If I got priced out of the neighborhood I probably won't move off the beach, I probably wouldn't live in Miami anymore" (Renter 2, interview May 23, 2013).

Similarly homeowners I interviewed had many things they loved about the neighborhood but were also concerned with property values as well. The owner of a condo since the early 2000's said she wouldn't move until her teenage daughter finished high school, but that "flooding definitely impacts how I think about the beach long term. I don't want to watch our apartment dissolve, I don't want it to lose its value and then we have nothing so you know. In four to five years I can imagine selling it or moving on. I can live with the flooding now because we've done it for so long, it's just, you know all indications look like it's going to get worse" (Owner 2, interview March 31, 2013). But the high degree of uncertainty makes it impossible to time this decision. Another homeowner couple who had lived in the same house since the early 1980's said they had thought recently about selling, but had no immediate plans to. When I told them that the SFRCCC was developing an action plan for transportation, infrastructure, and other 
aspects of climate adaptation and had issued projections for two feet of sea level rise by

2060 we had the following exchange:

Homeowner 1: Shit. Two feet, I mean that's terrible in terms of South Beach we're at one or two feet above sea level as it is, so if it's two feet as an average and then you get these flooding events it's going to be a mess. Like Venice. Yeah, we're trying to get out of here.

Emily: Are you really?

Homeowner 1: Well not trying right now, but we talk about it.

Homeowner 2: We think about it, we have thought about it, especially when the flooding happens. It does spark conversation around here.

Emily: Would you want to go somewhere else on South Beach or go completely off the beach or...

Homeowner 1: Our savings are tied in this house you know, so we would want to be able to leave before the real estate value would go down. At a certain point it will become inevitable and no one's going to want to buy here because it's, you would assume, because you don't want to buy swamp land. So we joke about selling the next time it reaches its maximum and before-you're saying it's 2060? Emily: That's what the projection says.

Homeowner 1: So that's in fifty years. Well we won't be alive.

Homeowner 2: We'll be long gone.

From there the conversation turned to weighing the pros and cons of their current location and the uncertainty of trying to decide where they might move.

Homeowner 1: It's not that we want to live in an urban environment but we like to have access to culture. But a good mix of culture and certain critical mass of people but at the same time access to nature. So here the nature you have, South Florida's beautiful and we have the water and so we can ride our bike to the beach, so somewhere like that. But I guess it wouldn't be coastal again. SoHomeowner 2: If we move we're not going to move coastal. For sure.

Homeowner 1: Well nothing's for sure.

Homeowner 2: Pretty much that is part of the conversation.

Homeowner 1: Well there are coasts where there are mountains right up on the coast. If your only concern is sea level rising - but we talk-

At this point I asked why they would want to leave the coast, and the conversation continued:

Homeowner 2: We feel like, global warming is a real issue. And it's going to get worse. And if we do make a move, we'd rather move somewhere where we're not really going to have to worry about it. 
Homeowner 1: Well that's not the only thing that global warming will change is the sea level. It's hard to anticipate where the weather will be relatively stable and hurricanes don't come or, it's hard to-if it changes, continues to change so dramatically all bets are off, it's like very nerve-wracking. It's like the anxiety of the unknown, until now was always known. Well if you go to South Florida it's going to be warm and humid or if you go to, whatever, and you knew what to expect there. But now it seems like, at least in my mind, it's hard to anticipate what the weather pattern will be somewhere in ten to twenty years. It may not be at all like what it is now.

Homeowner 2: But I think that's what I'm really saying is that lately we have real conversations about global warming and the effects of it and that they're going to, that we will feel the effects of it. Or we don't really know whether we will or not, but it could. It could escalate and who really knows, you can't really say with certainty oh that won't happen for years because nobody really knows. Is it going to be years or you already can see climate change. And it's pretty apparent in the last couple of years it's been really apparent. I mean the weather has changed, the climate here is completely different than it used to be. (Owner 3, interview March 9, 2013).

This exchange shows that the value of the investment in property is a great concern for homeowners, and protecting it is of utmost importance. But there is not yet enough information available to make an accurate assessment of the risk that sea level rise poses to that investment, and especially not when weighed against the other considerations such as quality of life and connection to a community that one likes and a home one has lived in for decades. At first the amount of projected sea level rise is a shock, but then the 50 year timeframe seems to ameliorate the concern. Still, the magnitude of the uncertainty quickly enters the conversation, that weather changes are occurring everywhere, and nowhere seems safe. The discussion ends without a resolution.

Cost of living was on the minds of renters, but for homeowners interestingly it did not figure very much into our conversations. Insurance was the main complaint, and everyone said that windstorm insurance had been going up and they were frustrated by that. But not many had concerns about flood insurance or about other increases in the cost 
of living like property taxes or utilities. One condo owner did say, "Buildings are helpless," he says, "it's bigger than us and there's not much we can do. It's going to be expensive" (Owner 4, interview February 14, 2013). But when I discussed the storm water plan with one condo owner he was unconcerned about the cost, "I don't think the City of Miami Beach is broke by any means. I think there's plenty of money there to be used. They're using it for beautification and all these other extraneous things which are nice but they're not important. This is important" (Owner 5, interview January 16, 2013). When I said that storm water utility fees would likely go up, and perhaps taxes as well due to the issuance of bonds, he replied, "I know that my taxes really haven't changed throughout these years. I pay more or less the same property tax every year that I have been. There were even a couple years there that we got a rebate, we got like a $\$ 200$ or $\$ 300$ rebate on the taxes. That's what I mean, I think the city's doing ok.” He was more concerned about the impacts of dealing with construction in the neighborhood than he was with the cost. This is quite different from the opinion of resident activists on climate change, who, as I will show in the next chapter, believe the cost of climate change adaptation will be one of the most important decision factors for Miami Beach residents.

\section{Conclusion}

In this chapter I have described and analyzed the impacts of urban flooding that Miami Beach is currently experiencing, and how residents and businesses are perceiving, reacting and adapting to these impacts. The dominant, though not consensus, opinion is that the flooding has gotten worse in recent years, and this is borne out by an analysis of water height data which shows that the four years with the most hours of significant 
flooding have occurred over the last six years. Changing water levels makes it difficult to know which measure to rely on. My work is an attempt to derive a socially significant measure. 2012 was a particularly bad year, due to Hurricane Sandy and to generally elevated water levels throughout the year. October and November saw several weeks straight of flooded streets in low-lying sections of South Beach, prompting residents and businesses to adjust to disruptions in their lives and businesses, and to create physical methods to cope with the impact of the flooding, some of which became semi-permanent or took on a learned character.

However even with the direct experience with increasing flooding, and even though most believe it is connected with sea level rise, knowledge of climate change and its potential impacts on Miami Beach was still minimal. Residents and businesses mostly just "dealt with it," and were just beginning to incorporate climate change into their decision making, although it was not clear how to do so. For businesses, particularly small businesses, relocation is not an option. For some, the cost of moving is prohibitive. For others, their business is tied to the location, and simply wouldn't work anywhere else. For all, the economics at present are that flooding is not nearly costly enough to prompt consideration of relocation. At present climate change is not a factor in business decision making, but we can start to see the calculus that will come into play as knowledge of sea level rise increases. How will sea level rise impact the timeframe for the return on investment? Will it increase risk to the point where values start to come down? How will this affect the intergenerational transfer of assets, thus both the retirement security of an older generation and the level of risk taken on by the younger? 
For homeowners, there is no formula for a "return on investment" but we can start to see a calculus that weighs cost and risk versus quality of life. Renters may have more flexibility, but also face rising costs, and those who have lived on Miami Beach a long time have seen housing costs more than double in fifteen years. As costs of living on the coast go up, the cost of insurance and the cost of infrastructure upgrades and protection will increase the cost of living further. However the coast itself, the proximity to the water, is only one part of Miami Beach's attractiveness. For many people the ease of getting around and the community connections are the more important factors.

Vulnerability concerns are different for renters and property owners. Owners are concerned about the value of their property and losing their investments or savings. Renters are not facing that loss but still have to deal with increasing costs, and the development of Miami Beach over the last few decades shows that rising rents are an important concern for renters, the choice being either to simply spend more on rent, look for subsidized housing, or leave the area. An important exception is that business owners who may not own the property nevertheless have significant money invested in improvements to the property that cannot readily be transferred, and this is especially a burden for small self-employed businesses. Even if the business could physically be relocated, for those which tailored their business to serve the customer base in a particular location relocation would essentially mean starting over.

This ethnography of the early impacts of sea level rise shows that awareness is starting to grow and people are beginning to connect it with their situation but are not really sure what they're factoring in, not really sure what's changed and what it means. Although businesses are not thinking about relocating, residents who are attuned to 
information about sea level rise express concern about the future of the area. Even for those who have lived in the area for a long time and experienced flooding and hurricanes, the experience of the last several years with increased flooding plus the knowledge that sea level is rising combines to make them question the future. The people I spoke with were for the most part not plugged in to local government or planning processes around climate change, and those who were concerned about sea level rise seemed to feel isolated, anxious about the uncertainty and unclear about the proper course of action. The structure of governance and public participation on climate change adaptation is the subject of my next chapter. 


\section{CHAPTER V - ADAPTATION PLANNING}

In the last chapter I focused on impacts and adaptation to sea level rise by individual households and businesses. I described the physical drivers of flooding in Miami Beach, the impacts on urban life for residents and businesses, perceptions of the flooding and the connection with climate change. These data show the un-coordinated responses which can be seen as coping strategies or as the beginning of autonomous adaptation. But as impacts have become more apparent and more disruptive, collective and institutional responses have emerged as well. In this chapter I will focus on the emergence of collective adaptation in Miami Beach by analyzing a City storm water infrastructure planning process. By examining the use of accelerated sea level rise projections in the design and planning process and the responses of resident activists, I show how different perspectives and values shape emerging adaptation efforts. I argue these conflicting logics highlight important challenges for an iterative or "adaptive management" approach to sea level rise in a highly urbanized context.

\section{Adaptation Planning in Miami Beach}

While actions of the Compact at the regional level create momentum for climate change adaptation planning, the work of implementing adaptation projects largely falls to local governments, the counties and cities. The City of Miami Beach began a storm water master planning process in 2009 which included projections for accelerated sea level rise, the first municipality in the region and perhaps the country, to do so. But as this case study illustrates, climate adaptation planning challenges traditional infrastructure planning processes in several ways. The strategies needed to protect low-lying coastal 
areas from sea level rise present large costs above and beyond normal capital budgets, and trigger deeper thinking about the longevity of the investment. The lack of guidance on adaptation strategies and standards from higher levels of government means coastal communities are left on their own to deal with long-term planning issues that go beyond the traditional bounds of city level planning.

These issues became apparent as a group of resident activists emerged to challenge Miami Beach’s Storm Water Management Master Planning (SWMMP) process. In this section I explore the nature of the conflict and the different "logics" held by stakeholders, by which I mean the different attitudes and beliefs about the nature of the threat and the best course of action. These conflicting logics reveal some of the major fault lines in climate adaptation, but are also rooted in locally specific debates. Two main camps emerged, the City as leader and implementer of the infrastructure plan, and a group of resident activists with close ties to environmentalism, climate science and local development politics. The City took a pragmatic, managerial approach based on a traditional infrastructure planning process but included sea level rise projections as a proactive step, a sign that climate change is becoming mainstreamed into government operations. The resident activists however challenged the city's efforts as inadequate to deal with the major challenges that sea level rise presents for the City, and took the process as an opportunity to voice fears and frustrations over the slow pace of action on climate change and the direction of development in the city in general.

What is unique about this case study is that Miami Beach's particular context-its political character, its economic base, its geography and geology—created a situation where local activists, instead of opposing climate adaptation based on a denial mindset as 
was happening at the time in other parts of the country, called for more and different action based on the belief that sea level rise will ultimately overwhelm the City within a relatively short time frame. This presented a challenge not just for traditional infrastructure planning but also to accepted frameworks and strategies for climate change adaptation, not only from a technical standpoint but also from the standpoint of providing the certainty and security expected from a major city. When incremental adaptation meets its limits, whether they are physical or social, then a transition or transformation is called for (Kates, Travis and Wilbanks, 2012). Miami Beach is a city on the edge of transformative change, and it provides a compelling case to study the complex interface of science and decision making.

\section{Sustainability}

Climate change, although it affects multiple sectors of government operations, tends to fall within the scope of environmental concerns. Like other cities with environmentally conscious citizens and staff, Miami Beach had a growing interest in sustainability. In 2007 the City formed an Ad-hoc Green Committee, which in 2009 became the Sustainability Committee - a permanent committee made up of citizen volunteers who's “role was to identify and promote policies and practices within the City to help achieve a sustainable environment" (Analysis of Evaluation and Appraisal Report 2010). Each commissioner appointed a member of the committee, and several of the members were leaders of local environmental organizations. The committee was chaired by a sitting commissioner, and it met monthly to review items referred by the Commission as well as serving as a forum for discussion on other sustainability related issues brought by citizens. The committee was staffed by the Environmental Resources 
Division of the Public Works Department which had a staff of two plus one intern. The major staff responsibilities were dealing with water quality issues related to runoff into Biscayne Bay, and maintaining and restoring the dune system along the beaches.

In 2009 the staff led the Sustainability Committee through the process of creating a comprehensive Sustainability Plan which included ten program areas: Green Building and Housing, Solid Waste Management, Water Conservation and Quality, Energy Conservation, Alternative Transportation, Natural Resources \& Ecosystem Management, Community Outreach and Participation, Green Procurement, Economic Development and Planning, and Air Quality \& Climate Change. The plan was framed as a response to climate change, as indicated in the introductory paragraph, "Recent research points to scientific consensus on potential changes to our local environment related to global climate change," and elsewhere, "The City of Miami Beach may be especially vulnerable to some of these changes given its location, elevation, and strong economic and social ties to a healthy environment" (Sustainability Plan 2011,2). The plan lists goals and recommendations linking the reduction of greenhouse gasses with reduced climate impacts on Miami Beach.

The use of fossil fuel emits GHG's that contribute to climate change, reduce air quality and affect the health of residents. Future impacts of climate change, such as sea-level rise, may affect the health of residents. Future impacts of climate change, such as sea-level rise, may affect quality of life and property within the city as well. By reducing GHG emissions where possible, the City of Miami Beach can meaningfully contribute to local air quality and the avoidance or reduction of anticipated climate change impacts (21).

It calls for reducing the city's carbon footprint in order to "decrease the risk or severity of climate change impacts, such as storm-related flooding, sea-level rise, and frequency of 
extreme weather events such as hurricanes, and extreme temperatures and/or precipitation" (21).

The plan was unanimously adopted by the Commission in January 2011, making it official City policy. It doesn’t distinguish between climate "mitigation" and "adaptation" although most of the initiatives related to climate change would fall under what would typically be considered "climate mitigation," that is, efforts to reduce greenhouse gasses. It lists two initiatives that would typically fall under adaptation, the SWMMP which was already underway, and a possible future initiative to explore the Florida Building Code "for adaptivity to sea-level change." This plan reflects the focus of the Sustainability Committee, which was working mostly on issues that would fall under mitigation or environmental quality such as passing a recycling ordinance, establishing an Energy Economic Zone, and environmental education activities. Although several committee members attended the public meetings about the SWMMP, it was not an issue the committee took up or discussed in any detail, and the only time the committee formally weighed in on storm water issues was to recommend that plans for the convention center renovation include underground water storage capacity. Thus while the committee was the officially recognized voice of sustainability for the City, it was not an active leader on climate change adaptation.

\section{The Boundary Condition}

Miami Beach began experiencing the effects of sea level rise earlier than most other areas of the region, and from 2009 to 2012 undertook a storm water management master planning process to deal with the increased flooding the City was experiencing. Sea level rise that had already occurred in the last 80 years had begun to overwhelm the 
1930's era drainage system and cause water to back up into city streets more frequently during extreme high tides. In 2009 when Miami Beach began the SWMMP process climate change was an intensely politicized topic at the national level, but was only beginning to be discussed at the local level, and very few resources were available to local governments to assist with climate adaptation planning. Miami Beach thus took a standard infrastructure planning approach, with the additional step of including accelerated sea level rise projections. The goal of the new plan was to improve the City's ability to deal with flooding, but it was not initially conceived of as a climate change adaptation project.

The impetus for the new plan came from the gradually increasing flooding events impacting the city, and from several large flooding events in 2009. Although the City had not been keeping data on flooding events, the increasingly frequent events had been noticed by Public Works officials, who are responsible for maintaining the drainage system. One long-time staff member said,

I've been with the city close to 15 years and little by little I've seen more flooding due to high tides rising.... Every year we say it's getting higher and higher. We see it because we didn't see it a couple years ago, like Dade Boulevard, right here in Miami Beach High School, which is Collins Canal. Right now we're building a brand new sea wall. It's going to be like a sidewalk, bicycle, pedestrian but when years and years ago I never used to see Collins Canal, the water coming out into Dade Boulevard. Now it is, so that tells you something (Administration Official 1, interview June 5, 2012)

Noticing these gradual but steady changes led the city to take actions to address high tide flooding in the areas they had observed that were particularly prone to it. Beginning in 2007 Public Works began to address high tide flooding in low-lying areas by installing tide-flex valves, or "backflow preventers" onto outfalls. According to City 
Public Works officials these were expensive and not foolproof however, and in some locations where drain pipes were cracked water flowed into low-lying places on the streets anyway. The valves could also do nothing to prevent flooding from extremely heavy rains that coincided with high tides. The existing storm water plan, in place since 1997, was not primarily designed to address flooding at all, let alone high tide flooding. It had been created as a requirement for a state permit that dealt with eliminating pollutants from runoff into Biscayne Bay (SWMMP 2011). The plan was based on water quality standards, flooding potential, City staff rankings, and complaints but was limited in scope and by 2009 was technologically out of date (SWMMP 2011). In addition to beginning their own planning, Public Works officials said they had also begun sending pictures of high tide flooding on Alton Road to the Florida Department of Transportation which had jurisdiction over the right-of-way, which had some of the worst spots in the city. In 2009 FDOT began planning for drainage improvements on Alton Road, and ultimately settled on a plan to install 3 pumps under the southern end of the road where flooding was most frequent and disruptive.

In the year 2009 the City experienced several significant flooding events which caused officials to propose the development of a new SWMMP to upgrade to the drainage system. A major storm on June 5, 2009 dumped 9.88" of rain on the city in a matter of hours, just before high tide, which caused streets to be flooded with 2-3' of water for several hours until the tide receded. Then in September 2009 the city experienced unusual high tide flooding in several low-lying locations such as the Alton Rd. and $10^{\text {th }}$ St. intersection. In a memo from City administration to the Commission from September 18, 2009, the City administration proposed to the commission that a new 
storm water management study be conducted and a new system designed, which would use new LiDAR technology and result in a more comprehensive and cohesive plan. The letter also included mention of sea level rise, stating "sea level rise... may be exacerbating the effects of seasonal high tides" and cited a talk by University of Miami geology professor Hal Wanless, one of the most quoted local climate change experts. The letter indicates that staff was "investigating the feasibility of commissioning a technical/scientific study that will analyze the impacts of sea level rise from the past decades and the potential impacts to our City in the future" (Letter to commission on seasonal flooding, September 18, 2009).

As I have described elsewhere, despite the fact that in 2009 climate change was an extremely politically charged issue in national politics during this period, at this point there was not widespread awareness of potential climate change impacts or planning activities in South Florida. The mention of sea level rise in Miami Beach public documents aroused no notice or comment from the public. I found no hint of criticism of the SWMP from a climate-skeptic point of view either in public forums, media references, or any of the interviews I conducted with city leaders. The fact that this was around the same time as other localities in the country were experiencing backlash for incorporating sea level rise projections into coastal planning (Rawlins 2012) made the lack of opposition in Miami Beach somewhat surprising. One official I interviewed attributed the lack of opposition to the generally liberal political environment of Miami Beach, and to rational economic thinking. "Miami Beach isn't your typical place in South Florida, it's a little more progressive, a little more forward looking. I'd heard, I don't know if this number is true or not, there's like $\$ 23$ billion in private property here in 
Miami Beach. And I think if you're a property owner \$200 million is a lot of money to spend on storm water but if you're thinking I've got $\$ 23$ billion of assets to protect, $\$ 200$ million's a good insurance policy" (Administration Official 5, interview October 18, 2012).

The decision to include sea level rise projections that were above historical trends in the SWMMP originated with engineers in the Public Works department who were responsible for overseeing the planning process, were aware of sea level rise and believed that including projections was a rational and responsible action. In an interview a Public Works official stated that they had made the decision to include sea level rise projections in the plan because "we knew that if we're going to be spending $\$ 100$ million or whatever the number is on infrastructure, that infrastructure can't be obsolete a decade later. So we recognized that sea levels are rising, and so we wanted to incorporate that into our planning" Administration Official 5, interview October 18, 2012). An elected official offered a similar view, that given the large investment using realistic projections was necessary. In the elected official's political calculus, "the alternative, which is you guys blew $\$ 200$ million, was worse" than potential opposition from climate deniers (Elected Official 1, interview October 1, 2012).

But the City was entering new territory and had to develop methods for dealing with several kinds of uncertainty, which opened room for controversy. The first problem was how to determine the actual numbers for sea level rise to be used in the storm water modeling. The difficulty was due to the uncertainty in the projections of sea level rise that

\footnotetext{
${ }^{7}$ This does not mean that everyone on Miami Beach believed that sea level rise was happening, as I described in the previous chapter. But since climate change denial is associated with right-wing views (Pew Research Center for People and the Press 2013), lack of organized conservative political presence in Miami Beach likely explains why no opposition camp appeared.
} 
were available and the lack of actionable guidance available from higher levels of government. According to the SWMMP (2012) the engineering firm that the City hired to do the modeling and write the storm water management master plan used the U.S. Environmental Protection Agency Storm Water Management Model for hydrologic and hydraulic modeling for planning Miami Beach's drainage system. Since storm water from Miami Beach drains into Biscayne Bay, the storm water planning model takes into account the height of the Bay (ocean height) in order to determine what drainage capacity is needed to move water out of the city during a rain storm. Normally the model would use the one-year tidal stillwater elevation, which is a number derived from the local FEMA Flood Insurance Study. However when the engineering firm calculated this number for Miami Beach it turned out to be too low, being below the initial water level and according to the report "results in flooding at the initiation of the SWMM simulation" (2-40). So a different method of determining the boundary condition had to be used, and the City wanted one that took sea level rise into account. A second engineering firm was subcontracted as a consultant to look at ocean height data and sea level rise projections. At a meeting with the U.S. Geological Survey and representatives from the IPCC it was decided to use the Army Corps of Engineers (ACE) guidance on sea level rise projections, shown below in Figure 20, which provided curves for low, intermediate, and high projections of sea level rise (SWMMP 2011).

But selecting a starting point for the curves, i.e. the current ocean height, proved difficult. The consultant produced a report reviewing ocean height data from NOAA but did not recommend the use of the official NOAA datum, according to a Public Works official, because it was too low. The NOAA datums are standardized to eliminate 
periodic trends in sea level, and to provide a common reference throughout the United States. The NOAA official Mean High Water (MHW) datum is based on averaged data over the previous "epoch" from 1983 to 2001. As seen in the chart below, which is from a public presentation of the SWMMP report, this datum for the Virginia Key tide station, the closest one to Miami Beach, is lower than the annual averages for all but four of the most recent thirteen years. As noted in Chapter 4 accounting for such small variations is extremely complex and NOAA officials acknowledge that it is possible that sea level has risen since the period on which the datum is based (Ehret 2013). But no guidelines were available for a different estimation method of arriving at the current "true" Mean High Water for a given locality. So the City selected $0.29^{\prime}$ as a starting point, which was the MHW for 2009 and the fourth highest of the annual averages for the last fourteen years for which annual data is available (SWMMP Public Presentation, August 17, 2012). Using the intermediate ACE curve an additional $0.38^{\prime}$ is added to account for sea level rise over the twenty year life of the plan, to arrive at a final number of 0.67 ' NAVD. This was the number ultimately used as the boundary condition in the model (Resolution Adopting 2011 Citywide Storm Water Master Plan, October 24, 2012).

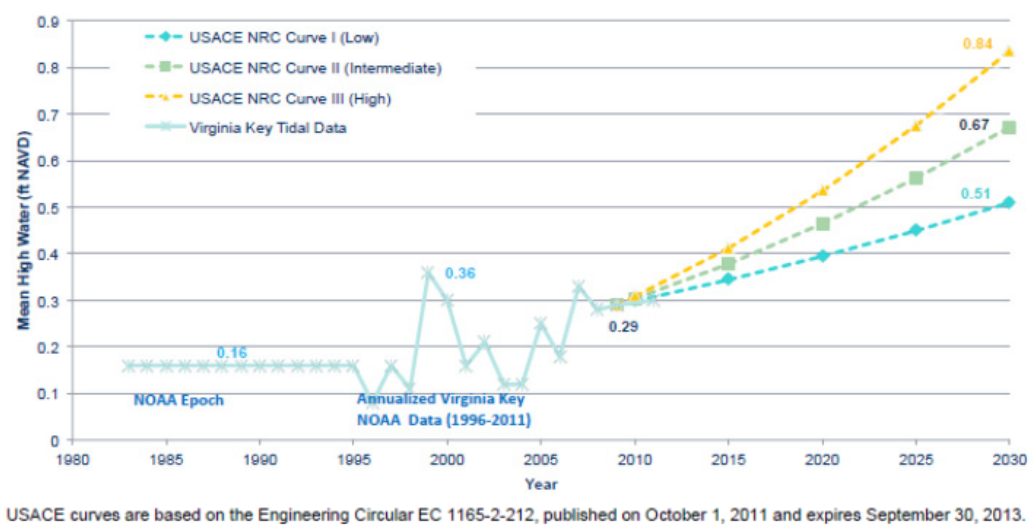

Figure 20: Historic and Projected Mean High Water Levels at Virginia Key, Chart from Miami Beach SWMMP Public Presentation, August 17, 2012 
This figure was arrived at only after some debate, both public and internal, and this chart represents a revision from the first draft of the SWMMP for which the engineering firm had used $0.50^{\prime}$ NAVD as a boundary condition (Draft SWMMP report 2011). The 0.50 ' number had been selected because it "conservatively approximates the tidal boundary condition elevation used by FDOT" in their Alton Road project, which was $0.45^{\prime}$ NAVD (Draft SWMMP report 2011, 2-40). A group of resident activists, initially several men who were concerned about rising sea levels and wanted the City to be more proactive about addressing climate change, had gotten involved in the SWMMP process and expressed concern that the boundary condition used was too low to deal with the high tide flooding that Miami Beach was experiencing (Resident Activist 2, interview October 3, 2012). They asked for meetings with City officials, sent emails to the City Manager, and spoke at committee hearings on the plan, prompting the City to hold a public meeting at which the above chart was presented explaining the selection of the boundary condition used for the model.

It is notable that at the same time as denial of climate change seemed to hold sway in most parts of the country, Miami Beach's decision prompted action from the opposite end of the spectrum, from those who believed the city wasn't doing enough and should use higher projections. City officials confirmed that they had not received complaints about the inclusion of sea level rise in the plan. Said one, "Surprisingly nobody has said what are you doing including sea level rise. The opposition we've had, I wouldn't even say it's opposition, it's a technical disagreement on not even so much the rate of sea level rise but the starting point, what elevation is the high tide right now" (Administration Official 5, October 18, 2012). As I argue though, the disagreement was more than 
technical, but a signal of opposing views on how the City should approach climate change adaptation.

The resident activists considered the $0.67^{\prime}$ number an improvement over 0.50 ' but still too low. They pointed out that the consultant who performed the analysis of tidal data recommended "a minimum MHW level of 0.36" (SWMMP Appendix H 2011), which would have given the curve a higher starting point. They also objected to the use of MHW, which was in accordance with Florida Department of Transportation drainage standards, instead of Mean Higher High Water (MHHW) as recommended by the MiamiDade Climate Change Task Force. MHHW incorporates the highest tides and so is a slightly higher figure than MHW, by 0.06 ' to be exact. Even after the plan was finally approved by the commission in November 2012, one of the resident activists wrote in an email to the mayor, acting city manager and commissioners, that $0.67^{\prime}$ 'was too conservative, noting that in 2012 the city had seen a significant number of high tide flooding events well above 0.67 ' and stating that 'the storm water master plan was out of date the day it was approved" (Resident Activist email, March 2013).

The group of resident activists who were challenging the SWMMP had been involved with City government for many years, serving on various committees and participating in civic forums. Several had backgrounds in science, engineering, environmentalism or natural resources advocacy. They communicated with local scientists who were working on climate change and had versed themselves in studies on climate change and sea level rise. They were attuned to the more extreme predictions and believed that "sea level is coming, faster than you think," as one told me in an interview (Resident Activist 2, interview October 3, 2012). Another told me he had "never been 
skeptical" about climate change because he had noticed the rise in tides in Miami Beach over the years, and had involved with environmental causes for many years. He was very pessimistic about the political will to deal with the problem, both nationally and locally. "All these guys that are in congress made this problem, like I made this problem, we're the old guys. Our consumption and our growth, you had to have six percent growth per year, new clothes, new cars every year, made that... and God forbid if they're going to change anything" (Resident Activist 3, interview October 5, 2012). But he also believed it was possible to tackle the problem with major action, on a scale which he compared with the scale of the Manhattan project. He saw his activism as prodding the City government, residents and businesses to have a greater sense of urgency about climate change in order to get to meaningful large scale action both on mitigation and adaptation.

The resident activists were not necessarily unified on how they thought the City should deal with climate change, but they agreed on criticisms of the storm water plan: the boundary condition was too low, the projections were too low, and the time frame was too short. They pointed out that the City's original proposal for the SWMMP was to plan for fifty years, but the timeline in the report was shortened to twenty years for the drainage system, although it kept the planning horizon for raising seawalls at fifty years. These objections to the plan came to a head of sorts at a public meeting I attended in August 2012 at City Hall, at which the two engineering consultant firms and the South Florida Water Management District presented the plan and answered questions from the public. The meeting was held at 10:00 a.m. in City Hall and had about forty attendees, including members of the press. The presenters explained the data on tides and sea level rise, the Level of Service (LOS) the plan would achieve, and the Tiered Best 
Management Practice Treatment Train Approach to strategies for dealing with storm water. The Treatment Train consisted of interventions ranging from lower intensity and lower cost, such as swales and backflow preventers, to high intensity high cost interventions like pumping and outfall upgrades. The consultants explained that this scaled approach made the plan flexible and would support allow for later upgrading if needed to increase capacity. During the question and answer period one of the resident activists stood up and said "I don't buy it." He said the City was presenting a rosy scenario that was weak and glossed over the reality of the situation. He asked if the design would be different if they looked at a longer time frame, and didn't they want to design for the life of a mortgage which was thirty years? He said citizens needed information to take into account when deciding the location of their homes and buildings. "Tell us the cost," he said. The City's response was that the program would be the same at twenty or thirty years, and twenty years is the City's Capital Improvement Projects time frame. The major difference with a thirty year time frame, they said, would be additional pumping which could be accommodated within the present approach if needed at a later time.

The City ultimately addressed some of the concerns raised by resident activists, however, for example by including an additional cost estimate for the highest sea level rise curve (a boundary condition of $0.87^{\prime}$ ). The additional cost was $\$ 10$ million on top of the $\$ 196$ million plan (SWMMP Public Presentation, August 17, 2012). But they downplayed the importance of the specific number chosen for the boundary condition, and emphasized the flexibility and adaptability of the plan. They maintained that even with higher projections or a longer time frame the basic strategy would remain the same, 
but as sea levels rose it was likely that larger pumps would be needed, and they would

have to run more frequently. As one of the Public Works engineers put it in an interview,

We've been trying to emphasize that but it kind of gets lost in people saying well you didn't choose this number right or that number right. The importance is the system needs to be flexible. When we design pump stations we need to be sure the structure that we're putting them in is big enough so that later if we do have to go out and put in bigger pumps they'll fit. That's the type of thing we're looking at doing. Even if we're right and 0.67 ' is the number in 20 years, it's not going to be but if we are, it still is going to keep rising 21 years from now, 22 years from now it's going to be different, and so we are going to have to have a flexible system that's going to have to adapt to a higher level at some point. So we need to make sure we design what goes in the ground now it has that flexibility. (Administration Official 5, interview May 28, 2013)

Public Works did not see the boundary condition as the determining factor in the success of the plan. From the engineer's perspective a model is just a model, and actual conditions vary.

We're designing for a five-year one-day storm. And that's six inches over 24 hours. I mean, how often do you have an exact, five-year storm. And so it's just, there are all sorts of parameters which kind of guide you to a certain pipe size or designing your system in a certain way, but you just kind of have to remember they are just guidelines. Particularly when we go to pump systems, there are so many losses through valves, through the pump itself, through the piping, that a couple inches just gets lost in the background. So it's not that big a deal. What you really need to do is design a flexible system. (Administration Official 5, interview May 28, 2013).

In addition the City emphasized that tidal data would be monitored and the science would be reevaluated in three years to determine if the plan needed to be changed (SWMMP Public Presentation, August 17, 2012). In the end, the plan was approved by the commission in December 2012 with the 20 year time horizon and the 0.67 ' boundary condition (Resolution Adopting 2011 Citywide Storm Water Master Plan, October 24, 2012). 
The conflict over the SWMMP centered on a set of numbers, but it could not be resolved because the numbers had different characters and different meanings to the City engineers and to the resident activists. The seeming precision of the numbers that were at issue, the $0.29,0.36$ and 0.67 , was misleading, implying a level of certainty that could never exist, sea level rise or no. The engineers in the City understood that although modeling presents itself as exact, using numbers and calculations that are as precise as humans and current technology can make them, the results are only approximations of a reality too complex to be fully knowable. Uncertainty is already a challenge, and with the added uncertainty of future sea level rise, the best solution the engineers could offer was a plan that was flexible, vigilant, and adaptive.

But to the resident activists, the numbers were signals of the seriousness with which the City approached the issue of climate change. Most already shared a distrust of the City government for various reasons, including its handling of past infrastructure projects, its perceived preference for large scale development, and the refusal of elected officials, especially the mayor, to publicly acknowledge that climate change was real. They interpreted the decision to user a lower number as meaning that the City was downplaying the potential impacts of sea level rise and refusing to consider longer term strategies. They believed the reason for this was that the City did not want to be upfront about the likely costs of adaptation. As one of the resident activists put it, "They should use the most scientific information possible, the latest information possible. And the recommendation in there is pretty close to what they should be using for the initial. But the whole report is done to minimize any expenditures that would be needed" (Resident Activist 2, interview October 3, 2012). 
Despite this belief held by the resident activists however, cost never appeared as an explicit factor in the City's decision making. The engineering firm had in fact prepared an estimate of the cost-savings that the plan would bring from avoided flood damage $^{8}$, approximately $\$ 4.5$ million annually, in order to respond to potential concerns about cost. But these figures were not mentioned at any of the meetings or discussed more than in passing in any memos. When I asked a Public Works official about the estimates he said, "It wasn't really talked about that much. We thought it was important to show that you do nothing and there's still a cost, but most people know that already. They know you have to do something, so we didn't need to bring it up much" (Administration Official 5, interview October 18, 2012). As for the cost of the plan itself, the City did finally ask the engineering firm to estimate the additional cost for the higher sea level rise projection, and it turned out to be only a fraction of the cost of the entire plan - \$10 million.

Still, city leaders did recognize that engineering is expensive, and from their perspective planning in phases was appropriate for conserving resources. As one explained in an interview,

As an elected official and as a resident, one of the things we're always trying to balance are the needs and the costs. And you know it's kind of like buying insurance. That's what we're doing here. We're insuring the survivability of the City and that we're not going to drown and that the buildings aren't going to be under water. And those that aren't on waterfront don't end up with waterfront property eventually. It's like, you could become insurance rich and house poor. You could buy so much insurance whether it's long term care, life insurance, health insurance, that you don't have any money to live. So you can't insurance every last nickel.... Once you sell bonds, if we were to say well let's sell $\$ 400$ million of bonds, people are going to be paying those bonds off. And maybe we didn't need it, or maybe we didn't need it for 50 years from now. So those that are

\footnotetext{
${ }^{8}$ Using the Federal Emergency Management Agency's Hazus model for estimating potential losses from disasters.
} 
here for the next 50 years why should we saddle them with something that may not be needed? So I think it makes sense to do it in stages, as long as the plan, and I'm being assured that the plan is flexible, and if we under or over-estimated our capabilities we can change." (Elected Official 1, interview October 1, 2012)

He went on to say,

I think the plan that is being put forth is a good one. So I think we are amongst the first cities to actually be planning dollars and capital dollars to address the situation, others are trying to pooh-pooh that it's not going to happen, just kick the can down the road, we're actually confronting it, and dealing with it in a head on manner and a reasonable manner. (Elected Official 1, interview October 1, 2012)

But the estimations of the cost, the increased estimate for the higher 20-year

scenario and the potential savings from avoided damage weren't convincing to the resident activists. One stated in an interview,

We are paying bonding. It's going to come back to me on my taxes. I don't know if I want to do that. It's already very expensive to live here. It's very expensive, this is the most expensive place to live. I don't know if I want to spend another 20 or $30 \%$ to live here because we flood when it rains. If you're going to spend this kind of money in my view you should look at it for 50 years and build the system, tell people what it's going to cost them. This is what it's going to cost you in assessments, water bills, this and that, it's going to cost this much to run these pumps all year, or whenever we have to, it won't start in the beginning but maybe 25 years out we might have to run them 60 days a year, 80 days a year to keep us dry. High tides and new moons and who knows. And start looking at a cohesive plan here..... And then you try to say, to keep our quality of life we can go this far down the road and then we don't go any farther but you need to give people parameters, you need to give them an end point where you won't keep sucking them dry. If you want to live here this is what you're going to have to do to get the next 50 years out of this. But after that there's no guarantees. And you really need to level with them. (Resident Activist 3, interview October 5, 2012)

For him, the perception that the City was minimizing the costs of the SWMMP meant that they were not informing the public about the individual, long-term costs of upgrading infrastructure to fight rising sea level. Not providing this information was withholding information that would be important for individual decision making, and had the effect of discouraging participation in the planning by not providing information that would help 
people to see the impacts on their lives. Another resident activist also expressed a desire for longer term thinking.

I believe the City has taken the approach of twenty years based on the logic that most systems have a life span that is independent of sea level rise. My personal thought is that if we were a society that is determined to be proactive in its approach to mitigating the impacts of sea level rise and we had a cultural bias to working with a common goal on this issue of national importance, we'd be able to take the approach of projecting out further than that. (Business Leader 2, interview August 8, 2013)

These statements show a desire to go beyond storm water infrastructure planning to climate change adaptation planning, and beyond an incremental to a long-term approach However there was not agreement among the resident activists about what a long term approach would look like, and few articulated a vision for the future of the city beyond the next couple decades. One who did proposed a plan that would require relocation and provide assistance in the event of a major disaster.

Well my feeling on this, and socially this would probably fly like a lead balloon, but it's the way it has to be. When your house gets knocked down, the insurance money that you would have been paid to get it back is not rebuild but to move somewhere else. So essentially you're paying not into an insurance premium to fix your house but a premium to buy another house somewhere else in a less stressed area and you won't be allowed to rebuild. Period. You're done. Whether it's a hotel like the Fountainbleu that gets knocked down, you cannot rebuild it, and if this house gets knocked down I won't be able to rebuild it. But I will have paid all these years into a fund, which is my insurance, you're not going to pay it back to me for repairs you're going to actually give me enough money so I can go to Tennessee or North Florida and buy another house out of the area. (Resident Activist 3, interview October 5, 2012)

Recognizing that a mandatory relocation plan would not be popular, he nevertheless felt that given the trajectory of sea level rise, relocation was something that should be seriously discussed. Others did not go so far as to question the future viability of the City, 
but said they simply wanted greater recognition of sea level rise and for the City to be more proactive.

These resident activists were the loudest resident voices in the debate, and their voices are important because they highlight many of the very challenging issues the City faces and illuminate challenges for adaptation planning. However I interviewed other resident activists as well who were involved in environmental causes or other local brands of activism, and who were concerned with climate change but not outspoken critics of the SWMMP. They had a hard time seeing the way forward. One talked about the issue of historic buildings, a very powerful interest in Miami Beach, noting that

[they were built] when sea level was lower and there was no flood insurance. Historic buildings in flood plains are exempt which is good for preservation but bad for sea level rise.... it's an issue because of the physical and economic threat. The City could easily become Venice - it's a tourist destination threatened by flooding. We don't have the options they do because we're not in a bay, surrounding by dykes isn't an option, it would damage tourism. It's a fairly intractable problem. (Resident Activist 6, interview February 1, 2013)

To the City officials I spoke with, sea level rise was a new challenge, significant but not insurmountable, and the path to adaptation was largely technical - engineering and beach renourishment. In the field of climate change adaptation these fall under "protection" or hardening of infrastructure and assets, as opposed to two other strategies: "accommodation" which is making room for periodic flooding, or "retreat/relocation" which is moving assets out of threatened zones (Few, Brown and Tompkins 2007). The "protection" approach is preferred by the City for two reasons. The major one is that since Miami Beach is already densely built out it has no flexible space for accommodation strategies, or empty space to relocate assets. As one City official put it, the 
problem here is that we don't really have any build out space.... We are limited in land and we really can't do this build out, we're going to have to put increased pump stations on the western quarters of our city, and perhaps as we do reconstruction build holding facilities under ground so that we can hold the water until we're able to pump it back out to sea. (Elected Official 2, interview March 5, 2013)

The Public Works Director also explained this in a presentation Miami Beach's SWMMP at the SFRCCC annual summit. He began by describing Miami Beach's residential density and its place as the economic engine of Miami-Dade County as the context for his work as an engineer, saying, "We're built out, so where could we relocate?" (SFRCCC $4^{\text {th }}$ Annual Climate Leadership Summit 2012). Essentially, Miami Beach has nowhere to go and still be Miami Beach.

As for the other adaptation strategy, beach renourishment, the wide sandy beach that is the heart of that economic engine is the product of a 1970's Army Corps of Engineers project to create a dune system on the beach, which at the time was nonexistent. Before urbanization the island had a few sandy beaches but they were narrow. Since the 1970's periodic beach renourishment has brought in sand lost to erosion or relocated sand that gradually washed from one place to another. As the Public Works Director stated at the SFRCCC summit, "That renourishment was adaptation and it's important to maintain that. We're building beach walks between the beach and hotels and redoing the dunes at the same time. Sometimes the hotels don't like it but we're making progress" (SFRCCC $4^{\text {th }}$ Annual Climate Leadership Summit 2012). The beach and the dunes serve to protect the island from hurricane storm surge, and are an important sea turtle nesting habitat. The City recently began partnering with non-profit organizations on restoration of the dune system, which will remove invasive plant species and restore 
native vegetation, reducing erosion and improving the habitat. Dune restoration was listed in the Sustainability Plan as an adaptation strategy, an example of a longestablished coastal protection strategy being re-framed as sea level rise adaptation (Sustainability Plan 2011).

Another reason that officials looked to engineering solutions for protection was to buy time. Given the uncertainty of the projections, they felt it was pragmatic to make infrastructure improvements now in the short term, and then see how the situation evolved. One City official told me he was interested in exploring underground water storage, a flood protection method wherein storm water is held in underground tanks until it can be pumped out to sea, as an option to "provide enough relief for another 50 years." Another former official told me,

You can't run around suggesting that we're all going to be under water in the next 50 years. If that's true, there's nothing we can do about it. If however it's more gradual, then yeah, sea walls need to be enhanced, and our dune structures need to be enforced, and instead of gravity we're going to need to use some injection and pumps. Bigger pipes, more pumps, that's not the end of the world. We can do that. (Administration Official 7, interview February 22, 2013)

This reflects one of the many different perspectives on the timing of sea level rise, and what that timing means. To the City officials, it is worth it to invest in engineering if it can feasibly be constructed to last at least fifty years. It's a matter of cost and will. He went on to explain,

To me it's a matter of dollars and cents. There is a solution, it's a willingness to implement the solution, an engineering solution, and the cost of it. We've got to raise the sea walls, and that's easy, it costs money but it's easy to do. And you've got to expand your outfalls, and you got to figure out how you're going to create retention wells, those are all easy solutions it's just a matter of cost. But the economics are there now. The threat to the economy is so great that you have to do this. So I don't worry, smart people, business people will see that you got to do 
it. It's an investment in the infrastructure. So I'm not worried about that. (Administration Official 7, interview February 22, 2013)

The City also recognized the limits of infrastructure planning, and heard the calls for a more comprehensive approach to climate change, but they felt this would require more assistance from other levels of government. The mayor, responding at the public meeting to the criticisms from resident activists, said that this was a storm water plan not a climate adaptation plan, and that climate adaptation needed a holistic approach that included the county. "It's not fair to put all these questions just on Miami Beach, we have to come up with a holistic plan," she said, "We are really looking to the county because we want to move together. Miami Beach shouldn't go out on a limb and do its own thing, we want to really work and follow the lead of the county. This is a start for us to continue to look at this" (SWMMP Public Presentation 2012). There was also recognition of the need for eventual federal help, as one official expressed in an interview,

I would hope that the 4 counties would get behind an effort to lobby for state and federal dollars to address this because whatever we do it's not going to be cheap, nor permanent. It's going to be an on-going process that you fund it as you go, with whatever adaptations are necessary along the way. It won't be cheap. Even as you've seen the county itself was talking about not so much for sea rise but even just the changing out of the sewage lines and everything we're talking about a billion dollars, all of a sudden it went from like I think a couple years ago they were talking $\$ 3$ billion and now they're talking $\$ 12$ billion, and they're probably off with that. So hopefully we can find some federal support. But you know what's interesting, just to show you nationally, we have a national flood policy, but yet we can't get states and governors and senators and congressman to agree to have some kind of national hurricane insurance. They say hey that's your problem. (Elected Official 1, interview October 1, 2012)

To public officials the costs were large but were not only due to sea level rise but to existing challenges of aging infrastructure. They expected to look for federal help, but 
understood the current national politics complicated that. In the current neoliberal era of retrenchment and devolution (Streek 2013), federal support is by no means guaranteed.

Though the work of implementation of adaptation actions falls to local levels and Miami Beach is moving to deal with flooding and sea level rise through its storm water plan, City leaders have consistently stated that dealing with climate change is not just a City problem. Partly this is due to the existing structure of jurisdictions and the need to coordinate between the County and the City especially over transportation, water, and environmental resources. Partly it is also due to the extra capacity and resources needed to deal with climate change, as referred to in the City engineer's statement above and to the eagerness of the City to receive assistance from federal agencies, foundations, universities, and others with expertise and resources. But it was partly also about taking cover on potentially contentious issues. As one county level official stated,

it's a politically charged issue, you're talking about investments, long term investments.... they're talking about we're going to need more pumps, so you're talking about spending a lot of money on something that we don't know exactly what's going to happen. We're saying ok based on the information we have now we think this is going to happen we think that is going to happen, and it's hard to make very expensive decisions, and politically charged decisions on speculation. So I totally understand where the mayor's coming from, and it makes sense. And that's, it's important, I think it's great that the mayor has made that connection, that statement, and it's important that we're all moving together with the same goal as opposed to cross purposes. (Governance Official 6, interview August 31, 2012)

Miami Beach has developed relationships with the SFRCCC and Miami-Dade County on climate change and sustainability and sought opportunities to work together with these different levels of governance also for resource and knowledge sharing. The Environmental Resources division has developed relationships with County's Sustainability Office, seeking to use the County's Green Business Certificate to offer 
incentives to Miami Beach businesses and collaborating on a grant proposal on climate resilience. Miami Beach became the second municipal representative on the Compact steering committee, officially representing Miami-Dade municipalities, and has studied the SFRCCC recommendations to determine to which recommendations apply to the City, and which are already in place and which could be considered for adoption/implementation.

This City's desire for this sort of cooperation may be indicative of a shift in municipal-county relationships, which traditionally have been characterized by resistance by municipalities to County control. As a County level official put it,

Municipalities incorporated because they want to be independent, they want to be able to do their own thing, within reason obviously they have to follow certain guidelines. So there's always that kind of well, we don't want the county to tell us what to do because we're doing our own thing and we're self-sufficient and we don't need the county because we're doing our own thing. (Governance Official 6 , August 31, 2012)

But as another County official stated,

One of the things that got brought up by the mayor of Miami Beach was they felt that regional transportation networks didn't consider MB often enough, that they were overlooked, and that may be a disadvantage where if you're a little bit separate then you don't get included sometimes..... So the fact that Miami Beach is now sitting on the compact staff steering committee they may suddenly have a voice in the region that they never would have had without the Compact. (Governance Official 7, interview June 24, 2013)

\section{Quality of Life vs. Economic Development}

But the resident activists suspected that the City had a bias against discussing climate impacts because of fears about the potential economic impacts. When I asked one resident activist what he thought about the mayor's statement that the City should look at climate adaptation planning in a holistic way, he said, 
But I don't think that she really wants that, because she said that her greatest responsibility is protecting the economic viability of this city. She said that she said we have to have hotels, we have to have the beaches, we have to have the convention center for the betterment of the people. Cause it brings jobs and this and that. Well I don't agree with that (Resident Activist 3, interview October 5, 2012).

What this comment belies is one of the main fault lines of Miami Beach politics, development versus neighborhoods. Since the mid-1990's when the economy really started to pick up and major development was happening, there had been conflict between developers who want to build hotels, entertainment venues and luxury condo towers, and residents who want smaller scale development, less traffic and less noise. Although development has continued at a rapid pace, residents have organized to have a strong voice in City Hall as well, for example in 1997 winning a campaign to pass a charter amendment requiring popular approval in order to increase the size of development projects beyond the current zoning (Posner 2009).

Some of the resident activists criticizing the SWMMP were very active as representatives of neighborhoods and generally took the stance of fighting back against what they perceived as incursions from hotels, noisy sidewalk cafés, and large scale development that would increase traffic. At the time when the SWMMP process was under way, the development debate was focused on the convention center, which was universally recognized as in need of upgrading. But there was a debate over whether to maintain the relatively small scale of the center or to conduct a major overhaul which would provide facilities for larger conventions and include retail and entertainment, as a "city center" type of project. The City Commission appeared to be in favor of the latter, having stipulated the inclusion of a hotel in the project, and having selected two 
development teams with world-renowned architects as finalists (Veiga and Viglucci 2013). The resident activists regarded the City as favoring large-scale development, which would be at risk from sea level rise in a matter of decades anyway. As one said in an interview,

Are we going to build out the convention center and put a hotel there, put three parking lots back on the other parking lots, put retail underneath them.... I mean it's going to take 10 years to build this stuff out, by the time they get done with it then we're really in deep trouble and its life expectancy will only be 20 years. I mean you want to spend a few billion dollars to do that? I like Miami Beach the way it is now, I don't want to live in more construction. (Resident Activist 3, interview October 5, 2012)

This is an expression of the intense skepticism towards more development and the fear that development would increase cost of living and make for a poorer quality of life. This skepticism contributed to fears that the City was preventing debate over climate change for fear of the impact on economic development.

But City leaders, along with business leaders, generally saw development differently. Political leaders had long argued that development and tourism are necessary to bring in taxes that fund services and upgraded infrastructure. As one official explained in an interview,

Tourism pays a good portion of the residential expense. The budget is sixty percent from non ad-valorem taxes. So, you're getting a sixty percent discount on your tax bill, but you have to put up with the tourists. And so finding that balance, and getting people to realize that there should be a balance, that it's not all or nothing, and you know the night clubs can't just run freely, and the residents can't expect them to close at midnight, then figuring out how to find that solution, is always the issue (Administration Official 7, interview February 22, 2012).

He applied this specifically to the convention center, saying, "it's not about keeping up with the Jones's it's about what do we need over the next twenty years.... a convention center hotel, and connectivity to all of our assets, and taking that land and redeveloping it 
so that it repositions Miami Beach as a new destination again" (Administration Official 7, interview February 22, 2012). But getting such large scale plans implemented wasn’t straightforward. A 2010 plan was rejected by the City Commission because of its scale, and a 2013 plan was similarly scrapped in part due to resident opposition. ${ }^{9}$

Business leaders also generally thought that development was necessary for the City, and so resident activists generally assumed that business interests like the Chamber of Commerce would be opposed to bringing attention to climate change impacts on Miami Beach, but in fact the opposite proved to be true. One resident activist stated, "well the Chamber of Commerce is going to deny all of this. They're the biggest climate deniers" (Resident Activist 3, interview October 5, 2013). But the Miami Beach Chamber of Commerce had a sustainability committee and had several members who paid close attention to climate change issues, who were also concerned that not enough action was happening and that businesses needed to get more involved. In June 2013 the Chamber hosted a panel discussion on sea level rise, called "High Tide on South Beach: What Every Business Leader, Citizen, and Government Official needs to know about how Rising Tides and Storm Water will reshape Miami Beach.” The speakers included, among others, representatives from the South Florida Water Management District, John Englander author of "High Tide on Main Street: Rising Sea Level and the Coming Coastal Crisis," and a representative from the Dutch consulate. One business leader I interviewed said he felt the City needed to be more proactive about planning for sea level

\footnotetext{
${ }^{9}$ Partly due to the support of resident activists who opposed the convention center plan, incumbent City Commissioners who had supported the plan were defeated in the 2013 elections, and the new commission send the project back to the drawing board.
} 
rise to maintain a favorable situation for investment, and that contrary to scaring real

estate investors away, planning would reduce risk and give the City time to adapt.

Your community will embrace the fact that you're forward thinking.... There are things that you can do that will add positive economic reinforcement. Like if you say, we're taking these precautions because we want to keep land values high, we want to keep insurance rates low, this is why we're doing it and we're starting now so that in 25 years we're not faced with a situation where we can't do anything. (Administration Official 7, interview February 22, 2012)

He argued that development was needed to bring in money to pay for infrastructure upgrades to deal with sea level rise.

If you don't have the money in the community coffers you can't do these improvements.... you also have to understand where's the money going to come from. If you keep advocating that, like on West Avenue there's a proposal that the commission's going to vote on that no more hotels on West Ave. Ok, well that might sound good for traffic purposes, and noise purposes but what about the money that you need? Hotels generate a lot of tax revenue for a community. So now if you don't have the tax revenue for the community you're going to have to raise it from the residents. (Administration Official 7, interview February 22, 2012)

But despite the willingness and even urgency of some business leaders to address sea level rise, they noted that most businesses and developers were not concerned and that investment was pouring in to Miami Beach. As one stated in 2012,

Right now Miami Beach has got to be the about the hottest city in the world from an investment standpoint. There is money coming in, not just the monies coming in, money that wants to come into this city that can't find a place to park it, is staggering. From all parts of the world, Wall St. has woken up and really discovered Miami Beach. Some of the bigger high profile projects I've been reading about now, the Crown Hotel... this is foreign money and lots of it. (FIU School of Architecture Symposium 2013)

But he pointed out that climate change and sea level rise would eventually increase development costs, if the cost of insurance rose, or if construction became more expensive due to stronger building codes. 
I'm sure that eventually the cities especially Miami Beach will have to amend their building code in order to deal with this at least in the interim and when that does that's going to drive construction costs up which right now on the beach are quite high, and of course you can't keep generating income something has to give and the values of the property will have to come down to compensate for that. (FIU School of Architecture Symposium 2013)

He also explained that rising risk would lead to reduced value.

At some point somebody, some analyst is going to say, you know what - you've got to look at this because, in twenty-five years when we finish paying this off, is Miami Beach going to be under water or... is there going to be a big assessment like they've done in other coastal places over the years? As the risks get higher the rate gets higher. And rate and value are in inverse proportion. At some point, the rate is going to factor into some long term and it's going to have a decreasing effect on the value. I don't know when. (FIU School of Architecture Symposium 2013)

The politics of development vs. neighborhoods took an unusual turn in the November 2013 elections. A prominent business figure who had not previously been involved in City politics was elected with the support of resident activists who opposed the large-scale convention center plan (Del Vecchio 2013). Phillip Levine and two commission candidates, widely perceived to be running as a "slate," defeated three incumbent commissioners, including Michael Gongora who had initiated the Sustainability Committee. Election campaign fliers from the "slate" criticized the scale and handling of the convention center project, promised to end corruption and fix the City's flooding problems. Two months after the election the mayor created a "blueribbon panel" on flooding and appointed a prominent realtor, a University of Miami engineer, and an outspoken critic of the storm water plan. After three public hearings the panel recommended that the boundary condition for the plan be increased to 2.7 feet NAVD "based on peak historical tidal values" (Resolution C7K February 12, 2014), and 
the cost of the new plan would be $\$ 400$ million, likely paid for in part through fee increases (Veiga 2014).

\section{Conclusion}

In such a contested situation as climate change, with all its uncertainty and complexity, understanding the differing "logics" held by different groups involved in the emerging governance networks of climate adaptation is key to understanding how the process is unfolding and what it may portend. As I have shown, there are areas of convergence and divergence in the different logics. The City's approach is largely a "protection" approach, given that there is little flexible space for accommodation or relocation of assets. Their approach has evolved from traditional infrastructure planning methods by using sea level rise projections together with a widely used storm water management modeling system. The results are framed as meeting current needs and being flexible enough to accommodate future needs as sea level rises. The City doesn't view the situation as a crisis but as something that can be managed with periodic monitoring and assessment. This represents a "mainstreaming" approach to climate change adaptation, which incorporates adaptations into existing structures and processes, and an "adaptive management" decision making framework that uses an iterative approach to dealing with environmental changes and planning for climate impacts.

Business interests also believe that a protection approach is the way the city should go, and think the City should be more proactive about directly addressing sea level rise across a wider range of areas such as planning and building codes. Instead of fearing growing awareness of climate change, as many suspected, they argue that having 
a proactive plan will signal confidence to the insurance market and lead to a stable climate for investors which will bring in needed money for the expensive infrastructure needs. They argue for a balance between development interests and neighborhood interests and fear that resident activists do not fully understand the consequences of the restrictions of development that they advocate for based on quality of life or historic preservation concerns.

The resident activists however do not have confidence in the City's leadership on climate change or the adaptive management approach. They believe that it will lead to higher cost of living and that the City should be upfront about this with the public. They argue that the City's plans should be based on "the best science available" which to them would mean much higher projections than the ones currently in use. Those who believe that protection efforts are ultimately futile would rather that the City emphasize quality of life than further development.

Miami Beach is on the front lines of a larger region that is grappling with these questions, and the City believes that they should not have sole responsibility for dealing with sea level rise, that it should be addressed regionally and that policy guidance should come from higher levels of government. However the experience of the City with this SWMMP, their first effort at adaptation and one of the first in the region and in the country, reveals many challenges and difficult questions about the fitness of a "mainstreaming" approach in this unique context. 


\section{CHAPTER VI - CONCLUSION}

To conclude I want to return to the question of South Florida's vulnerability to climate change. I have examined how the physical dimensions and human dimensions of climate change adaptation interact at multiple scales, from the household to the regional scale. I have taken Miami Beach as a case-study because it is one of the first municipalities in the region to be dealing with sea level rise impacts, and the first to implement adaptation actions directly in response to those impacts. I present this dissertation as an ethnography of the onset of sea level rise on Miami Beach that explores the factors that produce vulnerability to climate change.

While approaches to vulnerability vary among researchers and practitioners, I am writing mostly from a "human security" perspective, principally concerned with what makes people vulnerable, particularly those who are already socially vulnerable. I draw on several strains of literature concerned with vulnerability as related to humanenvironment interactions. I draw on the sociology of disasters, which has demonstrated that those who are economically disadvantaged, have physical limitations, or are otherwise socially or politically marginalized, suffer greater impacts from disasters. I also draw on the framework of political ecology which holds that the vulnerability of communities to their environment is determined as much or more by political and economic structures as natural causes. Relatedly, I consider environmental justice, which is concerned with the greater exposure of low-income and minority communities to environmental hazards and the processes that lead to this spatial injustice. Although in my case study location is not the main factor in the exposure of vulnerable groups to climate impacts, spatiality does and will matter as climate adaptation goes forward and 
decisions are made about where to invest in infrastructure, where to make land use changes, who will pay the costs and who will receive the benefits of these actions. As adaptation planning signals which locations are viable and which are not, the consequences for people who have invested and built lives in neighborhoods are potentially significant and not unlike the impacts of a decision to locate a toxic waste dump in a certain neighborhood, thereby negatively impacting property values and quality of life.

Climate adaptation decisions are one way in which vulnerability is produced, and understanding those decisions is part of the larger understanding of vulnerability as produced by "conditions that are created and maintained through a series of historical relationships that interact across spatial scales" as Dooling and Simon $(2012,5)$ articulate it, speaking to a wide field of vulnerability research. By seeing vulnerability not as a static state either in context, location, or outcome but as dynamic, then efforts to understand and assess vulnerability must take a wide variety of factors and processes into account and seek to understand their interactions in a particular context, and consider how they may evolve over time. Vulnerability isn't just about location, or lack of protection from hazards, or an immutable condition, but about the ever-changing contexts, processes, and multiple stressors that create and perpetuate disadvantage. With respect to climate change, that disadvantage increases harm from environmental impacts or their second-order socio-economic impacts.

To shed light on how vulnerability to climate change is produced in South Florida I have collected empirical research on the drivers and impacts of urban flooding in the early stages of sea level rise and explored where they interact with current socio- 
economic conditions and trends. I have also documented the response to this flooding and the beginnings of climate adaptation planning at the regional and local scale, in order to draw conclusions about the different and conflicting logics at work and to expose gaps in adaptation planning theory and practice that contribute to vulnerability.

In this final chapter I will summarize my findings and draw conclusions about how people are potentially vulnerable to climate change in South Florida. I will reveal how South Florida's context is unique but shows important gaps in our knowledge of climate change adaptation. The reason I want to do this is because it is important in a practical sense for adaptation planning and because there are some rich theoretical contributions about vulnerability and adaptation.

\section{Findings}

1. Urban flooding is disruptive for residents and businesses. The established theories of vulnerability to environmental hazards, such as the sociology of disasters and environmental justice, tell us that those who are already socially vulnerable are more likely to suffer from environmental impacts. Certainly this is true on Miami Beach as well, where disruptions of routines or work cause greater hardship for those with fewer resources. Small businesses that lose customers when streets are flooded are concerned about the loss of revenue, particularly when they face multiple stresses from competition. Residents who can't get to school lose time due to flooding, and elderly or disabled residents are endangered attempting to navigate flooded streets.

2. Residents and businesses are finding ways to deal with flooding but not making major changes - yet. Some residents and business owners/managers I interviewed were 
beginning to take steps to adapt their property such as constructing walkways over flooded sidewalks, but most were coping on the spot. Although everyone acknowledged the disruption, only a few expressed strong emotion about it and none indicated that it had influenced their decision making or future plans. The flooding was attributed to a variety of causes including human caused climate change, improper development on the island, problems with the drainage system, and that flooding is simply a fact of life on a barrier island. A few were beginning to think about how sea level rise might impact their future plans, but none were making immediate changes. Businesses in particular stated unequivocally that they would stay as long as they had customers. Smaller businesses with large sunk costs felt particularly tied to their current locations.

3. Infrastructure planners and managers face challenges incorporating even small amounts of sea level rise into existing models in low-grade areas. The City has created a plan to improve storm water infrastructure to deal with the flooding. The plan incorporates projections for accelerated sea level rise, and provides flexibility for further infrastructure upgrades should they be necessary. The plan is based on a widely used storm water management modeling system, but incorporating sea level rise estimates proved challenging and provoked controversy. Miami Beach has very low elevation and a "flat" grade, which means that a difference of a matter of inches in ocean height makes a large difference in the extent of urban flooding due to high tides or storm surge, as I have shown. Sea level rise has made such flooding events more common and more problematic, and the NOAA datums currently in use for predicting and measuring tide levels are not fine-tuned enough for reliable use by 
infrastructure planners working in this type of environment. The lack of an accepted alternative method of estimating the boundary condition opens room for controversy. Given the uncertainty about the current boundary condition and future sea level rise, the City has adopted an "adaptive" approach that provides for flexibility and includes monitoring and periodic re-assessment to ensure the desired Level of Service.

4. Rising cost of living is a concern for homeowners and renters. The SWMMP is a 20 year plan that will cost approximately $\$ 400$ million, financed by bonds and increases in storm water utility fees. This will undoubtedly contribute to increased costs for residents through fees or taxes but exactly how much is unclear. However the cost of living has been rising on Miami Beach due to other factors, especially rising property values and insurance increases. This is a concern for renters, both middle-income and low-income who may be priced out of the area, as well as homeowners who face rising insurance costs.

5. There is tension between iterative adaptation and long-term planning under a scenario of rapid change. The iterative process addresses uncertainty by incorporating new information and adjusting strategies as needed. However it is not clear whether, if change occurs rapidly, the process could be speeded up to gather data, assess options, and make new decisions enough in advance of increased impacts to avoid major disruption. Mainstreaming sea level rise projections into existing infrastructure planning was a logical first step for the City of Miami Beach for dealing with the increased flooding due to the onset of accelerated sea level rise. The City added adaptive elements to the strategy such as monitoring and flexibility in order to deal with future increased impacts. But this does not represent, nor was it intended to, a comprehensive climate change 
adaptation strategy. Flooding is the major climate change impact that Miami Beach faces, and adaptation will likely center around flood control for some time to come. The approach to flood control that the City outlined is adaptive, with the ability to accommodate future higher levels of impacts, but the adaption is conceived as quantitative, meaning more, of the same approach - pumping. It does not indicate when a qualitatively different or transformational approach might be called for, such as relocation. But this makes long term planning difficult, as residents pointed out, not knowing how much costs would go up, or whether property values would be stable. In addition to the uncertainty about impacts this creates uncertainty about how they'll be dealt with, which severely complicates decision making for households and businesses.

6. An iterative adaptation framework does not adequately deal with the temporal dimension of decision making. In the iterative approach to climate adaptation favored in much of the literature (NRC 2010), the impacts of climate change are assumed to be slow enough that data can be gathered and decisions can be made and implemented with time to adjust. Felgenhauer and Webster (2012), who argue that investments can be made in adaptation stock and then adjusted later depending on the progression of change, state "All but the longest-lived investments in adaptation will have useful lifespans that are shorter than the several decades required for mitigation to take effect. Over this long timeframe then, a role for adaptation is as a series of repeated investments whose value is not in reducing the demand for mitigation but rather in increasing the strategy's longevity until the benefits of near-term mitigation are realized" (1558). But given the accelerating impacts this may not be the case for 
Miami Beach. If the current predictions come true and sea level rises by two feet in 50 years, or more, $28 \%$ of the city island will be below sea level (Harlem, unpublished). Although there may be engineering solutions that can protect against this amount of sea level, all indications are that sea level will continue to rise which means that eventually a qualitatively different approach will be needed. Pursuing an incremental engineering centered approach encourages further development, which is path dependent and cannot easily and quickly be shifted when data begins to indicate the system is in imminent danger of being overwhelmed and a transformation is called for. The challenge is to anticipate this transformation point with enough time in advance to implement changes that minimize harm and disruption. The recommended adaptation decision making models do not offer adequately guidance on the temporal dimensions of the decision process.

7. Climate adaptation cannot fully be dealt with locally. Conventional wisdom has been that mitigation is global but adaptation is local, given the endless variety of different local contexts. While it is true that there is no one-size-fits-all solution, the case of Miami Beach shows that adaptation cannot just be the burden of a single municipality. This is true in several senses. For one, many crucial public services such as water and sewer, transportation, emergency management and environmental resources management, are all the shared responsibility of Miami Beach and the County. For another, Miami Beach's economy is fully integrated with the region and it is the main economic engine of the entire region. Much of its workforce lives elsewhere, and its property values are a huge part of the county's tax base. What affects Miami Beach affects the region. And in an even larger sense, Miami Beach is 
part of a global real estate market with its own logic and drivers. The forces that drive development in Miami Beach, which provide funding for and strongly influence the course of adaptation, cannot be fully controlled locally. As scholars have previously noted, "inaction at higher levels of collective action effectively transfers responsibility for adaptive responses to lower levels of collective action or to individual actor such as firms or households, with attendant consequences for the range of available alternatives and burden sharing" (Adger et al. 2006, 7). The ability to develop alternatives is also limited by state and federal policy such as on taxes. In Florida local governments only source of revenue is property taxes, since they do not have the power to levy sales tax, income tax, or other taxes that would bring in funds without encouraging dependency on development (Alm, Buschman and Sjoquist 2012).

\section{Logics}

As I have argued climate change has a growing governance network in South Florida, made up of scientists, activists, government officials, businesses, and residents. These sectors are involved in transdiciplinary processes of crafting action and policy changes based on science and the mandate of government. The different "logics" of groups in the governance network illuminate the challenges of embarking on adaptation planning with its inherent uncertainty, different values, and competing interests. Analyzing these logics allows us to better understand the processes that are driving socio-ecological change and how vulnerability may be produced.

Government 
The logic of local government is practicality, taking care of problems. In my interviews with local government staff and officials, they often emphasized this. One told me,

My approach has always been much more practical, and yes it's a 50-100 year problem, but what can we do in this next 5 years? And there are things that are happening today, there's flooding happening today all the time even more. The days are getting hotter. All these things are happening. So what can we do now in your realm, in your 4 year election cycle, or in your job as a planner? What can we do to start to make these changes? That's been my approach. (Governance Leader 4, interview August 14, 2012)

Local government officials believed their job was to get the work of adaptation started, and to do the work that's possible now, and fulfills their responsibility to manage the sectors within their purview. A Miami Beach official expressed,

So I think we are amongst the first cities to actually be planning dollars and capital dollars to address the situation, others are trying to pooh-pooh that it's not going to happen, just kick the can down the road, we're actually confronting it, and dealing with it in a head on manner and a reasonable manner. (Elected Official 2, March 5, 2013)

This practical, incremental approach is also at the heart of the Regional Climate Action Plan, the most comprehensive effort to deal with adaptation to date. The plan states,

The overall objective was and remains to integrate climate adaptation and mitigation into existing decision-making systems and to develop a plan that can be implemented through existing local and regional agencies, processes and organizations. It is in that spirit that this plan provides the common integrated framework for a stronger and more resilient Southeast Florida starting today and for tomorrow. (SFRCCC 2012, vi)

This statement reflects the mainstreaming and incremental approaches, which I have argued cause frustration for residents and businesses because it does not provide for longterm planning that takes account of the potential need for qualitatively different or 
transformative approaches, particularly on an accelerated time scale. Mainstreaming is a logical first step for adaptation, but different decision making frameworks need to be sought.

Business

As I showed in Chapter 5, business interests were pressing the City of Miami Beach to create an adaptation plan that would demonstrate that the City is aware of the challenges and taking action to minimize loss. They argued that such a plan would reassure investors and insurance companies, and provide more certainty and stability necessary for businesses to operate. The logic of businesses is return on investment, and risk is inherently part of that calculation. Business leaders who recognized that climate change would eventually mean increased risk did not indicate they foresee a "crash" but a gradual increasing of costs as construction and insurance expenses rise. For a business then, adaptation means understanding the increased risk and adjusting plans accordingly, but as long as there is sufficient revenue stream there is incentive to stay. Although this is true for large and small businesses, the adjustment is much more difficult for small, proprietor owned businesses. For business owners who have sunk substantial costs into setting up their business relocating is cost-prohibitive, and many are financially vulnerable where they are because they do not have flood insurance due to the high cost. They have little choice but to absorb the lost revenue caused by the flooding, and in extreme cases this leads to frustration and feeling trapped.

\section{Residents}

The logic of residents is quality of life and their personal investments. Residential property owners face similar problems as businesses of increasing costs and risk to their 
investment, with one major difference - they do not have a revenue stream that can absorb losses. Residential property owners only get a return when they sell the property, and so increased risk means loss, period. The impossibility of judging what risk sea level rise presents for this investment means that residential property owners in areas of high risk have little protection against loss under the current system of residential property ownership. Property insurance pays (in the best case) for destruction due to disasters, but it does not pay for loss of value over time, whether rapidly or gradually. For most middle class residents the investment in property is such a substantial part of the household finances that its loss would be catastrophic, and this is a major source of vulnerability for these households in Miami Beach.

In the absence of sufficient information for judging risk, residential property owners prioritize other concerns such as quality of life, family needs, and community connections. To some, they appear to be making a non-rational choice to ignore the risk from climate change. This is likely true for some, but for others it could be interpreted as a different calculation of Return On Investment, one that takes into account quality of life and other factors. Despite the difficulty of monetizing these factors, there is no doubt they play a part in the decision calculus, perhaps balanced against the household's tolerance for risk.

For renters, the return on investment is the flip side of quality of life, and they are monetized in rent. But renters also face opportunity costs of deciding to remain a renter in a location because of unknown risk to the investment in property, whereas all other things being equal such an investment would make sense. Over time this could add up to financial disadvantage, which in the adaptation literature translates to reduced adaptive 
capacity and therefore greater vulnerability. Renters and homeowners therefore are both vulnerable due to lack of ability to assess risk of climate impacts, but for different reasons.

\section{Cities}

These logics of businesses, residents, and local governments are all based on the core logic of cities, which is growth (Logan and Molotch 1987). Businesses expect revenue growth, property owners expect a return when they sell and residents expect improving quality of life. Local government functions are at heart about supporting and protecting these processes through planning and regulation. In order to do that they must balance sometimes competing interests in order to raise the revenue to support these functions. This is why the logical first step of climate adaptation is to mainstream adaptation into existing functions, and then take an incremental approach to planning. This is also why the question of transformative adaptation is so difficult. Miami Beach is having a difficult time developing a long-term plan and looking at transformative solutions because it fears interfering with the city's economy as it is currently structured. But in fact, trying to maintain the status quo is putting people at risk. Private property ownership means that risk is individualized and detached from the original risk-taking decisions made to develop Miami Beach a century ago by the state which sold the land, the developers who improved it, and the citizens who settled there and built the city. The risk has been passed down through sales of property to the present day, based on the assumption implicit in all land sales - that the land will continue to exist and its approximate present use will continue to be viable. If that ceases to be the case, who bears responsibility for those losses? 


\section{Vulnerability and Adaptation}

Miami Beach's, and South Florida's, vulnerability to climate change is thus the result of a century's worth of decisions made at multiple scales. People are vulnerable to the physical impacts of flooding and storms, and to the socio-economic impacts of decisions made to adapt to environmental changes, decisions which raise costs, promote continued development in exposed areas, and do not adequately involve the public in decision making and knowledge sharing. These impacts are greater on groups with less adaptive capacity such as lower income, less mobile residents. This study captures the very beginnings of these impacts and as yet considerations of justice are largely missing from adaptation planning, but incorporating justice considerations could point the way to transformative solutions. A transformative approach will mean rethinking the goals of adaptation and finding new ways to think about the problem. As I have noted a full solution is not possible through local decision making alone, but below I will offer two possible ways of rethinking this problem in South Florida.

First, coastal cities threatened by sea level rise could redefine "growth." Since the 1970's some economists have been working on alternative models of growth, incorporating things like sustainability and quality of life (Söderbaum 1994). Currently Miami Beach's, and South Florida's, primary economic drivers are tourism and real estate, and these are primary drivers of decision making and tax spending. If cities redefined sustainability as a top priority, they may be able to continue to generate revenue from tourism that is sustainability oriented, and they could continue to attract residents and businesses interested in a different quality of life. Cities around the world are already experimenting with this, such as Madrid which recently announced the entire 
downtown would become a pedestrian zone (O'Sullivan 2013). As interest in urban living resurges in the U.S. cities like Miami Beach with good "bones" for a pedestrian lifestyle. Miami Beach is already one of the top cities in the U.S. for biking and walking to work according to Census figure (Eisenhauer 2013) are becoming increasingly attractive. The interest in urban living has undertones of sustainability, with research showing that cities use less energy per capita (Glaeser 2011). If a more environmentally concerned urban population will support adaptation solutions that work through natural processes, such as the protection offered by mangroves and sand dunes, Miami Beach may be able to reconfigure its land area in a way that offers more longevity.

The other way that Miami Beach and South Florida could rethink the growth logic of cities is to place human security at the center of the city's purpose. Instead of designing adaptation to protect the built environment, adaptation would first focus on human needs. As Edward Glaeser argued in Triumph of the City (2011), poverty in cities is not necessarily a bad thing. People move to cities because there are opportunities, and it should be the job of cities to help people access them. This is certainly true of Miami, which has drawn enormous numbers of immigrants from Latin America over the last five decades, both wealthy and poor. They are still coming, because Miami is less risky in many ways than where they have come from, and the threat of climate impacts will not change that. If adaptation planning put human security at the center of efforts, different answers would emerge, ones that may be less costly than major engineering, and that in fact are already available. This has been observed by researchers particularly in development contexts, but has not been as widely discussed in industrialized, "first world" contexts. 
The reality, of course, is that adaptation is already mainstreamed. The roof over your head, complex reinsurance contracts for disasters or, indeed, every other institution, technology and policy that helps people to live safely and prosperously in the face of climatic variability, change and uncertainty are mainstream. The challenge is to move more of humanity into this mainstream. (Pielke et al. 2007)

I would argue that this is precisely Miami's major opportunity for climate change adaptation, that even in the face of rising seas, it can improve the lives of people who seek refuge here by placing human security at the center of efforts to reduce socioecological vulnerability.

Scholars have noted that "questions of justice and democracy are inescapable even if policy objectives are guided by science" (Beckman and Page 2008). Despite the prominent role that science plays in climate change policy, adaptation planning is still a political process, at least proactive adaptation. This means that vulnerabilities, how they manifest and how they are produced, must be paid attention to. Scholars working on vulnerability to climate change from a human security perspective have argued that individuals and communities must "have the options necessary to end, mitigate or adapt to risks to their human, environmental, and social rights and have the capacity and freedom to exercise those options" (O'Brien et al. 2007, 77). The voices of the most vulnerable, the elderly, poor, working class, and politically marginalized groups, are rarely heard in adaptation planning, and so a golden opportunity is at risk of being lost the opportunity that comprehensive adaptation planning harbors to reduce vulnerability in important ways, by providing better housing options, health care, emergency services and assistance with increased costs. South Florida's unique climate challenges and socioecological context mean that decision making on climate adaptation will always be 
uncertain. But adaptation decisions based on principles of reducing social vulnerability is the true "no-regrets" strategy. 


\section{REFERENCES}

Adger, W. Neil. 2001. "Scales of governance and environmental justice for adaptation and mitigation of climate change." Journal of International Development 13: 921-31.

--- 2006. "Vulnerability.” Global Environmental Change. 16 (3): 268-281.

Adger, W. Neil, Nigel W. Arnell, and Emma L. Tompkins. 2005. "Successful adaptation to climate change across scales." Global Environmental Change 15 (2): 77-86. doi:10.1016/j.gloenvcha.2004.12.005.

Adger, W. Neil, Jouni Paavola, Saleemul Huq, and M.J. Mace. 2006. Fairness in Adaption to Climate Change. Boston: Massachusetts Institute of Technology.

Alm, James, Robert D. Buschman and David L. Sjoquist. 2012. Rethinking Local Government Reliance on the Property Tax. Tulane Economics Working Paper Series. http://econ.tulane.edu/RePEc/pdf/tul1215.pdf.

Barnett, Jon, Saffron O’Neill, Steve Waller, and Sarah Rogers. 2013. "Reducing the risk of maladaptation in response to sea-level rise and urban water scarcity." In Successful Adaptation to Climate Change, edited by Susanne C. Moser and Maxwell T. Boykoff, 37-49. London and New York: Routledge.

Beckman, Ludvig, and Edward A. Page. 2008. "Perspectives on justice, democracy and global climate change.” Environmental Politics 17(4): 527-535.

Benford, Hashim, Jason Reece, Emily Eisenhauer, and Matthew Martin. 2009. How Fair is Florida? Recession, Recovery, Equity and Opportunity in Florida. Publication of the Research Institute on Social and Economic Policy, the Miami Workers Center, and the Kirwan Institute for Race and Ethnicity. http://www.kirwaninstitute.org.

Berkes, Fikret. 2007. "Understanding uncertainty and reducing vulnerability: lessons from resilience thinking." Natural Hazards 41: 283-295.

Berkes, Fikret, Johan Colding, and Carl Folke 2000. Rediscovery of traditional ecological knowledge as adaptive management. Ecological Applications 10:1251-1262. http://dx.doi.org/10.1890/1051-0761(2000)010[1251:ROTEKA]2.0.CO;2

Benzie, Magnus, Alex Harvey, and Karen Miller. 2011. "Adaptation in UK Cities: Heading in the Right Direction?" In Resilient Cities: Cities and Adaptation to Climate Change Proceedings of the Global Forum 2010, edited by Konrad Otto-Zimmermann and Monika Zimmermann. 1:231-242. doi: 10.1007/978-94-007-0785-6_1.

Berry, Len, Fred Bloetscher, Nicole Hernández Hammer, Marguerite Koch-Rose, Diana Mitsova-Boneva, Jorge Restrepo, Tara Root, and Ramesh Teegavarapu. 2011. Florida 
Water Management and Adaptation in the Face of Climate Change. Publication of the Florida Climate Change Task Force. http://floridaclimate.org/whitepapers/.

Billick, Ian, and Mary V. Price. 2010. The Ecology of Place: Contributions of PlaceBased Research to Ecological Understanding. Chicago: University of Chicago Press.

Blaikie, Piers, Terry Cannon, Ian Davis, and Ben Wisner. 1994. At Risk: Natural Hazards, People's Vulnerability, and Disasters. London and New York: Routledge.

Blake, Nelson. 1980. Land into Water-Water into Land. Tallahassee: University Presses of Florida.

Bloetscher, Frederick, Daniel E. Meeroff, and Barry N. Heimlich. 2010. Improving the Resilience of a Municipal Water Utility Against the Likely Impacts of Climate Change A Case Study: City of Pompano Beach Water Utility. Florida Atlantic University. http://www.ces.fau.edu/files/projects/climate_change/PompanoBeachWater_CaseStudy.p df

Borenstein, Seth. 2010. “Global Warming To Bring Stronger Hurricanes, Scientists Predict." Huffington Post, February 21. http://www.huffingtonpost.com/2010/02/22/ global-warmingto-bring-s_n_471227.html\#

Brown, Casey. 2012. Decision-scaling for Robust Planning and Policy under Climate Uncertainty. Publication of World Resources Institute.

http://www.worldresourcesreport.org.

Brunkard, Joan, Gonza Namulanda, and Raoult Ratard. 2008. "Hurricane Katrina Deaths, Louisiana, 2005." Disaster Medicine and Public Health Preparedness. American Medical Association. http://www.dhh.louisiana.gov/assets/docs/katrina/deceasedreports/ KatrinaDeaths_082008.pdf

Bullard, Robert D. 2000. Dumping in Dixie: Race, Class and Environmental Quality. Boulder, CO: Westview Press.

Cannon, Terry. 1994. "Vulnerability Analysis and the Explanation of 'Natural' Disasters." In

Disasters, Development and Environment, edited by Ann Varley. Chichester, U.K.: John Wiley \& Sons.

“C40 Cities Climate Leadership Group.” Accessed January 20, 2014. http://www.c40.org/.

Campo-Flores, Arian, and Conor Dougherty. 2013. "Overseas Money Pours Into Miami Real Estate.” The Wall Street Journal, December 1. 
Carter, Luther. 1974. The Florida Experience: Land and Water Policy in a Growth State. Baltimore and London: Johns Hopkins University Press, Resources for the Future.

CDM Smith Inc. 2012. Storm Water Management Master Plan. Prepared for City of Miami Beach.

Checker, Melissa. 2005. Polluted Promises: Environmental Racism and the Search for Justice in a Southern Town. New York: New York University Press.

Clark, Alice C. and George H. Dalrymple. 2003. "\$7.9 Billion for Everglades Restoration: Why Do Environmentalists Look So Worried?" Population and Environment 24(6): 541-569.

Corbin, Juliet, and Anselm Strauss. 2008. Basics of Qualitative Research: Techniques and Procedures for Developing Grounded Theory. Third edition. Los Angeles: Sage Publications.

Cutter, Susan. 1996. "Vulnerability to Environmental Hazards." Progress in Human Geography, 20: 529-539.

Cutter, Susan L., Jerry T. Mitchell, and Michael S. Scott. 2000. "Revealing the vulnerability of people and places: A case study of Georgetown County, South Carolina." Annals of the Association of American Geographers 90(4): 713-737.

Cutter, Susan L., Lindsey Barnes, Melissa Berry, Christopher Burton, Elijah Evans, Eric Tate, and Jennifer Webb. 2008. "A place-based model for understanding community resilience to natural disasters." Global Environmental Change 18(4): 598-606.

Dawson, Ashley. 2010. "Climate justice: The emerging movement against green capitalism.” South Atlantic Quarterly 109 (2): 313-338.

de Sherbinin, A. M., F. Castro, M.M. Gemenne, S. Cernea, P.M. Adamo, G. Fearnside, S. Krieger, A. Lahmani, A. Oliver-Smith, A. Pankhurst, T. Scudder, B. Singer, Y. Tan, G. Wannier, P. Boncour, C. Ehrhart, G. Hugo, Pandey, and G. Shi. 2011. "Preparing for Resettlement Associated with Climate Change" Science 334 (6055): 456-457, doi: $10.1126 /$ science. 1208821 .

Dooling, Sarah, and Gregory Simon. 2012. "Cities, Nature and Development: The Politics and Production of Urban Vulnerabilities." In Cities, Nature and Development: The Politics and Production of Urban Vulnerabilities, edited by Sarah Dooling and Gregory Simon. Burlington, VT: Ashgate.

Ehret, Todd. 2012. Telephone interview by author. July 10. Silver Springs, MD.

--- 2013. Email communication with author. May 15. Silver Springs, MD. 
Eisenhauer, Emily. 2013. "Part 2: Miami Beach Bikes and Walks to Work." February 16. http://emilyeisenhauer.blogspot.com/2013/02/part-2-miami-beach-bikes-and-walksto.html

Ekstrom, Julia A., and Susanne C. Moser. 2013. "Institutions as key element to successful climate adaptation processes: results from the San Francisco Bay Area." In Successful Adaptation to Climate Change, edited by Susanne C. Moser and Maxwell T. Boykoff, 97-113. London and New York: Routledge.

Eriksen, Siri, and Julie A. Silva. 2003. "The Impact of Economic Liberalisation on Climate Vulnerability Among Farmers in Mozambique.” Presentation at the Open Meeting of Human Dimensions Research Community, Montreal, October 16-18. http://sedac.ciesin.columbia.edu/openmtg/docs/Eriksen.pdf

Eriksen, Siri, Paulina Aldunce, Chandra Sekhar Bahinipati, Rafael d'Almeida Martins, John Isaac Molefe, Charles Nhemachena, Karen O'Brien, Felix Olorunfemi, Jacob Park, Linda Sygna and Kirsten Ulsrud. 2011. "When not every response to climate change is a good one: Identifying principles for sustainable adaptation." Climate and Development 3: 7-20. doi: 10.3763/cdev.2010.0060.

Fanelli, Colleen, Paul Fanelli, and David Wolcott. 2013. NOAA Water Level and Meterological Report: Hurricane Sandy. National Oceanographic and Atmospheric Administration (NOAA). Center for Operational Oceanographic Products and Services. http://www.tidesandcurrents.noaa.

gov/publications/Hurricane_Sandy_2012_Water_Level_and_Meteorological_Data_Repo rt.pdf.

Felgenhauer, Tyler, and Mort Webster. 2013. "Multiple adaptation types with mitigation: A framework for policy analysis." Global Environmental Change 23 (6): 1556-1565.

Few, Roger, Katrina Brown, and Emma Tompkins. 2007. Public participation and climate change adaptation: Avoiding the illusion of inclusion. Climate Policy 7 (1): 46-59.

Finch, Christina, Emrich,Christopher T., and Susan L. Cutter,. (2010). "Disaster disparities and differential recovery in New Orleans." Population and Environment 31: 179-202.

Fischetti, Mark. 2001. “Drowning New Orleans.” Scientific American 285:77-85.

Flaherty, Jordan. 2010. Floodlines: Community and Resistance from Katrina to the Jena Six. Chicago: Haymarket Books.

Fung, Archon, and Erik Olin Wright. 2001. "Deepening democracy: Innovations in empowered participatory governance.” Politics \& Society 29 (1): 5-41. 
Füssel, Hans-Martin, and Richard J.T. Klein. 2006. "Climate change vulnerability assessments: an evolution of conceptual thinking. Climatic Change 75 (3): 301-329.

Gibson-Graham, J. K. and Gerda Roelvink. 2010. "An Economic Ethics for the Anthropocene." Antipode 41: 320-346.

Giddens, Anthony. 2009. The Politics of Climate Change. Cambridge: Polity Press.

Glaeser, Edward. 2011. Triumph of the City. New York: Macmillan Publishers Limited.

Goldman, Mara J., Paul Nadasdy, and Matthew D. Turner. 2011. Knowing Nature: Conversations at the Intersection of Political Ecology and Science Studies. Chicago: University of Chicago Press.

Goodell, Jeff. 2013. “Goodbye Miami.” Rolling Stone, June 20.

Grothmann, Torsten. 2011. "Governance Recommendations for Adaptation in European Urban Regions: Results from Five Case Studies and a European Expert Survey." In Resilient Cities: Cities and Adaptation to Climate Change Proceedings of the Global Forum 2010, edited by Konrad Otto-Zimmermann and Monika Zimmermann. 1:231-242. doi: 10.1007/978-94-007-0785-6_1.

Hannigan, John. 1995. Environmental Sociology. Second edition. London: Routledge.

Haque, C. Emdad, and David Etkin. 2007. "People and Community as Constituent Parts of Hazards: The significance of societal dimensions in hazards analysis." Natural Hazards 41: 271-282.

Harlem, Peter. 2011. "Sea level rise mapping: Some examples from Miami-Dade County." Presentation to Empowering Capable Climate Communicators IV, Miami, March 26.

Hayward, Bronwyn. 2008. "'Nowhere far from the sea': Political challenges of coastal adaptation to climate change in New Zealand." Political Science 60 (1): 47-59.

Hicks, Steacy D. 2006. Understanding Tides. Silver Spring, MD: National Oceanographic and Atmospheric Administration Center for Operational Oceanographic Products and Services. http://tidesandcurrents.noaa.gov/publications/Understanding Tides_by_Steacy_finalFINAL11_30.pdf

Hodson, Mike, and Simon Marvin. 2009. “'Urban ecological security': A new urban paradigm?" International Journal of Urban and Regional Research 33 (1):193-215.

Hollander, Gail. 2008. Raising Cane in the Glades: The Global Sugar Trade and the 
transformation of Florida. Chicago: The University of Chicago Press.

ICLEI - Local Governments for Sustaniability. 2011. San Diego Bay Sea Level Rise Adaptation Strategy. http://www.icleiusa.org/climate_and_energy/Climate_Adaptation _Guidance/san-diego-bay-sea-level-rise-adaptation-strategy-1/san-diego-bay-sea-level -rise-adaptation-strategy

Florida International University International Hurricane Research Center. "LIDAR Technology.” Accessed February 10, 2013.

Intergovernmental Panel on Climate Change (IPCC). 2007. Climate Change 2007:

Synthesis Report of the Fourth Assessment of the Intergovernmental Panel on Climate Change. New York: Cambridge University Press.

Kasperson, Roger E. and Bonnie Ram. 2013. Rapid transformation of the US electric power system: Prospects and impediments." In Successful Adaptation to Climate Change, edited by Susanne C. Moser and Maxwell T. Boykoff, 114-131. London and New York: Routledge.

Kates, Robert W., William R. Travis, and Thomas J. Wilbanks. 2012. "Transformational adaptation when incremental adaptations to climate change are insufficient." Proceedings of the National Academy of Sciences. 109 (19): 7156-7161.

Kleinberg, Howard. 1994. Miami Beach. Miami: Centennial Press.

Logan, John R. and Harvey Molotch. 1987. Urban Fortunes: The Political Economy of Place. Berkeley, CA: University of California Press.

Leichenko, Robin M., Karen L. O’Brien, and William D. Solecki. 2010. "Climate Change and the Global Financial Crisis: A Case of Double Exposure." Annals of the Association of American Geographers 100(4): 963-972.

Manuel-Navarrete, David. 2010. "Power, Realism, and the Ideal of Human Emancipation in a Climate of Change." Wiley Interdisciplinary Reviews: Climate Change 1 (6): 781785 .

Misra, Vasubandhu, Elwood Carlson, Robin K. Craig, David Enfield, Benjamin Kirtman, William Landing, Sang-Ki Lee, David Letson, Frank Marks, Jayantha Obeysekera, Mark Powell, Sang-lk Shin. 2011. Climate Scenarios: A Florida-Centric View. Publication of the Florida Climate Change Task Force. http://floridaclimate.org/whitepapers/

Montgomery, Marilyn C. 2013. Using Dasymetric Modeling to Assess the Environmental Justice Implications of Flood Hazards in Miami, Florida. Presentation at Association of American Geographers, Los Angeles, April 10. 
Morgan, Curtis. 2012. "Rising sea comes at a cost for South Florida cities." The Miami Herald, September 2.

Morrow, Betty Hearn. 1999. "Identifying and Mapping Community Vulnerability." Disasters 23 (1):1-18.

Moser, Susanne C. 2005. "Impact assessments and policy responses to sea-level rise in three US states: An exploration of human-dimension uncertainties." Global Environmental Change 15(4): 353-369.

Moser, Susanne C., and Maxwell T. Boykoff. 2013. "Climate change and adaptation success: The scope of the challeng." In Successful Adaptation to Climate Change, edited by Susanne C. Moser and Maxwell T. Boykoff, 1-33. London and New York: Routledge.

Muir, Helen. 2000. Miami, U.S.A. Expanded Edition. Gainesville: University Press of Florida.

National Climate Assessment and Development Advisory Committee (NACADAC). 2011a. "Chapter 26: Decision Support." National Climate Assessment - Draft for Public Comment. U.S. Global Change Research Program. http://www.globalchange.gov/whatwe-do/assessment.

--- 2011b. “Chapter 28: Adaptation.” National Climate Assessment - Draft for Public Comment. U.S. Global Change Research Program. http://www.globalchange.gov/whatwe-do/assessment.

National Research Council. 2010a. America's Climate Choices: Adapting to the Impacts of Climate Change. Washington, D.C.: National Academies Press. http://www.nap.edu/catalog.php?record_id=12783.

--- 2010b. America's Climate Choices: Informing an Effective Response to Climate Change. Washington, D.C.: National Academies Press. http://www.nap.edu/catalog. php?record_id=12784.

Nicholls, R. J., S. Hanson, C. Herweijer, N. Patmore, S. Hallegatte, J. Corfee-Morlot, Jean Chateau, and Robert Muir-Wood. 2008. "Ranking Port Cities with High Exposure and Vulnerability to Climate Extremes: Exposure estimates." OECD Environment Working Papers, No. 1, OECD Publishing. http://dx.doi.org/10.1787/011766488208

Neumann, Roderick P. 2005. Making Political Ecology. London: Hodder Education.

National Oceanographic and Atmospheric Administration (NOAA). Center for Operational Oceanographic Products and Services. 1998. Our Restless Tides. http://www.co-ops.nos.noaa.gov/restles1.html. 
National Oceanographic and Atmospheric Administration (NOAA). Digital Coast. "Sea Level Rise and Coastal Flooding Impacts Viewer." http://www.csc.noaa.gov/digitalcoast/ tools/slrviewer/.

Nordenson, Guy, Catherine Seavitt, Adam Yarinsky, Stephen Cassell, Lizzie Hodges, Marianne Koch, James Smith, and Michael Tantala. 2011. On the water: Palisade Bay. http://www.palisadebay.org/.

Obeysekera, Jayantha, and Joseph Park. 2013. "Scenario-based projection of extreme sea Levels." Journal of Coastal Research 29 (1): 1-7. http://dx.doi.org/10.2112/JCOASTRES-D-12-00127.1

O'Brien, Karen. 2011. "Global Environmental Change II.” Progress in Human Geography 36 (5):667-676.

--- 2006. "Are we missing the point? Global environmental change as an issue of human security." Global Environmental Change 16: 1-3.

O'Brien, Karen, Siri Eriksen, Lynn P. Nygaard, and Ane Schjolden. 2007. "Why different interpretation of vulnerability matter in climate change discourses." Climate Policy 7(1): 73-88.

O'Sullivan, Feargus. 2013. "Madrid's Big Plan to Swear Off Cars." The Atlantic Cities. December 4. http://www.theatlanticcities.com/commute/2013/12/madrids-big-planswear-cars/7744/

Parry, M.L., O.F. Canziani, J.P. Palutikof and Co-authors. 2007. "Technical Summary." Climate Change 2007: Impacts, Adaptation and Vulnerability. Contribution of Working Group II to the Fourth Assessment Report of the Intergovernmental Panel on Climate Change, edited by M.L.

Parry, O.F. Canziani, J.P. Palutikof, P.J. van der Linden and C.E. Hanson. Cambridge, UK: Cambridge University Press.

Peacock, Walter Gillis, Betty Hearn Morrow, and Hugh Gladwin. 1997. Hurricane Andrew: Ethnicity, Gender and the Sociology of Disasters. London: Routledge.

Pew Research Center for People \& the Press. 2013. "GOP Deeply Divided Over Climate Change.” November 1. http://www.people-press.org/2013/11/01/gop-deeply-dividedover-climate-change/.

Pielke, Roger Jr., Gwyn Prins, Steve Rayner and Daniel Sarewitz. 2007. "Climate Change 2007: Lifting the taboo on adaptation." Nature 445: 597-598.

Posner, Gerald. 2009. Miami Babylon. New York: Simon and Schuster. 
Programme of Research on Climate Change Vulnerability, Impacts and Adaptation (PROVIA). 2012. The PROVIA Guidance on Assessing Vulnerability, Impacts and Adaptation to Climate Change. Consultation document, United Nations Environment Programme. http://www.unep.org/provia/Portals/24128/PROVIA_guidance_report_ low_resolution.pdf

Rawlins, Wade. 2012. North Carolina lawmakers reject sea level rise predictions. Reuters Edition U.S., July 3. http://www.reuters.com/article/2012/07/03/us-usa-northcarolinaidUSBRE86217I20120703

Renn, Ortwin. 2004. "Participatory processes for designing environmental policies." Land Use Policy 23: 34-43.

Rosa, Eugene A., and Thomas Dietz. 2010. "Global Transformations: PaSSAGE to a New Ecological Era." In Human Footprints on the Global Environment: Threats to Sustainability, edited by Eugene A. Rosa, Andreas Diekmann, Thomas Dietz, and Carlo Jaeger. Cambridge, MA: MIT Press.

Rothman, D. S. \& Robinson, J.B. (1997). Growing pains: A conceptual framework for considering integrated assessments, Environ. Monit. Assess. 46, 23-43.

Scholz, Roland W. 2010. "Transdisciplinary Transition Processes for Adaptation to Climate Change." In From Climate Change to Social Change: Perspectives on SciencePolicy Interactions, edited by Peter Driessen, Pieter Leroy and Wim Van Vierssen. Utrecht: International Books.

Söderbaum, Peter. 1994. "Rethinking Economics From GNP Growth to Ecological Sustainability." In Evolutionary and Neo-Schumpeterian Approaches to Economics. Recent Economic Thought (36) : 277-299.

Southeast Florida Regional Partnership. 2013. Seven Counties, 50 Years: SE Florida Prosperity Plan. http://seven50.org/wpcontent/uploads/2013/11/Seven50_011414_sm.pdf.

Southeast Florida Regional Climate Change Compact (SFRCCC). 2012a. A Region Responds to a Changing Climate- Southeast Florida Regional Climate Change Compact Counties Regional Climate Action Plan.

http://southeastfloridaclimatecompact.org/pdf/Regional\% 20Climate\%20Action \%20Plan\%20FINAL\%20ADA\%20Compliant.pdf.

--- 2012b. A Unified Sea Level Rise Projection for Southeast Florida. http://southeastfloridaclimatecompact.org/compact-documents/. 
--- 2012c. Analysis of the Vulnerability to Southeast Florida to Sea level Rise. http://southeastfloridaclimatecompact.org/compact-documents/.

South Florida Water Management District (SFWMD). 2009. Climate Change and Water Management in South Florida. Interdepartmental Working Group.

http://www.sfwmd.gov/portal/page/portal/xrepository/sfwmd_repository_pdf/climate change_and_water_management_in_sflorida_12nov2009.pdf

Sharma, Divya, and Sanjay Tomar. 2010. "Mainstreaming climate change adaptation in Indian cities." Environment and Urbanization 22 (2): 451-465.

Sonenshein, Roy S. 1995. Delineation of Saltwater Intrusion in the Biscayne Aquifer, Eastern Dade County, Florida. United States Geological Survey. http://fl.water.usgs.gov/Miami/online_reports/wri964285/

Streek, Wolfgang. 2013. "The Politics of Public Debt Neoliberalism, Capitalist Development, and the Restructuring of the State." Discussion Paper 13/7. Cologne: MaxPlanck-Institute for the Study of Societies. http://www.mpifg.de/pu/mpifg_dp/dp13-7.pdf

Swyngedouw, Erik and Nik Heynen. 2003. "Urban political ecology, justice and the politics of scale." Antipode 35 (5): 898-918.

Taylor, Bruce, Tabatha Wallington, Sonja Heyenga and Ben Harman. 2014. "Urban Growth and Climate Adaptation in Australia: Divergent Discourses and Implications for Policy-making." Urban Studies 51(1): 3-21.

Taylor, Dorcetta E. 2000. "The rise of the environmental justice paradigm: Injustice framing and the social construction of environmental discourses." American Behavioral Scientist 43(4): 508-580.

Titus, James G. 2010. Rolling Easements. U.S. Environmental Protection Agency Climate Ready Estuaries Program. water.epa.gov/type/oceb/cre/upload/rollingeasementsprimer.pdf.

Turner, Robin Lanette, and Diana Pei Wu. 2002. Environmental Justice and Environmental Racism: An Annotated Bibliography and General Overview, Focusing on U.S. Literature, 1996-2002. Berkeley Workshop on Environmental Politics of the Institute for International Studies. http://dlc.dlib.indiana.edu/dlc/handle/10535/3889.

Turner II., B.L., Roger E. Kasperson, Pamela A. Matson, James J. McCarthy, Robert W. Corell, Lindsey Christensen, Noelle Eckley, Jeanne X. Kasperson, Amy Luers, Marybeth L. Martello, Colin Polsky, Alexander Pulsipher, and Andrew Schiller. 2003. "Framework for vulnerability analysis in sustainability science." Proceedings of the National Academy of Sciences of the United States of America 100: 8074-8079. 
Veiga, Christina. 2013. "Real Housewives' star and husband can tear down historic home," The Miami Herald. February 13.

--- 2014. "Miami Beach to spend up to $\$ 400$ million to deal with flooding issues," The Miami Herald. February 12.

Veiga, Christina, and Andres Viglucci. 2013. Two teams, two visions presented for Miami Beach Convention Center redevelopment," The Miami Herald, May 14.

Watts, Michael. 1983. Silent Violence: Food, Famine and Peasantry in Northern Nigeria. Berkeley, CA: University of California Press.

Willows, Robert, and Richenda Connell. 2003. Climate adaptation: Risk, uncertainty and decision-making. UKCIP Technical Report. Oxford: UKCIP. http://www.ukcip.org.uk/ wordpress/wp-content/PDFs/UKCIP-Risk-framework.pdf . 
APPENDICES 


\section{DATA SOURCES}

$\underline{\text { Interviews }}$

\section{Miami Beach Residents}

Owner 1. Interview by author. Notes. January 18, 2013.

Owner 2. Interview by author. Digital recording. March 31, 2013.

Owner 3. Interview by author. Digital recording. March 9, 2013.

Owner 4. Interview by author. Digital recording. February 14, 2013.

Owner 5. Interview by author. Digital recording. March 14, 2013.

Renter 1. Interview by author. Digital recording. May 2, 2013.

Renter 2. Interview by author. Digital recording. May 23, 2013.

Renter 3. Interview by author. Notes. February 6, 2013.

Renter 4. Interview by author. Notes. February 7, 2013.

Renter 5. Interview by author. Digital recording. May 2, 2013.

\section{Miami Beach Businesses}

Small business 1. Interview by author. Notes. November 28, 2012.

Small business 2. Interview by author. Digital recording. November 28, 2012.

Small business 3. Interview by author. Digital recording. November 30, 2012.

Small business 4. Interview by author. Digital recording. December 3, 2012.

Small business 5. Interview by author. Notes. January 16, 2013.

Small business 6. Interview by author. Notes. December 14, 2013.

Small business 7. Interview by author. Notes. December 19, 2013.

Large business 1. Interview by author. Digital recording. December 4, 2012.

Large business 2. Interview by author. Notes. February 5, 2013. 


\section{Miami Beach Resident Activists}

Resident activist 1. Interview by author. Digital recording. September 19, 2012.

Resident activist 2. Interview by author. Digital recording. October 3, 2012.

Resident activist 3. Interview by author. Digital recording. October 5, 2012.

Resident activist 4. Interview by author. Digital recording. November 21, 2012.

Resident activist 5. Interview by author. Digital recording. December 4, 2012.

Resident activist 6. Interview by author. Notes. February 1, 2013.

\section{Miami Beach Business Leaders}

Business leader 1. Interview by author. Digital recording. April 3, 2013.

Business leader 2. Interview by author. Digital recording. August 8, 2013.

\section{Miami Beach Officials}

Administration Official 1. Interview by author. Digital recording. June 5, 2012.

Administration Official 2. Interview by author. Digital recording. August 28, 2012.

Administration Official 3. Interview by author. Digital recording. October 2, 2012.

Administration Official 4. Interview by author. Digital recording. October 12, 2012.

Administration Official 5. Interview by author. Digital recording. October 18, 2012.

Administration Official 6. Interview by author. Digital recording. November 30, 2012.

Administration Official 7. Interview by author. Digital recording. February 22, 2013.

Administration Official 8. Interview by author. Digital recording. July 9, 2013.

Elected Official 1. Interview by author. Digital recording. October 1, 2012.

Elected Official 2. Interview by author. Digital recording. March 5, 2013.

\section{Other Local and Regional Governance Network Leaders}

Governance Leader 1. Interview by author. Digital recording. June 11, 2012. 
Governance Leader 2. Interview by author. Digital recording. July, 32012.

Governance Leader 3. Interview by author. Digital recording. August 13, 2012.

Governance Leader 4. Interview by author. Digital recording. August 14, 2012.

Governance Leader 5. Interview by author. Digital recording. August 24, 2012.

Governance Leader 6. Interview by author. Digital recording. August 31, 2012.

Governance Leader 7. Interview by author. Digital recording. June 24, 2013.

Governance Leader 8. Interview by author. Digital recording. July 17, 2013.

Meetings

\section{State and Regional Conferences and Workshops}

National Environmental Journalists conference, Miami, October 19-23, 2011

Florida State University System Climate Change Task Force workshop, Gainesville, FL, November 14-15, 2011

SFRCCC $3^{\text {rd }}$ annual Climate Leadership Summit, Key Largo, FL, December 7-8, 2011

CLEO Anniversary Celebration, Pinecrest, FL, December 1, 2012

SFRCCC $4^{\text {th }}$ annual Climate Leadership Summit, Jupiter, FL, December 6-7, 2012

University of Miami/CLEO Climate Communicators training, spring 2012

Florida Atlantic University Sea level rise conference, June 21, 2012

Good Government Initiative, "Is Miami the next Atlantis?" Miami, October 9, 2012

Urban Land Institute, "Can Southeast Florida Stay Afloat Despite the Changing Climate? How Sea Level Rise is Already Altering Our Built Environment," Miami, FL, January 8, 2013

National Climate Assessment regional town hall, Tampa, FL, February 19, 2013

South Florida Climate Action Partners workshop, Boca Raton, FL, March 2, 2013

FIU School of Architecture Symposium, Miami Beach, March 14, 2013 
Florida Sea Grant Adaptive Planning Workshop, Davie, FL, April 19, 2013

Miami Chamber of Commerce climate change forum, April 28, 2013

Seven50 Opening Summit, Delray Beach, FL, June 27, 2012

Seven 50 Miami-Dade County Workgroup, Miami, FL, November 15, 2012

Seven50 Second Summit, Miami, FL, January 23, 2013

Seven50 Third Summit: The Future in Focus, West Palm Beach, FL, June 11, 2013

\section{City of Miami Beach Government Meetings}

SWMMP Public Meeting, August 17, 2012

County Commission meeting, November 14, 2012

County Commission meeting, January 16, 2013

Land Use Committee Meeting, January 23, 2013

Sustainable and Authentic Conference Organizational meeting, January 29, 2013

Convention center public meeting, January 29, 2013

Sustainability Committee Meeting, February 11, 2013

SFWMD Public Meeting, February 25, 2013

Sustainability Committee Meeting, March 12, 2013

FDOT Alton Rd. meeting, March 21, 2013

Sustainability Committee Meeting, April 16, 2013

Sustainable and Authentic Conference organizational meeting, April 18, 2013

Resilient Miami Beach: A Dialogue with the Dutch, September 18, 2013

\section{Miami Beach Community Meetings}

Tuesday Morning Breakfast Club, emergency management, August 14, 2012

Tuesday Morning Breakfast Club, Dan Kipnis and Dwight Kraii, August 7, 2012

Flamingo Park Neighborhood Association, September 5, 2012 
CLEO press event, October

Tuesday Morning Breakfast Club, Commissioner Ed Tobin

16th Street meeting, October 13, 2012

Flamingo Park Neighborhood Association, October 28, 2012

Collins Canal Centennial, November 3, 2012

Flamingo Park Neighborhood Association, November 12, 2012

West Avenue Neighborhood Association, November 27, 2012

Tuesday Morning Breakfast Club, Convention Center, November 27, 2012

West Avenue Neighborhood Association, November 28, 2012

Flamingo Park Neighborhood Association, December 3, 2012

West Avenue Neighborhood Association, December 11, 2012

West Avenue Neighborhood Association, January 15, 2013

Flamingo Park Neighborhood Association, February 4, 2013

Flamingo Park Neighborhood Association, March 4, 2013

\section{Documents Reviewed}

\section{State and Regional Documents}

SFRCCC Agreement, January 20, 2010

FL Dept. of Community Affairs, Adaptation Action Areas white paper, 2011

U.S. Environmental Protection Agency, "Saving Florida" brochure, March 2002

SFRCCC $1^{\text {st }}$ Annual Climate Leadership Summit agenda, October 2009

Broward Climate Action Plan, May 2010

SFRCCC Draft Climate Action Plan, February 2011

Seven50, Draft Subsidiarity Report, May 202013 


\section{Miami-Dade County Documents}

CCTF Second Report and Initial Recommendations, April 2008

CCATF meeting minutes, 2009-2010

County Manager memo on climate change, September 2009

EAR townhall comments, August 2009

Green Jobs Pledge, 2009

ICLEI local vs. federal action, October 2009

EAR reports, 2010

Greenprint, 2010

ICLEI case study, 2010

ICLEI vulnerability assessment training, 2010

MDCCTF Annual Report and Supplemental Recommendations, April 2010

NOAA workshop, 2010

CCTF web page, Accessed August 28, 2011

Department of Environmental Resources, Climate Change Task Force website, accessed August 28, 2011.

Comprehensive Development Master Plan amendments, 2013

MDC RCAP approval, 2013

RCAP resolution, January 2013

State and federal legislative agenda, January 2013

\section{Miami Beach Government Documents}

Comprehensive Development Master Plan agreement, June 9, 2010

Miami Beach magazine flooding article, September 2009

Letter to Commission seasonal flooding, September 18, 2009

Miami Beach Economic Indicators, 2010 
Economic development assistance, 2010

Analysis of 2010 Evaluation and Appraisal Report, 2010

FDOT elevations 10th \& Alton, 2011

Draft SWMMP report, 2011

SWMMP Appendix H, 2011

Sustainability Plan, 2011

Miami Beach magazine Flood hazard information, 2012

Miami Beach magazine Hurricane Guide, 2012

National Flood Insurance Program Manual, 2012

Miami Beach Magazine Beaches awards. Spring 2012

Miami Beach Magazine EcoZone award, Spring 2012

Miami Beach Magazine Excellence survey results, Summer 2012

Miami Beach Magazine Recycling law, Summer 2012

Miami Beach Magazine Hurricane season, Summer 2012

Miami Beach Magazine Sunset Harbour garage, Summer 2012

Climate change resolution, June 22, 2012

Letter to Commission Alton Rd, June 2012

Letter to Commission Community Rating System Class Increse, July 13, 2012

Finance committee agenda, July 25, 2012

Letter to Commission SWMMP and sea level rise, August 14, 2012

SWMMP Public Presentation, August 17, 2012

Finance committee agenda, August 22, 2012

Miami Beach Magazine SWMP article, Fall 2012

Resolution Adopting 2011 Citywide Storm Water Master Plan, October 24, 2012 
Letter to Commission Miami Beach biking to work, November 2012

SWMP resolution, November 14, 2012

Commission Meeting Discussion Item, sea level rise, November 14, 2012

Letter to Commission Miami Beach United and residential uses, December 2012

Capital budget 2012-2013

Convention center LEED, 2013

Letter to Commission, Convention center, January 2013

Commission meeting, Netherlands engineers, January 2013

Land Use Committee meeting sea level rise report, February 2013

Land Use Committee Special Meeting on sidewalk cafes, February 2013

Commission meeting mayor's climate action pledge, February 4, 2013

Netherlands engineers presentation to commission, February 6, 2013

Energy Economic Development Zone ordinance, March 21, 2013

Commissioner Weithorn email, November 17, 2013

Resolution C7K, February 12, 2014

Flood hazard brochure, n.d.

\section{Miami Beach Community Documents}

Flamingo Park Neighborhood Association, Capital Improvement Program recommendations, 2002

16th St. Basis of Design report, September 2007

Miami Beach newspaper - Tony Goldman, September 20, 2012

16th Street meeting report, November 1, 2012

Miami Beach United position paper on city center, January 2013

Miami Beach United 2013 priorities survey, January 9, 2013 
Flamingo Park Neighborhood Association Alton Rd opposition paper, February 2013

Flamingo Park Neighborhood Association email on Alton Rd., February 12, 2013

Resident Activist email on SWMMP, March 2013

West Avenue Neighborhood Association blog on Alton Rd., March 20, 2013

Del Vecchio, Frank, various election emails, September - November 2013

Election campaigns mailed informational fliers, May - November, 2013.

Flooding Observations

\begin{tabular}{llcc}
\hline Date & Location & Hours & Pictures \\
\hline $10 / 29 / 2011$ & Alton & 0.5 & 8 \\
$11 / 2 / 2011$ & all sites & 1.5 & 24 \\
$11 / 9 / 2011$ & Alton & 3 & 37 \\
$11 / 25 / 2011$ & Alton & 0.5 & \\
$2 / 10 / 2012$ & Park & 0.5 & 4 \\
$5 / 23 / 2012$ & all sites & 1 & 19 \\
$6 / 8 / 2012$ & all sites & 1 & 4 \\
$6 / 18 / 2012$ & all sites & 1 & \\
$6 / 23 / 2012$ & all sites & 0.5 & \\
$8 / 20 / 2012$ & all sites & 3 & 71 \\
$8 / 23 / 2012$ & Alton & 1 & \\
$8 / 26 / 2012$ & 10th \& Alton & 1 & 6 \\
$9 / 18 / 2012$ & outfalls & 1 & \\
$10 / 14 / 2012$ & all sites & 2 & 33 \\
$10 / 15 / 2012$ & 6th St. & 2 & \\
$10 / 16 / 2012$ & 6th \& Meridian & 4 & 52 \\
$10 / 17 / 2012$ & 10th \& Alton & 5 & 73 \\
$10 / 26 / 2012$ & 10th \& Alton & 1.5 & 20 \\
$10 / 27 / 2012$ & 10th \& Alton & 0.5 & 15 \\
$10 / 28 / 2012$ & all sites & 5 & 45 \\
$10 / 29 / 2012$ & all sites & 3.5 & 38 \\
$10 / 31 / 2012$ & 10th \& Alton & 4.5 & 63 \\
$11 / 1 / 2012$ & 10th \& Alton & 0.5 & \\
$11 / 2 / 2012$ & 10th \& Alton & 4.5 & 13 \\
$11 / 7 / 2012$ & 10th \& Alton & 0.5 & 3 \\
$11 / 12 / 2012$ & 10th \& Alton & 1 & 4 \\
$11 / 13 / 2012$ & 6th \& Meridian & 0.5 & 3 \\
& & &
\end{tabular}




\begin{tabular}{|c|c|c|c|}
\hline $11 / 14 / 2012$ & 6th \& West & 3 & \\
\hline $11 / 16 / 2012$ & 10th \& Alton & 0.5 & \\
\hline $11 / 26 / 2012$ & 10th \& Alton & 0 & \\
\hline $4 / 24 / 2012$ & 6th \& Meridian & 1 & 3 \\
\hline $4 / 30 / 2013$ & all sites & 1 & 43 \\
\hline 32 & Total & 56 & 581 \\
\hline
\end{tabular}


VITA

\section{EMILY EISENHAUER}

Melbourne, Florida

1999

B.A. in Honors, Humanities and German

Stetson University

DeLand, Florida

2000-2002

Peace Corps, China

2006

M.A., Comparative Sociology

Florida International University

Miami, Florida

$2006-2011$

Research Associate

Research Institute on Social and Economic Policy

Center for Labor Research and Studies

Florida International University

$2011-2013 \quad$ Research Assistant

NSF Urban Long Term Research Area-Exploratory project

"Double Exposures: Socio-ecological Vulnerabilities in the Miami-

Dade Urban Region"

2013 - $2014 \quad$ Program Coordinator

Office of Civic and Community Engagement

University of Miami

\section{PUBLICATIONS AND PRESENTATIONS}

Eisenhauer, Emily. 2013. "The Construction of Socio-ecological Vulnerability to Climate Change in Miami Beach." 2013 J.X. Kasperson Award from the Hazards, Risks \& Disasters Specialty Group of the Association of American Geographers.

Smith-Cavros, Eileen M., and Emily Eisenhauer. 2013. Overtown: Neighborhood, Change, Challenge and "Invironment." Local Environment: The International Journal of Justice and Sustainability. Forthcoming.

Eisenhauer, Emily and Bruce Nissen. 2011. "University Based Research for Social Change: Lessons Learned." Theory in Action 4(2): 21-30.

Eisenhauer, Emily, Alejandro Angee, Brianne Barclay, and Jasney Cogua-Lopez. 2008. "Community Knowledge and Attitudes toward Refugees and Asylees in Miami-Dade and Broward Counties: An Analysis for the International Rescue Committee." NAPA Bulletin 27(1):224-236 